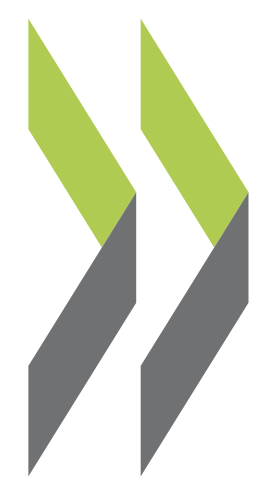

OECD Economics Department Working Papers No. 461 Assessing the value of indicators of underlying inflation for monetary policy

\author{
Pietro Catte,
} Torsten Sløk 
Organisation de Coopération et de Développement Economiques

Organisation for Economic Co-operation and Development

25-Nov-2005

ECONOMICS DEPARTMENT

English - Or. English

ASSESSING THE VALUE OF INDICATORS OF UNDERLYING INFLATION FOR MONETARY POLICY

ECONOMICS DEPARTMENT WORKING PAPERS NO. 461

By Pietro Catte and Torsten Sløk

All Economics Department Working Papers are available through OECD's Internet Web site at www.oecd.org/eco

JT00194888

Document complet disponible sur OLIS dans son format d'origine

Complete document available on OLIS in its original format 


\section{ABSTRACT/RESUME}

\section{Assessing the value of indicators of underlying inflation for monetary policy}

This paper considers a number of different measures of core inflation and tries to identify those containing the most useful information about future movements in headline inflation rates over the horizons relevant for monetary policy for the United States, the euro area, Japan, the United Kingdom and Canada. The paper shows that the adjusted indicators do considerably better than the headline rate at determining the underlying inflation trend and, being considerably less volatile, can also be used at higher frequencies to provide more timely information. Most of these indicators also contain information relevant to predicting future headline inflation and which is additional to that contained in the headline rate. However, the relative performance of different indicators varies considerably across economies, and in some cases across sample periods. There is evidence that headline inflation tends to converge toward core inflation over time horizons of between 12 and 24 months. However, the estimated model incorporating this relationship between headline and core inflation does rather poorly in out-of-sample tests, although out-of-sample performance is much better for other specifications.

JEL classification: E31

Keywords: inflation; core inflation; monetary policy

$* * * * *$

\section{Évaluer l'utilité des indicateurs de l'inflation sous-jacente pour la politique monétaire}

Ce document examine un certain nombre de mesures de l'inflation sous-jacente et tente d'identifier celles qui donnent les informations les plus utiles afin d'appréhender les mouvements à venir de l'inflation totale en vue de la politique monétaire pour les États-Unis, la zone euro, le Japon, le Royaume-Uni et le Canada. L'étude montre que ces indicateurs ajustés sont plus efficaces que le taux d'inflation total lorsqu'il s'agit de déterminer la tendance sous-jacente de l'inflation. De plus, étant considérablement moins volatiles, ces indicateurs peuvent aussi être utilisés à des intervalles plus courts afin d'apporter les informations les plus récentes. La plupart de ces indicateurs contiennent aussi des informations pertinentes pour prévoir les taux d'inflation futurs, et qui sont complémentaires à celles contenues dans le taux d'inflation total. Cependant, la performance relative des différents indicateurs varie énormément d'une économie à l'autre, et dans certains cas d'une période à l'autre. On observe que l'inflation totale tend à converger vers l'inflation sous-jacente à un horizon de 12 à 24 mois. Toutefois, le modèle estimé incorporant cette relation entre inflation totale et inflation sous-jacente se révèle plutôt médiocre dans des essais hors échantillon, bien que les résultats hors échantillon soient bien meilleurs dans des autres spécifications.

JEL codes : E31.

Mots-clés : inflation; inflation sous-jacente; politique monétaire

\section{Copyright OECD, 2005}

Applications for permission to reproduce or translate all, or part of, this material should be made to: Head of Publications Service, OECD, 2 rue André-Pascal, 75775 Paris Cédex 16, France. 


\section{TABLE OF CONTENTS}

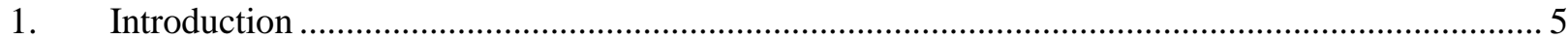

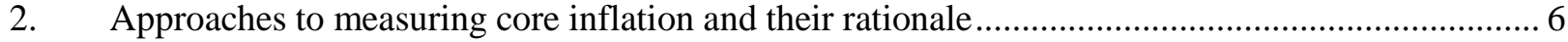

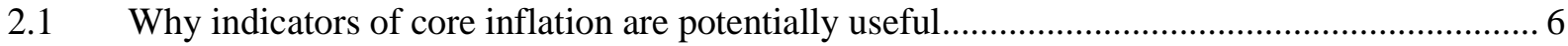

2.2 Approaches to constructing indicators of core inflation ......................................................... 7

2.2.1 Permanently excluding particular components ...................................................................... 9

2.2.2 Excluding the influence of CPI components on a period-by-period basis ............................. 9

2.2.3 Downplaying the influence of the most volatile items ..................................................... 10

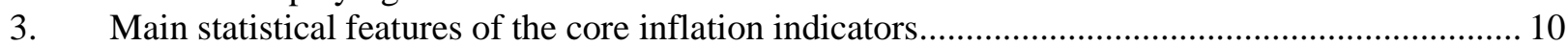

3.1 Some of the indicators are biased, but the bias may change over time.................................. 10

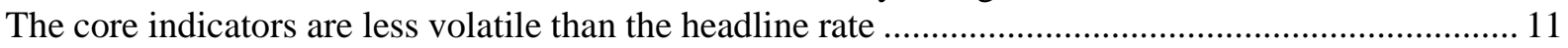

3.2 Some core indicators "track" a moving average of headline inflation remarkably well.......... 12

4. Do core indicators help forecast headline inflation? ................................................................. 13

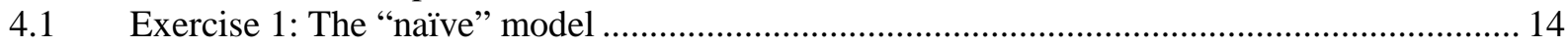

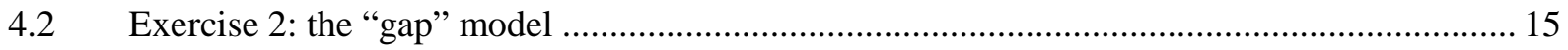

4.3 Exercise 3: A more general distributed lag model .................................................................. 17

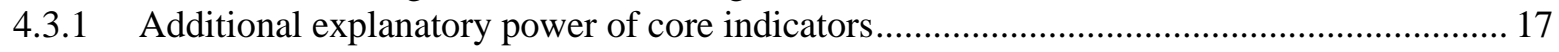

4.3.2 Comparative information content of data at different frequencies ...................................... 18

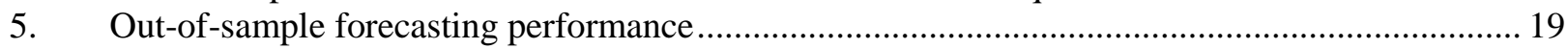

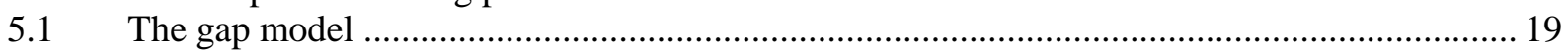

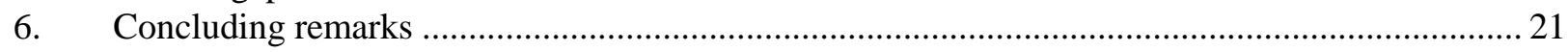

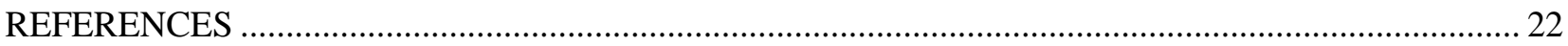

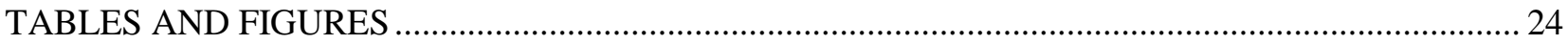

ANNEX 1. TECHNICAL DETAILS ON THE CONSTRUCTION OF CORE INFLATION

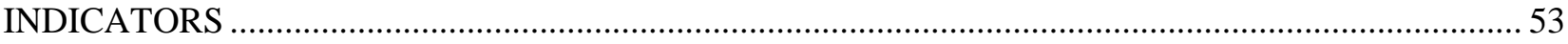

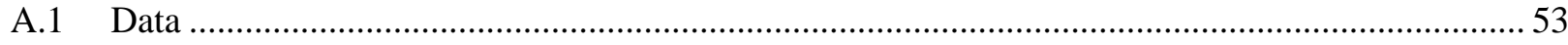

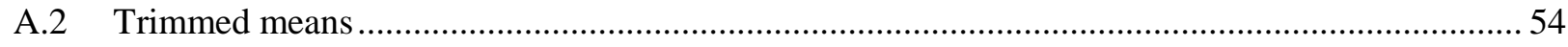

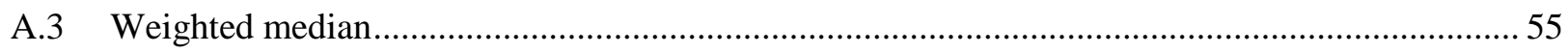

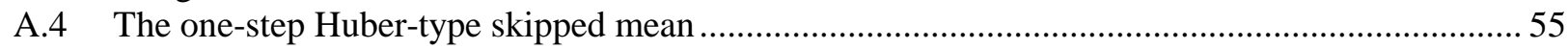

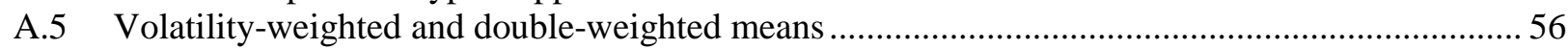

A.6 The influence of individual CPI components on the different core indicators.............................. 57

ANNEX 2. CHARACTERISTICS OF THE CROSS-SECTION DISTRIBUTION OF PRICE CHANGES

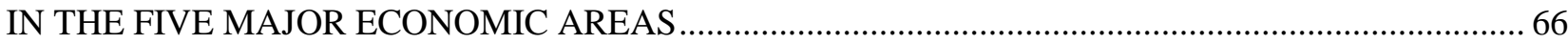




\section{ECO/WKP(2005)48}

\section{Boxes}

1. The indicators of core inflation used in this paper

2. The effect of sectoral price behaviour on individual core inflation indicators

\section{Tables}

1. Headline and core inflation: average values

2. Volatility of core inflation indicators

3. Performance of core inflation indicators in tracking trend headline inflation

4. Naïve forecasting exercise

5. Gap model

6. Distributed-lag model: explanatory power

7. Distributed-lag model: additional information of higher-frequency data

8. Gap model: out-of-sample forecasting performance at the 12-month horizon

9. Distributed-lag model: out-of-sample forecasting performance at the 12-month horizon

\section{Figures}

1. Headline rate and indicators of core inflation (year-on-year percentage change)

2. Main components of core inflation

3. Headline rate and indicators of core inflation (3-month percentage change) 
ECO/WKP(2005)48

\title{
ASSESSING THE VALUE OF INDICATORS OF UNDERLYING INFLATION FOR MONETARY POLICY
}

\author{
Pietro Catte and Torsten Sløk ${ }^{1}$
}

\section{Introduction}

1. Headline inflation rates can be volatile, often because of substantial movements in commodity or food prices. Such volatility in a key price index can make it difficult for policy makers to accurately judge the underlying state of, and prospects for, inflation. Therefore, indicators of core inflation -- which exclude or downplay the more volatile price changes so as to reveal the underlying, more persistent components -can be helpful. This paper discusses ways in which core consumer price inflation can be measured, as well as its potential usefulness for policy makers, based on evidence in the United States, the euro area, Japan, the United Kingdom and Canada.

2. The structure of the paper is as follows. In the next section, three broad types of core inflation measures are examined. The first excludes from the headline consumer price index (CPI) certain components based on the notion that their high volatility tends to reflect supply disruptions (e.g. oil and food prices). The second excludes each month the largest price changes, whatever the source, based on a predetermined statistical criterion. The third adjusts the weights of individual CPI components so as to reduce the impact of historically volatile components. In the following section the statistical properties of all these measures of core inflation are examined, focusing in particular on whether they are unbiased indicators of headline inflation, on whether they are less volatile than the headline rate and on how well they are able to track the "trend" in headline inflation. To explore further what these measures can say about underlying inflation pressures, three separate econometric tests are performed, discussed in the fourth section. Using alternative univariate and bivariate specifications, an attempt is made to evaluate how core inflation indicators can help predict future headline inflation at the time horizons most relevant from the standpoint of monetary policy. In section five, the two specifications that give satisfactory in-sample results are tested in out-of-sample forecasting exercises. The final section offers some tentative conclusions.

The main conclusions of the paper can be summarised as follows:

- Core inflation indicators are generally much less volatile than headline inflation. Partly because of this, they are definitely better at "tracking" current trend inflation -- proxied by a centred moving average of headline inflation -- than the headline rate itself. This is particularly the case when using higher-frequency measures, such as 3-month annualised inflation rates. Given their timely availability, when used at higher frequencies the indicators can therefore provide very up-to-date information on inflation trends.

1. The authors are economists at the OECD Economics Department. They wish to thank Luc Aucremanne, Marco Huwiler, Ivan Roberts and members of the OECD High-Level Group of Monetary Experts, as well as Jørgen Elmeskov, Mike Feiner, Mike Kennedy, Vincent Koen and other members of the department for useful comments on previous drafts of this paper. They also thank Catherine Lemoine and Laure Meuro for technical assistance. The views expressed are those of the authors and do not necessarily reflect the views of the OECD or its member countries. 
- Some core inflation indicators tend to differ in level from headline inflation, even when averages over relatively long periods are considered. This would seem to suggest that they are biased indicators. However, the size and even the sign of the bias can change over time, so correcting for it on the basis of past averages may prove misleading. In any case, the bias is not intrinsic to the construction of individual indicators: those that are biased in the context of one economy need not be biased in other economies. One source of such biases can be the presence of sharply divergent price trends between groups of CPI components (for example, goods and services) with a different impact on the various indicators. In these circumstances identifying what is "core inflation" may be more difficult.

- An attempt to project future headline inflation by simply extrapolating the most recent trends in core inflation indicators is rejected by the data for all five economies considered, and this regardless of the data frequency used. In other terms, none of the indicators considered in this study can be used as a ready-made "leading indicator" of headline inflation. In fact, the correlation between the headline rate and core inflation indicators seems to be mostly contemporaneous in Japan, the United Kingdom and Canada, while in the United States and the euro area most core inflation indicators tend to lag the headline rate to varying degrees, generally by between 6 and 12 months.

- There seems to be a tendency for headline inflation to converge toward core inflation (as proxied by the core indicators), although the strength and the speed of such convergence varies across economies. A model based on this hypothesis -- which implies that the projected change in headline inflation depends on the current "gap" between the headline and the core rate -- does remarkably well in terms of in-sample explanatory power, but rather poorly in out-of-sample tests. Nevertheless, a "restricted" version of the "gap model", where full convergence to core inflation within a given time horizon is imposed, does much better than the estimated version in out-of-sample tests.

- Using a more general distributed-lag specification it is found that, in most cases, core inflation indicators help significantly improve forecasts of headline inflation relative to specifications where only information about past headline inflation is used. In some cases -- that is, for some economies and some indicators -- this is particularly true if the model is specified using data at higher frequency than the standard year-on-year inflation rate, but this result does not seem to be a general one.

- Comparing the usefulness of the different indicators for forecasting headline inflation, in the case of Japan and Canada there are a few indicators that are always among the best, regardless of the model specification used. Interestingly, they are also the same that do best at "tracking" trend headline inflation, suggesting that their value added in forecasting comes in part from being reliable indicators of where inflation currently stands. By contrast, for the United States, the euro area and the United Kingdom the indicators that do best in the context of the "gap model" are in general not the same that give the best forecasts with the distributed lag model, and there is a less consistent relationship between an indicator's ability to track the current trend and it value in forecasting future inflation.

\section{Approaches to measuring core inflation and their rationale}

\subsection{Why indicators of core inflation are potentially useful}

3. In interpreting current inflation and predicting future developments, central banks need to disentangle the effects of many unobservable factors that drive the inflation process. Some of these factors 
have a more lasting effect than others. A common simplification is to visualise observed inflation as consisting of a persistent and a transitory component. The persistent component is connected to the fundamental drivers of the inflation process: excess demand for goods and services, changes in unit labour costs and, ultimately, monetary policy. The transitory component can reflect a variety of temporary shocks, such as changes in relative prices whose effects on the aggregate price level do not cancel out, as well as measurement errors, unusual seasonal patterns and one-off changes in indirect taxes. A further simplification identifies the persistent component with the generalised component of inflation -- that is, with the common factor (or a set of common factors) driving all CPI components -- while the temporary component is seen as resulting mainly from idiosyncratic shocks to the individual components. ${ }^{2}$

4. Not all facts about inflation fit easily within this simplified picture. For example, not all relative price changes are one-off: some of them -- like the decline in the relative price of computers or the rise in some service prices -- can give rise to long-term trends. Moreover, some relative price shocks -- energy price increases are an obvious example -- even though in principle they should have at most a one-off impact on the price level and therefore only a temporary effect on measured inflation, in practice tend to be transmitted gradually through the production chain and thus can have a relatively protracted influence on inflation, especially if in addition they feed into inflation expectations and wage behaviour.

5. Nevertheless, from the point of view of monetary policy, viewing inflation as consisting of a persistent common component and generic "noise" reflecting mostly idiosyncratic shocks may still be a useful simplification. For policy makers it is important to know whether an observed change in inflation is temporary or is likely to be persistent. Given its relatively long transmission lags, monetary policy cannot offset short-term, temporary shocks to inflation, but needs to focus on stabilising its more persistent component. In order to be able to conduct a forward-looking monetary policy, the challenge faced by a central bank is therefore to identify in a timely fashion changing trends in this persistent (or "underlying") component. Because the two components -- transitory and persistent, or "signal" and "noise" -- cannot be observed directly, central banks face a typical "signal extraction" problem. Indicators of "underlying" or "core" inflation are intended to help address this problem.

\subsection{Approaches to constructing indicators of core inflation}

6. In the economic literature, a variety of approaches to identifying "core inflation" have been proposed. Some of them are based on economic theory; ${ }^{3}$ others can be regarded as essentially "statistical", although some of them refer to the economics of pricing behaviour to justify their validity. Among the statistical approaches, some make use predominantly of cross-section information on the individual CPI components, while others also use the time-series properties of the aggregate CPI series, of its components and in some cases of other economic time series. ${ }^{4}$

7. In this paper, we focus on a number of indicators of core inflation, all of which can be characterised as based on a "statistical" approach and that use mainly cross-section information. The economic rationale underlying such indicators is discussed below, and further details about their

2. The distinction between the two views of core inflation as the persistent component of inflation and as the generalised component is explored in greater detail in Roger (1998).

3. Among these, the best known is probably the approach suggested by Quah and Vahey (1995), in which core inflation is defined as that component of CPI inflation that has no long-run effect on output, under the assumption of a vertical long-run Phillips curve.

4. An approach that combines cross-section and time-series information is the dynamic factor analysis approach initially proposed by Stock and Watson (1988) and applied to the analysis of core inflation by Bryan and Cecchetti (1993). A generalisation can be found in Cristadoro et al. (2005). While this approach has been widely used in the recent academic literature, it is not among those assessed in this paper. 


\section{ECO/WKP(2005)48}

construction and the data used are presented in Box 1. These indicators can be grouped in three broad categories, according to the underlying methodological approach:

- permanently excluding certain components of the CPI that have been identified in advance;

- $\quad$ excluding the price changes in certain CPI components that are identified on a period-by-period basis according to specific statistical criteria;

- downplaying the more volatile CPI components based on historically observed volatilities.

\section{Box 1. The indicators of core inflation used in this paper}

The indicators of core inflation considered in this paper can be grouped in three categories according to the methodological approach. Further details on their construction and on data sources are provided in Annex 1.

\section{a) Indicators where some CPI components are permanently excluded}

The standard core measure that excludes food and energy from the overall CPI index is referred to as Core 1 . For each economy, also an additional standard measure, referred to as Core 2, is included. This country-specific variable refers to the index excluding energy and unprocessed food for the euro area and the United Kingdom; excluding fresh food for Japan; and excluding the eight most volatile components and indirect taxes for Canada. For the United States, in addition to the CPIbased measure excluding food and energy (Core 1), the corresponding measure based on the private consumption expenditure (PCE) deflator is also included as Core 2.

\section{b) Indicators constructed by excluding individual CPI components on a period-by-period basis}

Trimmed means are a first group of indicators in this category. They are constructed by ranking in descending order the price changes recorded by all the individual CPI components in a given period and excluding the top and the bottom $\mathrm{x} \%$ -- that is, the components corresponding to $x \%$ of total CPI weights on each side. The price changes considered here are month-on-month. ${ }^{1}$ Year-on-year, 6-month and 3-month inflation rates are then obtained by compounding monthly trimmed mean inflation rates. Five thresholds were used: $2,5,10,15$ and $25 \%{ }^{2}$

A limiting case of trimmed mean is the weighted median, which corresponds to a trimming percentage of $50 \%$. In this case, only the middle component, which leaves $50 \%$ of the weights on each side of the distribution, is retained.

An additional indicator in this category, the one-step Huber-type skipped mean, is constructed using a different method for selecting the price changes to be excluded each period. After a standardisation procedure that is robust to non-normality, the price changes that differ from the median by more than $2 \frac{1}{2}$ standard deviations in absolute value are deemed to be "outliers" and excluded (Aucremanne, 2000). Unlike in the case of trimmed means, the total weight of the excluded items can vary from one period to another, and they need not be distributed symmetrically around the median.

\section{c) Indicators constructed by re-weighting CPI components according to their volatility}

Volatility-weighted indicators are constructed by replacing the expenditure-based CPI weights with weights that are inversely proportional to each item's price volatility over a reference period. Two alternative measures of volatility are considered: 1) the standard deviation of the component's monthly price change relative to the overall index; 2) the standard deviation of the price's second difference. The first measure focuses on the volatility of relative price changes, while the second one focuses on high frequency volatility. The indicators constructed using these two volatility definitions are referred to in the tables as Volatility-weighted mean 1 and Volatility-weighted mean 2, respectively.

An alternative are double-weighted indicators, where the original expenditure-based weights are not discarded but just re-weighted by being divided by one of the volatility measures indicated above and then re-scaled. Indicators of this kind are computed using the same two volatility measures referred to above. ${ }^{3}$

1. Trimmed mean and median inflation could also be calculated on the basis of 3-month, 6-month or 12-month price changes. Cecchetti (1997) and Aucremanne (2002) show that results will in general be different in these cases. The main advantage of using 1-month rates is that the monthly inflation rates can be used to construct an index series from which inflation rates at other frequencies can be calculated.

2. These percentages were chosen for illustrative purposes. Bryan et al. (1997) suggest a procedure for selecting the optimal trimming percentage over the entire sample period according to a pre-defined statistical criterion. Alternatively, Aucremanne (2000) describes a procedure for selecting the optimal trimming percentage each month based on the extent to which the observed sample distribution of price changes departs from normality. Moreover, trimming could be made asymmetric if needed to remove bias. None of these procedures was implemented for the indicators presented here. The Federal Reserve Bank of Dallas has recently started to publish a trimmed mean inflation rate for the United States calculated from the components of the personal consumption expenditure (PCE) deflator, with asymmetric trimming and the trimming percentage set so as to optimise tracking of a centred moving average of headline PCE inflation (see Dolmas, 2005 for details).

3. A measure of core inflation regularly published by the Bank of Canada (CPIW) approximately corresponds to the double-weighted mean based on definition 1 of volatility. However, it is calculated from 12-month rather than 1-month price changes. 


\subsubsection{Permanently excluding particular components}

8. The standard core measures that tend to receive the most public attention are usually those that exclude food and energy from the overall consumer price index. Other variants of this type of measure are also sometimes published by statistical agencies and commonly used by policy makers, with the excluded items usually selected among those easily identifiable CPI components that tend to be most volatile in the context of that particular economy. What all these measures have in common is that the exclusions are permanent.

9. The economic argument for excluding specific components such as food and energy from the calculation of headline inflation rates is that in their case price changes are more likely to reflect supply shocks (for example, changes in international oil prices and weather conditions, respectively) rather than changes in aggregate demand. In this case, and provided that the stance of monetary policy has not changed, the influence of such large, one-off price changes (whether positive or negative) will fade over time. Hence, excluding these changes in the CPI should provide a better picture of existing underlying inflation pressures. An additional advantage of these indicators from the point of view of policy makers is that, since the excluded items are well known and identified once and for all, they can be easily explained to the public.

\subsubsection{Excluding the influence of CPI components on a period-by-period basis}

10. A second method of calculating underlying inflation is to exclude the largest price changes (whether positive or negative) as they occur. As above, the economic rationale is that such "large" price changes are more likely to reflect relative price changes, rather than generalised inflation developments. A possible counter argument is that some price changes may be large because they occur at predetermined, discrete time intervals. ${ }^{5}$ In this case, such developments could just as well be due to a great many firms changing prices at a point in time in response to strong demand conditions in the economy. Removing them from the overall index would then risk excluding valuable information on inflation pressures, and may result in the core inflation measure being a biased indicator of "true" inflation. Whether this problem does in fact affect the properties of limited-influence indicators is an empirical question. ${ }^{6}$

11. There is also, however, a statistical case that can be made for removing the largest price changes. The calculated aggregate inflation rate is the average or mean of the several hundred individual price changes of various goods and services, weighted by their share in a particular consumption basket, that go into the overall price index. If the cross-section distribution of these price changes is not normal, then the calculated mean will not be an efficient measure of the "central tendency" of inflation, and a case can be made for limiting the influence of outliers when estimating the mean. Of particular importance is a situation where large price changes (both positive and negative) represent a substantial fraction of the overall distribution. This situation is often referred to as "fat tails". In this case, sampling errors are likely to cause the actual distribution to be skewed and, as noted, the sample mean of price changes will be a less efficient estimator of the "true" mean. ${ }^{7}$ Evidence presented in Annex 2 shows that in the case of the five

5. In point of fact, a number of studies have noted that the majority of firms change their prices at regular intervals, not in response to specific events and that the process can be lumpy. See for example Angeloni et al. (2004); Blinder (1994); Hall, Walsh and Yates (1997); and Kashyap (1995).

6. If the CPI breakdown used for the construction of such indicators is relatively aggregated (as is the case for the indicators presented here), each CPI component usually covers the prices of several individual goods, each of them measured at several different locations. Even if these individual prices change at discrete intervals, the effect of averaging should limit their impact unless there is a common factor causing them to change simultaneously.

7. See Bryan et al. (1997) who provide some more evidence on this. 
economies covered in this study the cross-section distribution of price changes does indeed present a significant departure from normality, with excess kurtosis and a high degree of skewness. ${ }^{8}$ The effect of these distortions can be exacerbated if the expenditure weights on the various items are updated only infrequently since, in this case, the importance of the larger price changes in the tails could be overstated. ${ }^{9}$

\subsubsection{Downplaying the influence of the most volatile items}

12. The third way of dealing with components that are felt to be too volatile is to reduce their influence on the aggregate index by reducing their weights, instead of permanently excluding them. In this case, the core indicator will be a weighted average of all CPI components where, however, the standard expenditure weights are replaced with weights that are inversely proportional to each item's volatility. There may be a number of variants depending on how the weights are computed and which measure of volatility is chosen.

13. The economic rationale underlying the use of such indicators, called edgeworthian by the name of their original proponent, ${ }^{10}$ is that more volatile prices are likely to contain a greater proportion of "noise" relative to the "signal" regarding underlying inflation trends. In the context of the policy maker's signal-extraction problem, an optimal use of the available information suggests that the weight of the more "noisy" components should be discounted. An objection to this reasoning is that volatility may not be a good guide to the proportion between noise and signal. An often cited example is asset prices, which tend to react quickly to market conditions and are therefore volatile, but at the same time convey forwardlooking information. Even among prices of goods and services, some react more promptly than others to situations of excess demand. This should presumably make them more rather than less informative.

\section{Main statistical features of the core inflation indicators}

14. Year-on-year inflation rates for the thirteen indicators of core inflation discussed in the previous section, as well as headline inflation, are shown in Figure 1 for each of the five economies. A number of general features emerge, both from inspection of these charts and from the analysis of the indicators' statistical properties.

\subsection{Some of the indicators are biased, but the bias may change over time}

15. A first issue is whether the indicators of core inflation are unbiased indicators of headline inflation, that is, whether they have the same mean value as the headline rate. A biased indicator may still convey useful information provided that the bias is stable over time and can be adjusted for. Tests of whether the mean of each indicator differs in a statistically significant way from that of headline inflation (Table 1) show that in the more recent sample period at least some indicators for each economy are biased, and in the case of the United Kingdom and Canada a majority of them are. However, the results vary sharply across sample periods. Not only fewer indicators were biased in the 1984-1995 period, but those that were biased were not necessarily the same as in the later period, and the sign of the biased changed in some cases. This suggests that even when a persistent bias can be observed over a given sample period, it is hard to draw conclusions that will be valid for out-of-sample predictions.

8. The skewness and the kurtosis of a distribution are, respectively, its third and the fourth scaled central moments. See Annex 2 for more precise definitions.

9. Over time, the actual shares of expenditure devoted to particular goods and services will change as consumers substitute from expensive to cheaper items, while the unchanged CPI weights would not capture these changes. Bakhshi and Yates (1999) make this point for the UK measures of inflation.

10. See Diewert (1995) for a modern restatement of Edgeworth's argument. 
16. Persistent differences in level between core inflation indicators and headline inflation generally reflect the interaction between how each indicator filters out the more volatile components and the characteristics of the distribution of price changes in each country. Because the latter varies across countries as well as over time, each indicator may be biased in one country but not in others, and in some periods but not in others. In particular, certain groups of CPI components tend to have persistently higher inflation rates than others during a given period, reflecting trends in relative price changes. If the more volatile items -- which are more likely to be excluded or downplayed in the indicators -- are not distributed equally across these groups, this may result in an indicator having a higher or lower mean than the overall index. Box 2 presents evidence that the divergence between the prices of non-food non-energy goods and those of services is particularly marked in some countries, and discusses how this might cause some core indicators to be biased.

\begin{abstract}
Box 2. The effect of sectoral price behaviour on individual core inflation indicators
Individual CPI components tend to have different patterns of variation, which cause them to affect the individual indicators in different ways. The behaviour of inflation rates for the core goods (i.e. goods excluding food and energy) and the service components in the five economies, shown in Figure 2, is a particular case in point. While the aggregate inflation rate of the service component is everywhere very persistent, the behaviour of core goods prices seems to differ across economies, with a greater responsiveness to cyclical conditions in the United States and the United Kingdom than, for example, in the euro area.
\end{abstract}

The marked dichotomy between the prices of core goods and of services is likely to be a factor explaining why in the United Kingdom the various indicators of core inflation differ so widely in level from one another. Because service prices tend to be in general less volatile than those of core goods, they are less likely to be downplayed in the construction of indicators such as volatility-weighted and double-weighted means or trimmed out from trimmed means and the Huber skipped mean.

This is supported by the tables presented in Annex 1, which provide statistics on the relative influence of individual CPI items on the different types of core indicators, as well as averages for the four main commodity groups: food, energy, non-food non-energy goods, and services. In all five economies service prices tend to have a larger influence on core indicators than on the headline rate, either simply because they are less volatile -- in the case of volatility-weighted or double-weighted means -- or because, partly as a result, they are also less frequently found in the "tails" of the distribution of price changes, and are therefore less likely to be excluded from the various trimmed means. What differentiates the United Kingdom from the other economies is the combination of two facts. First, because the volatility of goods prices is comparatively greater, the relative influence of services on core indicators as compared with the headline rate is even larger. Second, the difference between the average inflation rates of services and non-food non-energy goods is much wider (Figure 2). To the extent that certain indicators down-weight goods prices or trim them out more frequently, they may also end up down-weighting or partly trimming out not only the volatile element, but also their lower trend inflation rate, thus resulting in a positive bias.

A similar explanation probably applies to the large divergence observed in 2001-02 in the United States between the weighted median and the headline rate (Figure 1). Also in that case the prices of non-food non-energy goods diverged sharply from service prices (Figure 2). While the decline in goods prices drove down the overall CPI inflation rate, the median was most likely dominated by service prices, which for a while continued to accelerate in spite of the cyclical downturn. Not only do service prices represent over half of the total CPI weights in the United States, but also, being less volatile, one or the other of them was most frequently (over $80 \%$ of the times) the median item.

\title{
The core indicators are less volatile than the headline rate
}

17. A second issue is whether core inflation indicators are less volatile than the headline rate. A lower volatility would be consistent with the presumption that core inflation should reflect the more persistent component of inflation. Three alternative measures of volatility are considered (see Table 2): a) the standard deviation of observed inflation rates, which measures their dispersion around the mean over a given period, in panel $\mathrm{A} ; \mathrm{b}$ ) the standard deviation of month-to-month changes in annualised inflation rates, which is a measure of high-frequency volatility (how "jagged" a series looks like in a chart), in panel B; and finally c) the autocorrelation coefficients of 1-month inflation rates, which is a measure of 
persistence, in panel C. ${ }^{11}$ The first two indicators are presented for inflation rates at four different frequencies (12-, 6-, 3- and 1-month annualised inflation rates). The following findings emerge:

- Core inflation indicators are generally less volatile than the headline rate. The volatility reduction is substantial in the case of the United States and Canada, where moreover all three measures of volatility point in the same direction. In the case of the euro area and Japan, on the other hand, the difference between core indicators and the headline index in terms of high-frequency volatility (panel B) and persistence (panel C) is smaller, and for some indicators the 12-month inflation rates -- although not higher-frequency rates -- show a higher dispersion around 1996-2004 average values than the corresponding headline rates (panel A). ${ }^{12}$ The same partly applies also to the United Kingdom.

- Although higher-frequency inflation rates typically tend to be more volatile than 12 -month rates, the increase in volatility -- as measured by the standard deviation (panel A) -- tends to be proportionately smaller for core inflation indicators than for the headline rate. That is, the volatility reduction afforded by the indicators is larger at higher frequencies. In terms of high-frequency volatility (panel B) the difference between core indicators and the headline rate is approximately proportional at all frequencies, but is nevertheless so substantial that in the case of the United States, the euro area and Canada the 3-month annualised rates of change of the least volatile indicators are as smooth as the 12-month headline rate. Figure 3 also illustrates the fact that 3-month annualised inflation rates for core indicators are much less volatile than the corresponding headline rate. While this might suggest that core inflation indicators are less "noisy" than the headline rate, such a conclusion cannot be drawn without an assessment of the information content of these indicators.

- The indicators achieving the lowest volatility are not necessarily the same across all economies. However, some indicators (the weighted median, the Huber skipped mean and the trimmed means with high trimming percentages) appear to be consistently among the least volatile.

- The reduction in volatility achieved by core indicators relative to the headline rate can vary across sample periods. For example, in the United States and Canada it was larger in the more recent sample period (1996-2004), while in Japan it was larger in the earlier one (1984-1995).

\subsection{Some core indicators "track" a moving average of headline inflation remarkably well}

18. Being less volatile than the headline rate, core inflation indicators should provide a more reliable, less noisy picture of current inflation trends. Testing this proposition, however, requires the definition of a

11. These three indicators of volatility should be seen as complementing each other, as each covers a different aspect of volatility. Two inflation series may both show a high standard deviation, but for very different reasons: one of them may show large high-frequency oscillations around the mean, while the other may be relatively smooth but with highly persistent deviations from the mean. The former will have a high standard deviation of the first difference but a low (or even negative) autocorrelation, while the opposite will be true for the latter.

12. The difference in the degree of persistence between core indicators and the headline rate appears to be more modest in the euro area, where headline inflation is already quite persistent. However, inflation persistence as measured by autocorrelation coefficients can vary significantly from one sample period to another for the United States, Japan and Canada (Table 2, panel C). In each of them the degree of persistence seems to have declined between 1984-1995 and 1996-2004. This may be either the result of a time-varying mean (Marques et al., 2000) or it may be due to the nature of the shocks that affected inflation in different periods. 
benchmark, given that the "underlying inflation trend" is itself unobservable. A frequently used proxy for it is a centred moving average of headline inflation. Here we use a 25 -month centred moving average of year-on-year headline inflation rates. ${ }^{13}$ Using this benchmark it is possible to compare how closely individual indicators track the "trend" by comparing the respective root mean squared errors (RMSE) with the RMSE of the headline rate itself, used as a reference (Table 3). The comparison is carried out not only for 12-month inflation rates, but also for 6-month and 3-month rates. One problem with using RMSEs as a measure of how well indicators track the trend is that the RMSE may be high not only because an indicator is noisy but also because it has a different mean value than headline inflation over the period under consideration. As discussed above, a biased indicator may still provide useful information on whether inflation is trending upward or downward. For this reason, Table 3 presents, along with the standard RMSE (panel A), a "mean-adjusted RMSE" (panel B), where the effect of the mean bias is offset. These are the main conclusions from the comparison:

- Performance in tracking trend headline inflation varies considerably across indicators. For each economy, the best performing indicators do significantly better then current headline inflation. However, other indicators do much worse than headline, not only in terms of the unadjusted but also of the mean-adjusted RMSE, at least when year-on-year rates are compared.

- The gains in tracking accuracy (reduction in mean-adjusted RMSE relative to headline inflation) are much larger at higher frequencies than for year-on-year rates. To provide an order of magnitude, in the case of the best performing indicators for the United States, the euro area and Japan the gains are of the order of 25 to $30 \%$ for year-on-year rates, 40 to $60 \%$ for 6-month rates and 50 to $70 \%$ for 3-month rates; gains are even larger than this for Canada, a bit smaller for the United Kingdom. When 3-month rates are compared, all indicators track the trend better than headline inflation in mean-adjusted RMSE terms, and virtually all of them in unadjusted terms.

- Which indicators do best at tracking trend inflation varies across economies. Moreover, for each economy, it can vary across sample periods as well as across frequencies $(12,6$ or 3 -month rates). Specifically, the best performers are: $5 \%$ and $10 \%$ trimmed means and volatility-weighted means for the United States; $2 \%, 10 \%$ and 25\% trimmed means for the euro area; doubleweighted means for Japan; the weighted median and trimmed means for the United Kingdom; and the weighted median for Canada. The standard Core 1 and Core 2 indicators are never among the best at tracking trend inflation.

\section{Do core indicators help forecast headline inflation?}

19. Although core indicators seem to be able to provide information on the current level of underlying inflation, policy makers are usually more interested in indicators that help forecast future inflation. As the relevant information content is the "additional" information provided by the indicator, any assessment must be conditional on the information set assumed to be available to the forecaster. In real life the information set is very broad, as policy makers and forecasters look at a very wide range of variables to predict future inflation. In this paper, a much more limited approach is taken, comparing the information provided by each core indicator only with the information already available from the history of headline inflation, in either a univariate or a bi-variate context. The analysis concentrates on a particular range of forecasting horizons -- 12, 18 and 24 months ahead -- which are the most relevant from the point of view of monetary policy.

13. Bryan et al. (1997) and Vega and Wynne (2001) use 37-month centred moving averages of monthly inflation rates. A 25-month centred moving average of year-on-year rates covers the same number of periods but gives a lower weight to the monthly rates at the extremes of the time interval covered. 


\section{ECO/WKP(2005)48}

20. Three separate exercises are conducted in this section:

- The first tries to assess to what extent the most recent change in core inflation can, by itself, help predict future changes in headline inflation.

- The second focuses on the information content of the difference between the current levels of headline inflation and of core inflation (proxied by the various indicators) in predicting future movements in headline inflation.

- The third uses a more flexible specification: distributed lags of both headline and core inflation (proxied by the various indicators) at various frequencies are included as predictors of future 12-months headline inflation in order to assess whether the information contained in core indicators has any additional predictive power relative to that contained in the past history of headline inflation itself.

21. The remainder of this section consider the three exercises in turn, discussing the in-sample estimation results. The out-of-sample performance of the second and third model is discussed in the next section.

\subsection{Exercise 1: The "naïve" model}

22. This exercise can be seen as an attempt to forecast headline inflation by simply extrapolating recent changes in core inflation, on the assumption that core indicators can be interpreted as a "leading indicator" for headline inflation. The difference between year-on-year CPI inflation 12 months ahead and its current value at time " $\mathrm{t}$ " is regressed on the most recent change in each of the core indicators at 3,6 and 12-month frequencies, respectively. ${ }^{14}$ Indicating with $H_{t}^{12}$ the 12-month headline rate of inflation at time $\mathrm{t}$, and with $C_{t}^{k}$ the k-month rate of core inflation at time t, the following equation is estimated:

$$
H_{t+12}^{12}-H_{t}^{12}=\alpha+\beta\left(C_{t}^{k}-C_{t-k}^{k}\right)+\varepsilon_{t},
$$

with $\mathrm{k}=3,6$ and 12 months, and $\mathrm{C}$, a generic term representing, in turn, each type of core inflation indicator considered in this note. Based on the "extrapolation" interpretation of this equation, the parameter $\beta$ would be expected to have a positive value.

23. The results indicate a broad rejection of this "naïve" way of interpreting core indicators (Table 4). Using recent changes in core inflation as a ready-made "leading indicator" of similar changes in the headline rate does not seem to be justified in any of the five economies:

- In the euro area, Japan and the United Kingdom, recent changes in core inflation tell very little about future changes in headline inflation. Adjusted R-squares are close to zero and the coefficient $\beta$ has the wrong sign in the few cases where it is significant.

14. That is, for each core inflation indicator, the variable used as predictor is, alternatively, the latest 3-month inflation rate less the one 3 months earlier, the latest 6-month inflation rate less the one 6 months earlier, or the latest year-on-year inflation rate less the one 12 months earlier. Changes in 1-month rates were not used in this exercise because they are far too volatile, even after seasonal adjustment, for a single change to have predictive power. 
- In the United States and Canada, a few of the indicators seem to have some explanatory power, but also in these cases the coefficient $\beta$ has the wrong sign. In the case of the United States explanatory power is much lower in the earlier period (1984-1995) than in the more recent one.

24. The fact that the parameter $\beta$, whenever it is statistically significant, is always negative would imply that a recent rise in core inflation signals a future decline in headline inflation. A similar result (shown in the first line of Table 4) is obtained if the same equation is estimated extrapolating recent changes in headline inflation: also in this case $\beta$ is either insignificant or negative. These results seem to contradict the hypothesis that headline inflation can be forecast by extrapolating recent changes in core inflation. ${ }^{15}$

\subsection{Exercise 2: the "gap" model}

25. The second set of regressions examines the information content of the core inflation indicators by testing whether or not the current gap between headline and core inflation is significantly related to the gap between current and future headline inflation. This exercise in effect assesses whether there is a tendency for headline inflation to revert to some measure of core inflation in the short to medium run. The regression is estimated for predicted changes over 12, 18 and 24 months. ${ }^{16}$ In this case, the equation takes the following form:

$$
H_{t+j}^{12}-H_{t}^{12}=\alpha+\beta\left(C_{t}^{12}-H_{t}^{12}\right)+\varepsilon_{t} \text { for } \mathrm{j}=12,18 \text { and } 24 \text { months }
$$

26. If headline inflation tends to revert toward core, the parameter $\beta$ should be expected to take a positive value. ${ }^{17}$ The absolute value of $\beta$ should indicate the extent to which the gap is corrected over a particular forecasting horizon, although its interpretation is complicated by the fact that shocks affect not only headline inflation but also core indicators. ${ }^{18}$ As in the previous exercise, the explanatory power of the alternative indicators is assessed by examining whether the estimate of the coefficient $\beta$ is statistically significant and only those for which the $\beta$ s were significant at the $95 \%$ level or above are shown. Their respective adjusted $R^{2}$ s are used to compare the explanatory power of the competing core measures. To assess whether core indicators provide a better proxy of headline inflation's gravitation point than that

15 They would seem to be more consistent with a pattern whereby temporary shocks to headline inflation tend to be partly or fully reversed over the subsequent 12 months. To the extent that the shocks are also reflected in core indicators, the latter, too are negatively correlated with future changes in headline rates.

16. Similar exercises have been performed in a number of studies for individual economies. See Clark (2001) and Cogley (2002) for the United States, and Johnson (1999) and Macklem (2001) for Canada.

17. Strictly speaking, the coefficient is positive if a rise in inflation that is higher than trend is associated with a gap between core and headline that is larger than average. In other terms, when the equation is estimated, the gap between core and headline is automatically corrected for any difference in mean value between the two variables over the estimation period, which will be absorbed in the constant term.

18. If a temporary shock only affected the headline rate and not the core rate, $\beta=1$ would indicate full reversion to core at a given horizon and $0<\beta<1$ partial reversion. However, if the temporary shock affects the core indicator in the same direction as the headline rate and both will tend to return to their long-run values after the shock has faded, the current gap will be smaller than the total adjustment required for the headline rate to revert to its long-run value, and the estimated value of $\beta$ may be greater than 1 . 


\section{ECO/WKP(2005)48}

contained in the past history of the headline rate itself, a gap model estimated with a past average of headline inflation in place of the core rate is used as a benchmark. ${ }^{19}$

27. Turning to the results, presented in Table 5, the gap model seems to do remarkably well in terms of explanatory power, except in the case of the euro area. For most of the five economies, there are one or more indicators that outperform the benchmark (convergence to a past average). Usually, for most indicators the coefficient on the gap is significant, and the equation explains a significant proportion of changes in inflation.

28. In the most recent period (1996-2004) in the United States, Japan and Canada a past average of headline inflation does almost as well as the "attractor" as the best among core indicators, especially at the longer forecasting horizons. On the other hand, core indicators definitely do better than a past average in the 1984-1995 sample. Core indicators also do generally better than a past average in the euro area and the United Kingdom, for which data are available only for the recent period.

29. In the case of the United States and the euro area, the explanatory power of the gap model is greater at longer horizons, in the United Kingdom and Canada at the shorter one, while in Japan there is little difference. This may reflect different degrees of persistence of headline inflation, but is also probably affected by the nature and magnitude of shocks in the two periods. For example, in the period 1984-1995 there was very little difference across forecasting horizons in this respect.

30. Which indicators do best varies considerably across countries, and also in part across periods and forecasting horizons. In particular:

- For the United States, in the 1996-2004 sample period the Core 2 does best at the 12-month and 18-month horizons, Core 1 at the 24-month horizon. In 1984-1995 the 5\% trimmed mean does best at all horizons.

- For the euro area, the weighted median does best at all horizons.

- For Japan, in 1996-2004 the first double-weighted mean does best at all horizons; in the earlier sample period also the Huber-type skipped mean and most trimmed means do equally well.

- For the United Kingdom, the $25 \%$ trimmed mean and the first volatility-weighted mean do best.

- For Canada, in both periods the volatility-weighted mean and the double weighted mean based on the first volatility definition do best.

Overall, the weighted median, the Huber-type skipped mean, and the $25 \%$ trimmed mean do reasonably well in all economies and all periods. Volatility-weighted and double-weighted means do well in several countries but not for the euro area. The traditional Core 1 and Core 2 measures are among the best only in the United States. Among trimmed means, low trimming percentages do better in Japan (and in the United States in the earlier period), while high trimming percentages do better in most other cases.

19. Following Cogley (2002) this is constructed as a weighted average of inflation rates over the past five years with geometrically declining weights. The discount parameter in the geometric average was selected, for each economy, as the value providing the best results. See the notes to Table 5 for details. 


\subsection{Exercise 3: A more general distributed lag model}

31. The third exercise focuses on whether the information conveyed by core inflation indicators regarding future headline inflation is additional to that already contained in the recent headline rate itself. Regressions are run using a more general functional form where the dependent variable is the level of the 12-month-ahead headline inflation rate, and the explanatory variables are current and lagged values of both headline and core inflation (proxied by each indicator in turn), considered at alternative frequencies. ${ }^{20}$ Thus, the estimated equation has the following form:

$$
H_{t+j}^{12}=\alpha+\sum_{\substack{i=0 \\ \text { step } k}}^{12-k} \beta_{i} H_{t-i}^{k}+\sum_{\substack{i=0 \\ \text { step } k}}^{12-k} \gamma_{i} C_{t-i}^{k}+\varepsilon_{t} \text { for } \mathrm{j}=12,18 \text { and } 24 \text { months and } \mathrm{k}=1,3,6 \text { and } 12 \text { months, }
$$

where $\mathrm{k}$ indicates the frequency of the data used for the two explanatory variables $\mathrm{H}$ and $\mathrm{C}$. An F-test is then conducted to assess whether the $\gamma$ parameters are jointly significant; the adjusted $\mathrm{R}^{2} \mathrm{~s}$ for those specifications where this is the case are shaded in Table 6 . The benchmark estimates for each economy -- where only lagged headline inflation is used as a regressor -- are shown in the bottom line of the table.

\subsubsection{Additional explanatory power of core indicators}

32. For each economy, there are several core inflation indicators that add explanatory power relative to a specification where headline inflation is predicted only on the basis of its own history (Table 6, shaded cells), although the number of indicators that add information differs across economies, and also depends on the forecasting horizon considered. In the United States, the United Kingdom and Canada, headline inflation alone contains little information (as can be seen from the bottom line of each panel in Table 6), and the additional information provided by core indicators is very significant. By contrast, in the euro area and Japan the core indicators' additional information content is comparatively smaller, though still statistically significant in several cases. For the United States and the euro area, core indicators add more information at longer forecasting horizons, while the reverse is true for the other three economies, a pattern similar to the one found for the gap model. This may be an indication that inflation shocks are more persistent in these two economies.

33. In the 1996-2004 period (Table 6, panel I), in each country there are relatively clear hierarchies among indicators in terms of their additional explanatory power. In particular:

- In the United States trimmed means and the Huber-type skipped mean do well at all horizons; at longer horizons also Core 1 and Core 2 are among the most informative.

- In the euro area, trimmed means perform well at all horizons, while Core 1 and Core 2 are among the best only at the 12-month horizon.

- In Japan the double-weighted means consistently do best, but also Core 1 and the $2 \%$ trimmed mean are among the few that add some information; however, no indicators pass the F-test at the 24-month horizon.

20. That is, when the 1-month rates are used, all lagged values from time to time $\mathrm{t}-11$ are included; for 3 -month rates, the values included are those at times $\mathrm{t}, \mathrm{t}-3, \mathrm{t}-6$ and $\mathrm{t}-9$; for 6-month rates, those at time $\mathrm{t}$ and $\mathrm{t}-6$; and for the 12-month rates, only the current (time $\mathrm{t}$ ) value is included. The inclusion of only lagged values referring to non-overlapping periods is intended to ensure that the results are comparable across frequencies, as they can be seen as alternative ways of "packaging" the same information by aggregating it through time. 
- In the United Kingdom several trimmed means, the Huber-type skipped mean and Core 1 contain significant additional information, but only at the 12-month horizon.

- In Canada volatility-weighted and double-weighted means and the Huber-type skipped mean are the best performers; their additional information content is highest at the 12-month horizon, and declines sharply at longer horizons.

On the other hand, in the 1984-1995 period, differences across indicators in terms of explanatory power seem to be much smaller (Table 6, panel II).

34. In addition to F-tests to assess the additional information content of core indicators when headline inflation is already present, the reverse F-tests were also performed. In Table 6, cases where headline inflation provides additional information when the core indicator is present are marked with an asterisk. In many cases headline inflation seems to convey information that is additional to that contained in core indicators. In the United States, core inflation dominates (headline is insignificant) in a large majority of cases, while in the euro area there are more cases where headline dominates (core is insignificant), especially at the 12-month forecasting horizon. In the other three economies the numbers of cases where each dominates are approximately equal. Moreover, they tend to coincide, especially at the 12month horizon: when excluding headline is rejected, also excluding core is rejected; and when one is rejected, both are. This last result would seem at least intuitively consistent with the gap model, where the difference between core and headline inflation is the explanatory variable.

\subsubsection{Comparative information content of data at different frequencies}

35. By comparing the results obtained estimating the distributed lag model at different frequencies it is also possible to draw some evidence on whether the information content of core inflation indicators is particularly valuable at higher frequencies. As it may be recalled, this hypothesis arises from the observation that these indicators are much less volatile than the headline rate, particularly at higher frequencies, which naturally raises the question of whether they offer a better signal-to-noise ratio. The answer to this question can only be an empirical one, and ultimately depends on whether the indicators' lower volatility results from filtering out mainly noise or also relevant information. The definition of what represents "relevant information" is, of course, model-specific.

36. In the context of the distributed-lag model, the specification of the models at different frequencies -- which can be seen as different ways of "packaging" the same basic information through what is equivalent to restrictions on coefficients -- make it possible to compare the efficiency of estimates across frequencies. A simple way of doing this is by comparing the adjusted $\mathrm{R}^{2}$ shown in Table 6 across frequencies. A more formal comparison is also possible using a standard F-test. This is a test of whether the restrictions on coefficients involved in moving from a higher to a lower data frequency are supported or rejected by the data.

37. The F-test results, presented in Table 7, seem to support only in part the hypothesis that higherfrequency data become more valuable when core indicators are included in the estimated equation. The main conclusions are:

- Using data at the highest frequency (1-month inflation rates) appears to be much less efficient than using data at the 3-month, 6-month and 12-month frequencies, as indicated by generally lower adjusted $\mathrm{R}^{2}$ in Table 6 and very few cases where the restriction involved by moving from 1 to 3 months is rejected in Table 7. Differences are smaller between the other three frequencies. In a wide range of cases, 6-month rates seem to add information relative to 12-month rates. Only for 
a smaller number of indicators do 3-month rates add information relative to 6-month rates. However, there are also many cases where 12-month rates seem to contain sufficient information.

- There are some cases, particularly for the United States, where the restriction implied by using lower-frequency data involves no significant loss of information if only headline rates are present in the equation (the bottom line in Table 7), but a loss of information if certain core indicators are added. However, in a majority of cases the restrictions are either rejected or supported in both specifications. This suggests that the hypothesis that higher-frequency data become more valuable when core inflation indicators are included is supported in some cases, but not in general.

- Higher-frequency data seem to be more relevant at shorter horizon forecasts for the United Kingdom, but at longer horizons for the euro area, Japan and Canada. This latter result is somewhat counterintuitive.

\section{Out-of-sample forecasting performance}

38. The results presented in the previous section refer to the in-sample performance of three alternative models used here to forecast headline inflation. By construction, these estimates use information covering the entire sample period. An experiment closer to real-life situations would be, however, to test the same models out of sample, that is, to assess the forecasting performance of a model estimated only with data available at the time the forecast is made. In this section, out-of-sample exercises are performed for the two models that in the previous section were found to have satisfactory in-sample properties, leaving out the naïve extrapolation model. Moreover, in consideration of the fact that out-of-sample forecasting necessarily involves a shortening of the estimation period, which is more substantial the longer is the forecasting horizon, only the 12-month-ahead forecasting horizon was considered. Two periods are considered: 2002-2004 for all five economies, and 1995-2004 for the three economies for which longer data series are available. ${ }^{21}$ For the euro area and the United Kingdom the results must be taken with some caution, given the short span of available data. For all specifications, outof-sample performance is assessed by comparing root mean squared forecast errors (RMSFE). As a benchmark, the simplest naïve forecast will be used: the so-called "random-walk forecast", whereby the 12-month-ahead headline inflation rate is projected to be equal to the current rate.

\subsection{The gap model}

39. In the out-of-sample forecasting exercise, the estimated gap model never outperforms a randomwalk forecast, for any of the indicators and for any country (Table 8, panel A). Moreover, in the United States, Japan and Canada (but not in the euro area and United Kingdom) the forecasting performance of the gap model with core inflation indicators is also inferior to a gap model where a past average of headline inflation plays the role of core inflation (which anyway is also unable to beat the random walk forecasts). For the three countries where longer data series are available, out-of-sample forecasting performance evaluated over the longer (1995-2004) sample period is slightly better, but still inferior to the random-walk forecast.

40. On the other hand, if instead of estimating the gap model a "restricted" version is used, imposing a unit $\beta$ coefficient and a zero constant term, this "restricted" gap model does a lot better out-of-sample, and actually beats the random walk benchmark in most cases - including for the euro area (Table 8, panel

21. For each monthly forecast, the model is estimated from 1984 (or the earliest period available) to the forecast date. That means from 1984 for the United States and Japan, from 1986 for Canada, from 1996 for the euro area and from 1997 for the United Kingdom. 
B). A possible interpretation of the result that restricting coefficients actually improves forecasting performance is that the estimated coefficients in the gap model are very unstable -- possibly because the persistence of deviations between headline and core depends on the nature of the shocks, which changes very frequently -- so that estimates based on the past are not a good guide to the future, and it is possible to do better by setting fixed coefficients. The fact that the forecasts from the estimated gap model are constructed from a model specified in differences may also tend to amplify the resulting distortion.

41. However, forecasts constructed with the "restricted" gap model using core inflation indicators are outperformed (except in the case of Japan) by the same model with a past average of headline inflation playing the role of core. ${ }^{22}$ Overall, this result would seem to suggest that, at least for the economies and the periods covered in the analysis, inflation is well approximated by a simple mean reversion process. Where core inflation indicators perform relatively well it is probably because, by filtering out temporary shocks and remaining closer to the mean, they help capture some of this mean reversion. But a past average of headline inflation -- at least in periods where inflation was close to a stationary behaviour -- remained a better proxy of the underlying mean.

\subsection{The distributed lag model}

42. The distributed-lag model does definitely better than the estimated gap model in the out-of-sample forecasting exercise and approximately as well as the "restricted" gap model. It beats the benchmark in most cases (except for the euro area), although it must be recalled that a random-walk forecast -- which simply assumes future inflation to be equal to the current rate -- is not a particularly high standard for forecasting performance. The main results can be summarised as follows:

- Performance relative to the random-walk benchmark over the 2002-2004 sample period is relatively good in Canada, with RMSFEs about one half of the benchmark or less (Table 9, panel I). It is somewhat less good, but still superior to the benchmark for the United States and the United Kingdom (RMSFEs 20 to 30\% below the benchmark) and in Japan (10-15\% below). Results are rather bad for the euro area, with RMSFEs always above the benchmark.

- On the other hand, the out-of-sample forecasting performance tends to be less good when the longer sample period (1995-2004) is considered, for the three countries for which longer data series are available. In the United State and Japan, only few indicators beat the random-walk forecast and even then only by a small margin, while the models continue to do better in Canada in relative terms (Table 9, panel II).

- Relative to specifications with only headline inflation as an explanatory variable, adding core indicators to the equation improves forecasting performance for most indicators in Japan and Canada, only for a few indicators in the United States and the United Kingdom, for no indicators in the euro area.

- The in-sample performance of the individual indicators is not necessarily a good guide to their out-of-sample performance: the best performers in the two exercises coincide in some cases but not others. For example, in the case of the United States the Core 2 indicator does very well outof-sample, even though it is one of the worst performers in-sample. For Japan, the $2 \%$ trimmed mean is among the best in-sample, but does badly out-of-sample. When a longer sample period is considered (Table 9, panel II) there are also some changes in the relative performance of individual indicators.

22. This result applies not only to 12-month-ahead but also to 18- and 24-month ahead forecasts (not shown in the table). 
- In the United States, Japan and Canada the out-of-sample performance of distributed lag models is approximately equivalent regardless of the frequency of data used (3-month, 6-month or 12-month rates). That is, higher-frequency data neither improve nor worsen performance relative to 12-month rates. By contrast, higher-frequency specifications perform definitely worse for the euro area and the United Kingdom.

\section{Concluding remarks}

43. Indicators of core inflation are, like the standard headline CPI rate, ways of summarising the information contained in the distribution of price changes of individual CPI components. Because they apply different filters, the various indicators convey information about the behaviour of consumer prices that will in general differ from that contained in the headline rate. Thus, some of the measures considered here focus on a subset of CPI components, excluding those believed to be most volatile; others focus on the observed distribution of price changes each month and select the central portion; still others alter weights so as to privilege the least volatile components. Each of these perspectives illuminates a specific facet of the inflation process that is potentially of interest in its own right, and not only because it can help predict the behaviour of that particular inflation measure which is the headline rate, which -- it should be recalled -- is not necessarily free from distortions. For example, knowing that the central section of the distribution of CPI price changes -- or, alternatively, the bulk of the least volatile items, or the average excluding food and energy -- are moving in a certain direction is potentially relevant information in itself, which could indicate that some of the fundamental drivers of inflation are pulling in that direction. This would be relevant regardless of whether it helps predict the future behaviour of the headline rate. In this regard, alternative measures of core inflation can be seen as complementary elements of information. In assessing inflation trends, the conclusions will appear more robust if indicators constructed according to different approaches all point in the same direction.

44. In this paper, however, we have taken a narrower approach to evaluating the information content of indicators of core inflation, stipulating that they should be assessed according to their contribution to predicting headline inflation. This choice is dictated by the fact that headline CPI inflation is usually the reference measure according to which the achievement of price stability is assessed, so the headline rate is inevitably the variable policy makers are interested in forecasting. Moreover, we have chosen to look at alternative indicators as competing measures if core inflation, rather than as complementary. This approach can be seen as providing only a preliminary assessment of these indicators' informational value, and does not purport to illustrate how they are normally used by forecasters and policy makers.

45. Overall, the paper provides evidence that indicators of core inflation contain useful information both on headline inflation's current trend and on where it is heading. The indicators do considerably better than the headline rate at tracking a proxy of the underlying inflation trend and, being much less volatile, can also be used at higher frequencies to provide more timely information. A majority of indicators contain information that is additional to that contained in the past history of the headline rate and that is relevant to predicting future headline inflation. And there is evidence that headline inflation tends to converge toward core inflation (proxied by our core indicators) over time horizons of between 12 and 24 months. 


\section{REFERENCES}

ANGELONI, I., L. AUCREMANNE, M. EHRMANN, J. GALI, A. LEVIN and F. SMETS (2004), "Inflation persistence in the euro area: Preliminary summary of findings", paper presented at the ECB conference on inflation persistence held in Frankfurt-am-Main on 10-11 December 2004, available at www.ecb.int.

AUCREMANNE, L. (2000), "The use of robust estimators as measures of core inflation", National Bank of Belgium Working Papers - Research Series, No. 2.

BAKHSHI, H. and T. YATES (1999), "To trim or not to trim? An application of a trimmed mean inflation estimator to the United Kingdom", Bank of England Working Papers, No. 97.

BALL, L. and N.G. MANKIW (1995, "Relative price changes as aggregate supply shocks", The Quarterly Journal of Economics, Vol110, No. 1 (Feb), pp. 161-193.

BANK of ENGLAND (2004), Inflation Report, November.

BRYAN, M.F. and S.G. CECCHETTI (1999), "The monthly measurement of core inflation in Japan", Bank of Japan Institute for Monetary and Economic Studies, May.

BRYAN, M.F. and S.G. CECCHETTI (1993), "The consumer price index as a measure of inflation", NBER Working Paper Series, No. 4505.

BRYAN, M.F., S.G. CECCHETTI and R.L. WIGGINS (1997), "Efficient inflation estimation", NBER Working Paper Series, No. 6183.

CECCHETTI, S.G. (1997), "Measuring short-run inflation for central bankers", Federal Reserve Bank of St. Louis Review, May/June.

CLARK, T.E. (2001), "Comparing measures of core inflation", Federal Reserve Bank of Kansas City Economic Review, $2^{\text {nd }}$ quarter.

COGLEY, T. (2002), "A simple adaptive measure of core inflation”, Journal of Money, Credit and Banking, Ohio State University Press, Vol. 34.

CRISTADORO, R., M. FORNI, L. REICHLIN and G. VERONESE (2005) "A core inflation indicator for the euro area", Journal of Money, Credit, and Banking, Vol. 37, No. 3, June, pp. 539-560.

DIEWERT, W.E. (1995), "On the stochastic approach to index numbers", University of British Columbia Discussion Paper No. 95-31.

DOLMAS, J. (2005), “Trimmed mean PCE inflation", Federal Reserve Bank of Dallas Research department Working Papers, No. 0506. 
HALL, S., M. WALSH and A. YATES (1997), "How do UK companies set prices?", Bank of England Working Papers, No. 67.

KASHYAP, A.K. (1995), "Sticky prices: new evidence from retail catalogs", Quarterly Journal of Economics, Vol. 110(1), pp. 245-74.

JOHNSON, M. (1999), Core Inflation: A Measure Of Inflation For Policy Purposes, Paper presented at Workshop of Central Bank Model Builders, BIS, 18-19 February.

MACKLEM, T. (2001), “A new measure of core inflation”, Bank of Canada Review, Vol. 2001.

MARQUES, C., P. NEVES and L. SARMENTO (2000), "Evaluating core inflation indicators", Banco de Portugal Working Papers, No. 3-00.

QUAH, D. and S. VAHEY (1995), "Measuring core inflation”, The Economic Journal, Vol. 105, No. 432.

ROGER, S. (1998), "Core inflation: concepts uses and measurement", Reserve Bank of New Zealand Discussion Papers, G98/9.

STOCK, J.H. and M.W. WATSON (1988), "A probability model of the coincident economic indicators", NBER Working Paper Series, No. 2772.

VEGA, J-L. and M.A. WYNNE (2001), "An evaluation of some measures of core inflation for the euro area", European Central Bank Working Papers, No. 53. 
ECO/WKP(2005)48

TABLES AND FIGURES 
ECO/WKP(2005)48

Table 1 - Headline and core inflation: average values

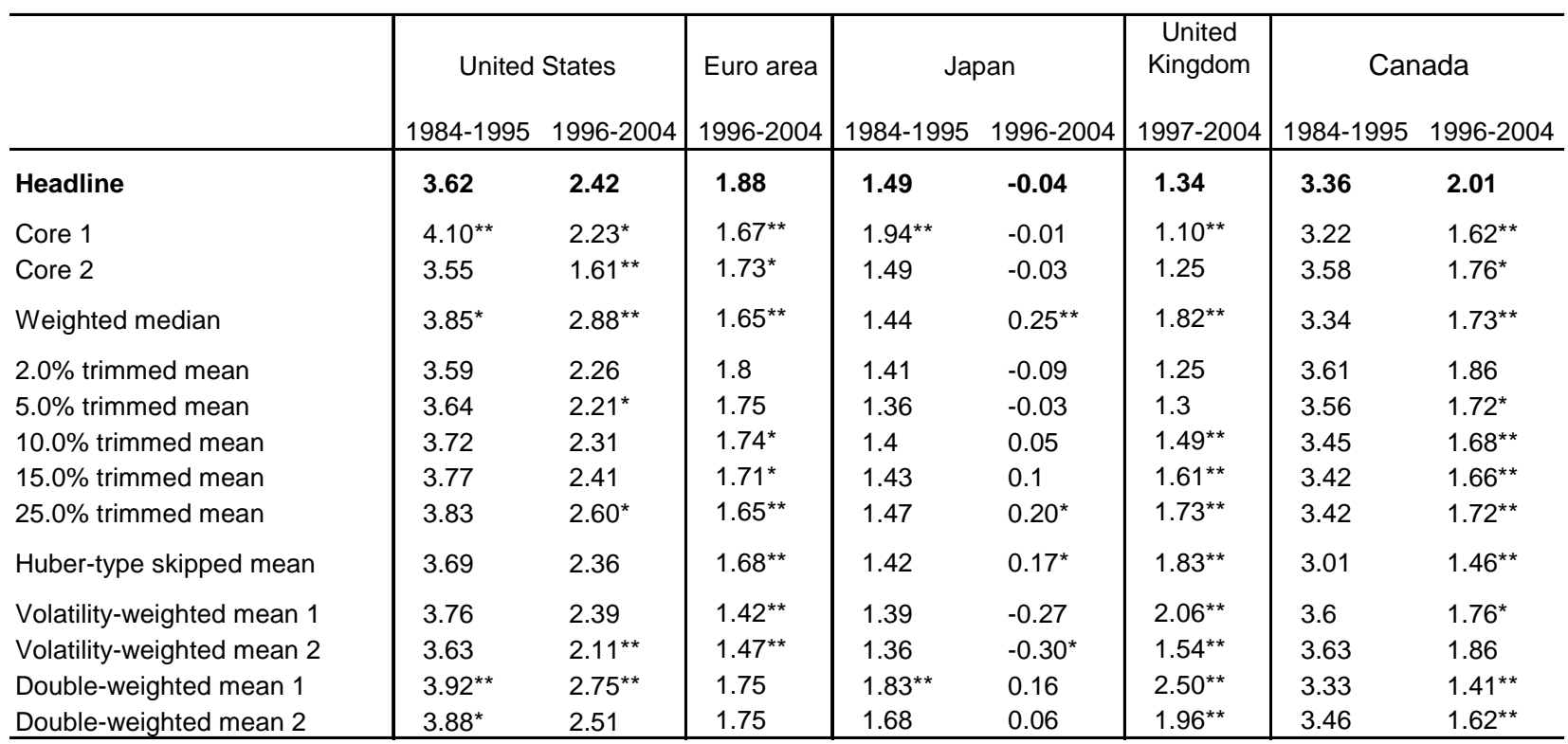

Note: asterisks denote where the mean of the core measure is significantly different (based on the ANOVA F-statistic) from the mean of headline inflation, with * and ** indicating that equality is rejected at the $5 \%$ and at the $1 \%$ confidence level, respectively. 


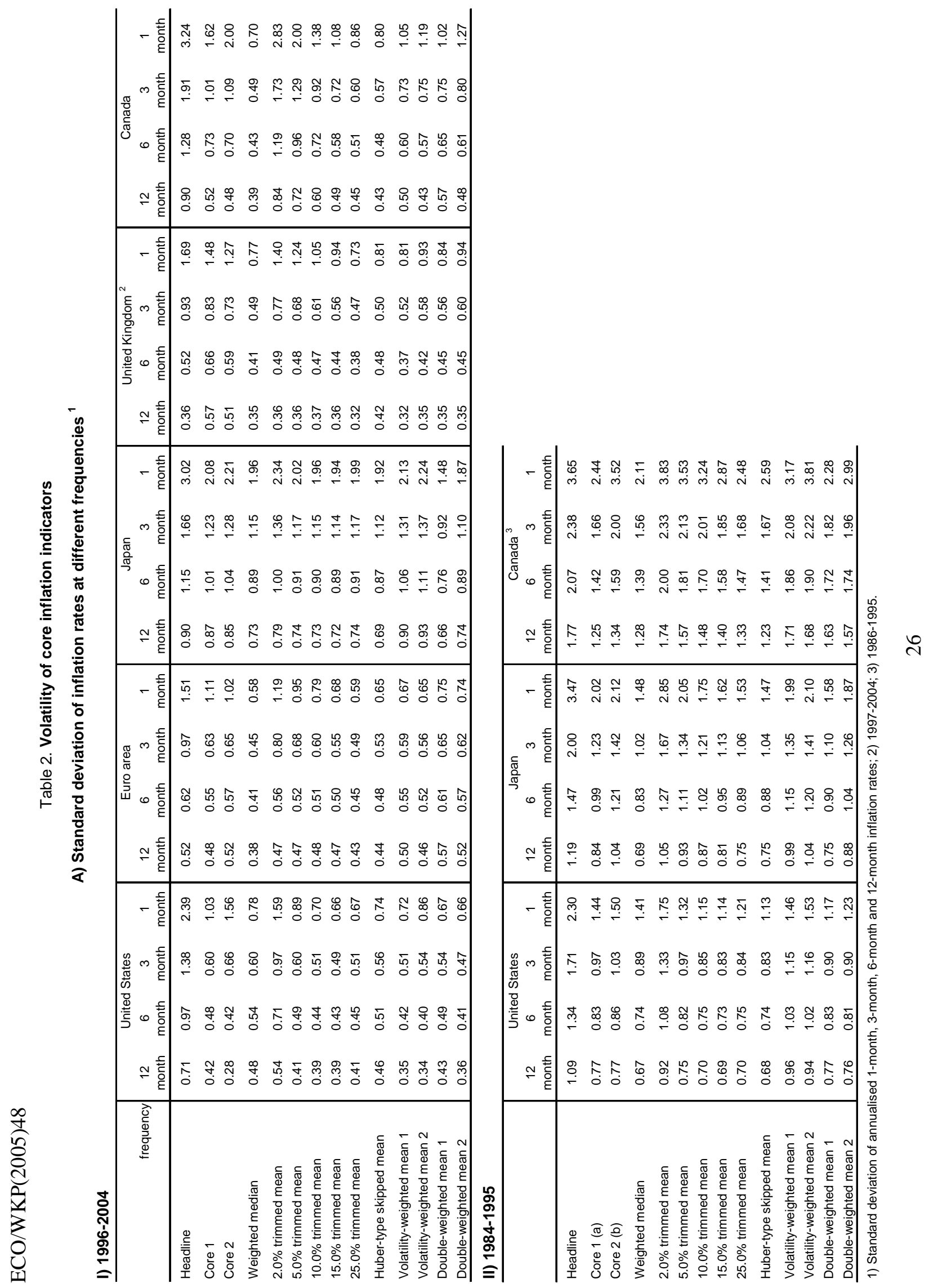




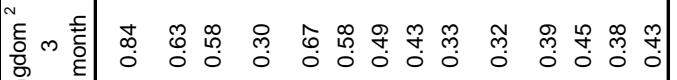

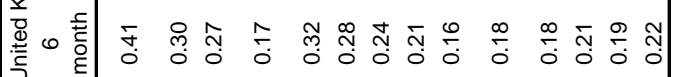

$\simeq$ 亮

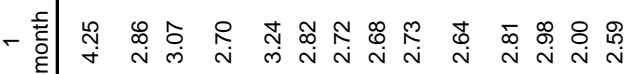

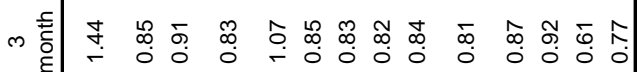

离

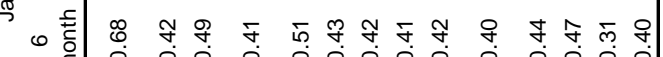

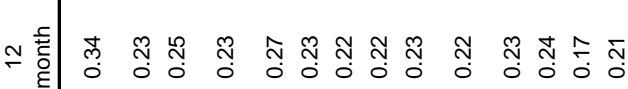

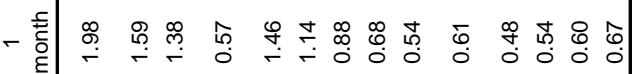

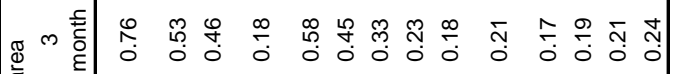

焉

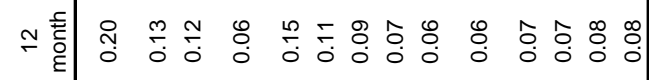

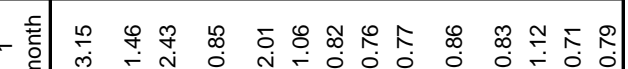

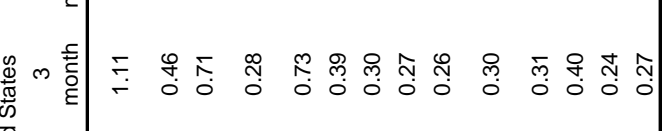

曾

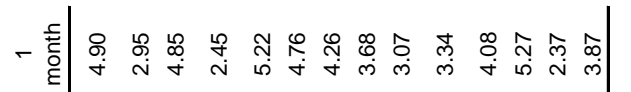

m 壳市

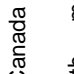

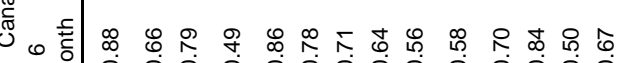

는 운

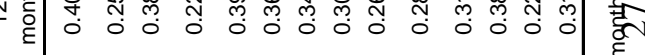

- 言 E

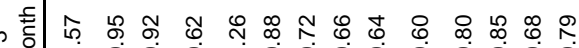

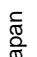

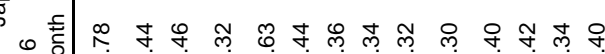

ำ $\approx$ ₹

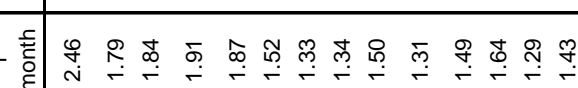

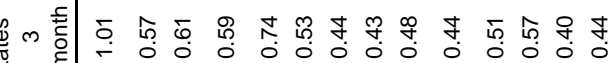

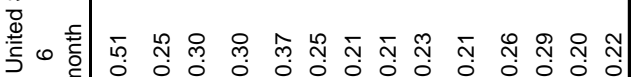

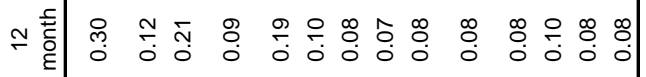

$\simeq$ 言言 
Table 2. Volatility of core inflation indicators (continued)

C) Autocorrelation of 1-month inflation rates ${ }^{1}$

\begin{tabular}{|c|c|c|c|c|c|c|c|c|}
\hline & $\begin{array}{r}\text { United } \\
\text { 1984-1995 }\end{array}$ & $\begin{array}{l}\text { States } \\
1996-2004\end{array}$ & $\begin{array}{l}\text { Euro area } \\
1996-2004\end{array}$ & $\begin{array}{r}\text { Ja } \\
\text { 1984-1995 } \\
\end{array}$ & $\begin{array}{l}\text { Jan } \\
1996-2004 \\
\end{array}$ & $\begin{array}{c}\begin{array}{c}\text { United } \\
\text { Kingdom }\end{array} \\
1997-2004\end{array}$ & $\begin{array}{r}\text { Can } \\
\text { 1986-1995 }\end{array}$ & $\begin{array}{l}\text { lada } \\
\text { 1996-2004 }\end{array}$ \\
\hline Headline & 0.57 & 0.11 & 0.62 & 0.51 & 0.31 & -0.45 & 0.62 & -0.15 \\
\hline Core $1(\mathrm{a})$ & 0.81 & 0.59 & 0.51 & 0.64 & 0.51 & 0.53 & 0.79 & -0.09 \\
\hline Core 2 (b) & 0.90 & -0.67 & 0.61 & 0.68 & 0.38 & 0.48 & 0.45 & -0.22 \\
\hline Weighted median & 0.77 & 0.72 & 0.78 & 0.61 & 0.37 & 0.66 & 0.80 & 0.72 \\
\hline $2 \%$ trimmed mean & 0.70 & 0.27 & 0.59 & 0.56 & 0.36 & -0.14 & 0.62 & -0.02 \\
\hline $5 \%$ trimmed mean & 0.83 & 0.57 & 0.66 & 0.65 & 0.38 & -0.02 & 0.60 & 0.26 \\
\hline $10 \%$ trimmed mean & 0.88 & 0.68 & 0.78 & 0.68 & 0.37 & 0.21 & 0.62 & 0.50 \\
\hline $15 \%$ trimmed mean & 0.87 & 0.72 & 0.82 & 0.66 & 0.35 & 0.35 & 0.66 & 0.57 \\
\hline $25 \%$ trimmed mean & 0.85 & 0.72 & 0.84 & 0.63 & 0.35 & 0.56 & 0.73 & 0.65 \\
\hline Huber-type skipped mean & 0.85 & 0.74 & 0.82 & 0.68 & 0.32 & 0.65 & 0.63 & 0.69 \\
\hline Volatility weighted 1 & 0.91 & 0.50 & 0.80 & 0.67 & 0.52 & 0.44 & 0.77 & 0.50 \\
\hline Volatility weighted 2 & 0.89 & 0.36 & 0.77 & 0.67 & 0.51 & 0.36 & 0.62 & 0.17 \\
\hline Double weighted 1 & 0.89 & 0.73 & 0.81 & 0.61 & 0.56 & 0.41 & 0.87 & 0.65 \\
\hline Double weighted 2 & 0.87 & 0.64 & 0.78 & 0.64 & 0.46 & 0.34 & 0.71 & 0.29 \\
\hline
\end{tabular}

1) Sum of the estimated autoregressive coefficients in a distributed lag equation of order 12. 
ECO/WKP(2005)48

Table 3. Performance of core inflation indicators in tracking trend headline inflation

A) Unadjusted RMSE

\begin{tabular}{|c|c|c|c|c|c|c|c|c|c|c|c|c|c|c|c|}
\hline & \multicolumn{3}{|c|}{ United States } & \multicolumn{3}{|c|}{ Euro area } & \multicolumn{3}{|c|}{ Japan } & \multicolumn{3}{|c|}{ United Kingdom } & \multicolumn{3}{|c|}{ Canada } \\
\hline & $\begin{array}{c}12 \\
\text { month }\end{array}$ & $\begin{array}{c}6 \\
\text { month }\end{array}$ & $\begin{array}{c}3 \\
\text { month }\end{array}$ & $\begin{array}{c}12 \\
\text { month }\end{array}$ & $\begin{array}{c}6 \\
\text { month }\end{array}$ & $\begin{array}{c}3 \\
\text { month }\end{array}$ & $\begin{array}{c}12 \\
\text { month }\end{array}$ & $\begin{array}{c}6 \\
\text { month }\end{array}$ & $\begin{array}{c}3 \\
\text { month }\end{array}$ & $\begin{array}{c}12 \\
\text { month }\end{array}$ & $\begin{array}{c}6 \\
\text { month }\end{array}$ & $\begin{array}{c}3 \\
\text { month }\end{array}$ & $\begin{array}{c}12 \\
\text { month }\end{array}$ & $\begin{array}{c}6 \\
\text { month }\end{array}$ & $\begin{array}{c}3 \\
\text { month }\end{array}$ \\
\hline Headline & 0.45 & 0.75 & 1.06 & 0.23 & 0.44 & 0.80 & 0.50 & 0.90 & 1.37 & 0.26 & 0.51 & 0.82 & 0.75 & 1.32 & 1.81 \\
\hline Core 1 & 0.45 & 0.52 & 0.56 & 0.50 & 0.55 & 0.64 & 0.43 & 0.69 & 0.93 & 0.52 & 0.64 & 0.79 & 0.64 & 0.88 & 1.04 \\
\hline Core 2 & 0.84 & 0.92 & 0.98 & 0.47 & 0.52 & 0.58 & 0.51 & 0.82 & 1.05 & 0.38 & 0.49 & 0.63 & 0.65 & 0.89 & 1.09 \\
\hline Weighted median & 0.89 & 0.92 & 0.94 & 0.31 & 0.34 & 0.37 & 0.64 & 0.85 & 1.08 & 0.56 & 0.60 & 0.64 & 0.42 & 0.48 & 0.52 \\
\hline $2.0 \%$ trimmed mean & 0.34 & 0.53 & 0.71 & 0.22 & 0.38 & 0.63 & 0.44 & 0.79 & 1.13 & 0.24 & 0.43 & 0.65 & 0.72 & 1.23 & 1.66 \\
\hline $5.0 \%$ trimmed mean & 0.35 & 0.42 & 0.48 & 0.25 & 0.33 & 0.49 & 0.44 & 0.73 & 0.99 & 0.24 & 0.39 & 0.57 & 0.61 & 0.96 & 1.23 \\
\hline $10.0 \%$ trimmed mean & 0.39 & 0.44 & 0.47 & 0.23 & 0.29 & 0.40 & 0.48 & 0.75 & 1.00 & 0.32 & 0.43 & 0.58 & 0.49 & 0.69 & 0.85 \\
\hline $15.0 \%$ trimmed mean & 0.46 & 0.51 & 0.53 & 0.25 & 0.30 & 0.35 & 0.52 & 0.78 & 1.02 & 0.39 & 0.47 & 0.58 & 0.46 & 0.59 & 0.71 \\
\hline $25.0 \%$ trimmed mean & 0.62 & 0.65 & 0.67 & 0.29 & 0.32 & 0.34 & 0.59 & 0.83 & 1.07 & 0.51 & 0.55 & 0.60 & 0.42 & 0.51 & 0.59 \\
\hline Huber-type skipped mean & 0.51 & 0.57 & 0.60 & 0.31 & 0.35 & 0.38 & 0.58 & 0.81 & 1.04 & 0.58 & 0.62 & 0.64 & 0.64 & 0.70 & 0.74 \\
\hline Volatility-weighted mean 1 & 0.37 & 0.41 & 0.47 & 0.50 & 0.53 & 0.56 & 0.50 & 0.80 & 1.06 & 0.83 & 0.85 & 0.90 & 0.41 & 0.57 & 0.69 \\
\hline Volatility-weighted mean 2 & 0.38 & 0.43 & 0.50 & 0.46 & 0.50 & 0.52 & 0.54 & 0.84 & 1.12 & 0.40 & 0.47 & 0.58 & 0.40 & 0.60 & 0.74 \\
\hline Double-weighted mean 1 & 0.72 & 0.75 & 0.77 & 0.35 & 0.41 & 0.45 & 0.43 & 0.60 & 0.76 & 1.27 & 1.31 & 1.33 & 0.68 & 0.78 & 0.85 \\
\hline Double-weighted mean 2 & 0.47 & 0.50 & 0.53 & 0.31 & 0.38 & 0.43 & 0.42 & 0.68 & 0.90 & 0.71 & 0.77 & 0.84 & 0.54 & 0.72 & 0.84 \\
\hline
\end{tabular}

II) $1986-1996$

\begin{tabular}{|c|c|c|c|c|c|c|c|c|c|}
\hline & \multicolumn{3}{|c|}{ United States } & \multicolumn{3}{|c|}{ Japan } & \multicolumn{3}{|c|}{ Canada } \\
\hline & $\begin{array}{c}12 \\
\text { month }\end{array}$ & $\begin{array}{c}6 \\
\text { month }\end{array}$ & $\begin{array}{c}3 \\
\text { month }\end{array}$ & $\begin{array}{c}12 \\
\text { month }\end{array}$ & $\begin{array}{c}6 \\
\text { month }\end{array}$ & $\begin{array}{c}3 \\
\text { month }\end{array}$ & $\begin{array}{c}12 \\
\text { month }\end{array}$ & $\begin{array}{c}6 \\
\text { month }\end{array}$ & $\begin{array}{c}3 \\
\text { month }\end{array}$ \\
\hline Headline & 0.58 & 0.97 & 1.35 & 0.50 & 0.90 & 1.38 & 0.83 & 1.39 & 1.69 \\
\hline Core 1 & 0.59 & 0.64 & 0.75 & 0.67 & 0.79 & 0.93 & 0.72 & 0.98 & 1.19 \\
\hline Core 2 & 0.65 & 0.73 & 0.81 & 0.41 & 0.68 & 0.90 & 0.84 & 1.20 & 1.55 \\
\hline Weighted median & 0.51 & 0.59 & 0.70 & 0.51 & 0.67 & 0.83 & 0.57 & 0.79 & 0.98 \\
\hline $2.0 \%$ trimmed mean & 0.40 & 0.68 & 0.95 & 0.42 & 0.75 & 1.15 & 0.81 & 1.30 & 1.63 \\
\hline $5.0 \%$ trimmed mean & 0.30 & 0.41 & 0.57 & 0.37 & 0.65 & 0.91 & 0.74 & 1.17 & 1.50 \\
\hline $10.0 \%$ trimmed mean & 0.36 & 0.42 & 0.51 & 0.38 & 0.62 & 0.83 & 0.69 & 1.09 & 1.40 \\
\hline $15.0 \%$ trimmed mean & 0.40 & 0.46 & 0.53 & 0.42 & 0.62 & 0.81 & 0.66 & 0.99 & 1.27 \\
\hline $25.0 \%$ trimmed mean & 0.45 & 0.50 & 0.58 & 0.46 & 0.64 & 0.82 & 0.62 & 0.89 & 1.12 \\
\hline Huber-type skipped mean & 0.38 & 0.43 & 0.50 & 0.46 & 0.62 & 0.78 & 0.81 & 1.06 & 1.30 \\
\hline Volatility-weighted mean 1 & 0.42 & 0.54 & 0.68 & 0.44 & 0.71 & 0.93 & 0.68 & 1.03 & 1.26 \\
\hline Volatility-weighted mean 2 & 0.39 & 0.54 & 0.70 & 0.45 & 0.73 & 0.97 & 0.76 & 1.21 & 1.52 \\
\hline Double-weighted mean 1 & 0.46 & 0.51 & 0.57 & 0.60 & 0.76 & 0.93 & 0.59 & 0.82 & 0.95 \\
\hline Double-weighted mean 2 & 0.45 & 0.51 & 0.58 & 0.46 & 0.69 & 0.92 & 0.64 & 1.00 & 1.24 \\
\hline
\end{tabular}

Note: in each column, the number in bold denotes the indicator that best tracks trend headline inflation (that with the lowest RMSE) 
Table 3. Performance of core inflation indicators in tracking trend headline inflation (continued)

B) Mean-adjusted RMSE ${ }^{1}$

I) 1997-2003

\begin{tabular}{|c|c|c|c|c|c|c|c|c|c|c|c|c|c|c|c|}
\hline & \multicolumn{3}{|c|}{ United States } & \multicolumn{3}{|c|}{ Euro area } & \multicolumn{3}{|c|}{ Japan } & \multicolumn{3}{|c|}{ United Kingdom } & \multicolumn{3}{|c|}{ Canada } \\
\hline & $\begin{array}{c}12 \\
\text { month }\end{array}$ & $\begin{array}{c}6 \\
\text { month }\end{array}$ & $\begin{array}{c}3 \\
\text { month }\end{array}$ & $\begin{array}{c}12 \\
\text { month }\end{array}$ & $\begin{array}{c}6 \\
\text { month }\end{array}$ & $\begin{array}{c}3 \\
\text { month }\end{array}$ & $\begin{array}{c}12 \\
\text { month }\end{array}$ & $\begin{array}{c}6 \\
\text { month }\end{array}$ & $\begin{array}{c}3 \\
\text { month }\end{array}$ & $\begin{array}{c}12 \\
\text { month }\end{array}$ & $\begin{array}{c}6 \\
\text { month }\end{array}$ & $\begin{array}{c}3 \\
\text { month }\end{array}$ & $\begin{array}{c}12 \\
\text { month }\end{array}$ & $\begin{array}{c}6 \\
\text { month }\end{array}$ & $\begin{array}{c}3 \\
\text { month }\end{array}$ \\
\hline Headline & 0.44 & 0.75 & 1.06 & 0.23 & 0.44 & 0.80 & 0.50 & 0.90 & 1.37 & 0.26 & 0.51 & 0.82 & 0.75 & 1.32 & 1.81 \\
\hline Core 1 & 0.44 & 0.51 & 0.55 & 0.43 & 0.49 & 0.58 & 0.42 & 0.68 & 0.92 & 0.45 & 0.58 & 0.74 & 0.52 & 0.80 & 0.96 \\
\hline Core 2 & 0.42 & 0.51 & 0.65 & 0.43 & 0.49 & 0.55 & 0.50 & 0.82 & 1.05 & 0.36 & 0.48 & 0.62 & 0.58 & 0.83 & 1.04 \\
\hline Weighted median & 0.64 & 0.73 & 0.73 & 0.20 & 0.25 & 0.29 & 0.50 & 0.74 & 1.00 & 0.29 & 0.37 & 0.44 & 0.30 & 0.37 & 0.45 \\
\hline $2.0 \%$ trimmed mean & 0.30 & 0.49 & 0.70 & 0.20 & 0.36 & 0.62 & 0.44 & 0.79 & 1.13 & 0.21 & 0.41 & 0.63 & 0.70 & 1.22 & 1.65 \\
\hline $5.0 \%$ trimmed mean & 0.31 & 0.37 & 0.45 & 0.18 & 0.28 & 0.46 & 0.43 & 0.72 & 0.99 & 0.23 & 0.38 & 0.57 & 0.54 & 0.92 & 1.20 \\
\hline $10.0 \%$ trimmed mean & 0.39 & 0.43 & 0.47 & 0.17 & 0.24 & 0.36 & 0.45 & 0.73 & 0.98 & 0.29 & 0.41 & 0.56 & 0.37 & 0.61 & 0.80 \\
\hline $15.0 \%$ trimmed mean & 0.46 & 0.50 & 0.52 & 0.18 & 0.24 & 0.30 & 0.48 & 0.74 & 0.99 & 0.28 & 0.38 & 0.52 & 0.30 & 0.47 & 0.63 \\
\hline $25.0 \%$ trimmed mean & 0.54 & 0.60 & 0.61 & 0.19 & 0.23 & 0.27 & 0.50 & 0.77 & 1.02 & 0.30 & 0.37 & 0.45 & 0.30 & 0.41 & 0.51 \\
\hline Huber-type skipped mean & 0.51 & 0.57 & 0.60 & 0.24 & 0.29 & 0.33 & 0.49 & 0.74 & 0.99 & 0.34 & 0.41 & 0.45 & 0.33 & 0.41 & 0.51 \\
\hline Volatility-weighted mean 1 & 0.37 & 0.41 & 0.47 & 0.28 & 0.34 & 0.37 & 0.47 & 0.78 & 1.05 & 0.32 & 0.40 & 0.50 & 0.33 & 0.51 & 0.66 \\
\hline Volatility-weighted mean 2 & 0.27 & 0.32 & 0.43 & 0.26 & 0.32 & 0.36 & 0.50 & 0.82 & 1.10 & 0.32 & 0.41 & 0.54 & 0.36 & 0.57 & 0.73 \\
\hline Double-weighted mean 1 & 0.55 & 0.62 & 0.62 & 0.32 & 0.39 & 0.43 & 0.36 & 0.54 & 0.72 & 0.33 & 0.48 & 0.58 & 0.37 & 0.49 & 0.65 \\
\hline Double-weighted mean 2 & 0.43 & 0.48 & 0.49 & 0.28 & 0.35 & 0.41 & 0.40 & 0.66 & 0.89 & 0.30 & 0.44 & 0.56 & 0.37 & 0.59 & 0.75 \\
\hline
\end{tabular}

\section{II) 1986-1996}

\begin{tabular}{|c|c|c|c|c|c|c|c|c|c|}
\hline & \multicolumn{3}{|c|}{ United States } & \multicolumn{3}{|c|}{ Japan } & \multicolumn{3}{|c|}{ Canada } \\
\hline & $\begin{array}{c}12 \\
\text { month }\end{array}$ & $\begin{array}{c}6 \\
\text { month }\end{array}$ & $\begin{array}{c}3 \\
\text { month }\end{array}$ & $\begin{array}{c}12 \\
\text { month }\end{array}$ & $\begin{array}{c}6 \\
\text { month }\end{array}$ & $\begin{array}{c}3 \\
\text { month }\end{array}$ & $\begin{array}{c}12 \\
\text { month }\end{array}$ & $\begin{array}{c}6 \\
\text { month }\end{array}$ & $\begin{array}{c}3 \\
\text { month }\end{array}$ \\
\hline Headline & 0.58 & 0.97 & 1.35 & 0.50 & 0.90 & 1.38 & 0.83 & 1.39 & 1.69 \\
\hline Core 1 & 0.48 & 0.55 & 0.67 & 0.57 & 0.70 & 0.86 & 0.71 & 0.97 & 1.18 \\
\hline Core 2 & 0.62 & 0.71 & 0.79 & 0.41 & 0.68 & 0.90 & 0.83 & 1.19 & 1.54 \\
\hline Weighted median & 0.46 & 0.55 & 0.67 & 0.50 & 0.67 & 0.83 & 0.57 & 0.79 & 0.98 \\
\hline $2.0 \%$ trimmed mean & 0.40 & 0.68 & 0.95 & 0.41 & 0.74 & 1.15 & 0.78 & 1.28 & 1.62 \\
\hline $5.0 \%$ trimmed mean & 0.30 & 0.41 & 0.57 & 0.37 & 0.64 & 0.90 & 0.72 & 1.16 & 1.49 \\
\hline $10.0 \%$ trimmed mean & 0.35 & 0.41 & 0.50 & 0.38 & 0.62 & 0.83 & 0.69 & 1.08 & 1.40 \\
\hline $15.0 \%$ trimmed mean & 0.38 & 0.44 & 0.51 & 0.42 & 0.62 & 0.81 & 0.66 & 0.99 & 1.27 \\
\hline $25.0 \%$ trimmed mean & 0.41 & 0.47 & 0.55 & 0.46 & 0.64 & 0.82 & 0.62 & 0.89 & 1.12 \\
\hline Huber-type skipped mean & 0.37 & 0.43 & 0.50 & 0.46 & 0.62 & 0.78 & 0.73 & 1.00 & 1.25 \\
\hline Volatility-weighted mean 1 & 0.40 & 0.53 & 0.67 & 0.43 & 0.70 & 0.93 & 0.66 & 1.01 & 1.25 \\
\hline Volatility-weighted mean 2 & 0.39 & 0.54 & 0.70 & 0.43 & 0.71 & 0.95 & 0.73 & 1.19 & 1.51 \\
\hline Double-weighted mean 1 & 0.39 & 0.45 & 0.52 & 0.47 & 0.66 & 0.86 & 0.59 & 0.81 & 0.95 \\
\hline Double-weighted mean 2 & 0.40 & 0.46 & 0.55 & 0.41 & 0.66 & 0.90 & 0.63 & 1.00 & 1.24 \\
\hline
\end{tabular}

Note: in each column, the number in bold denotes the indicator that best tracks trend headline inflation (with the lowest RMSE)

1) RMSE adjusted for the difference between the mean values of the core indicator and of headline inflation over the period indicated. 


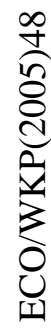
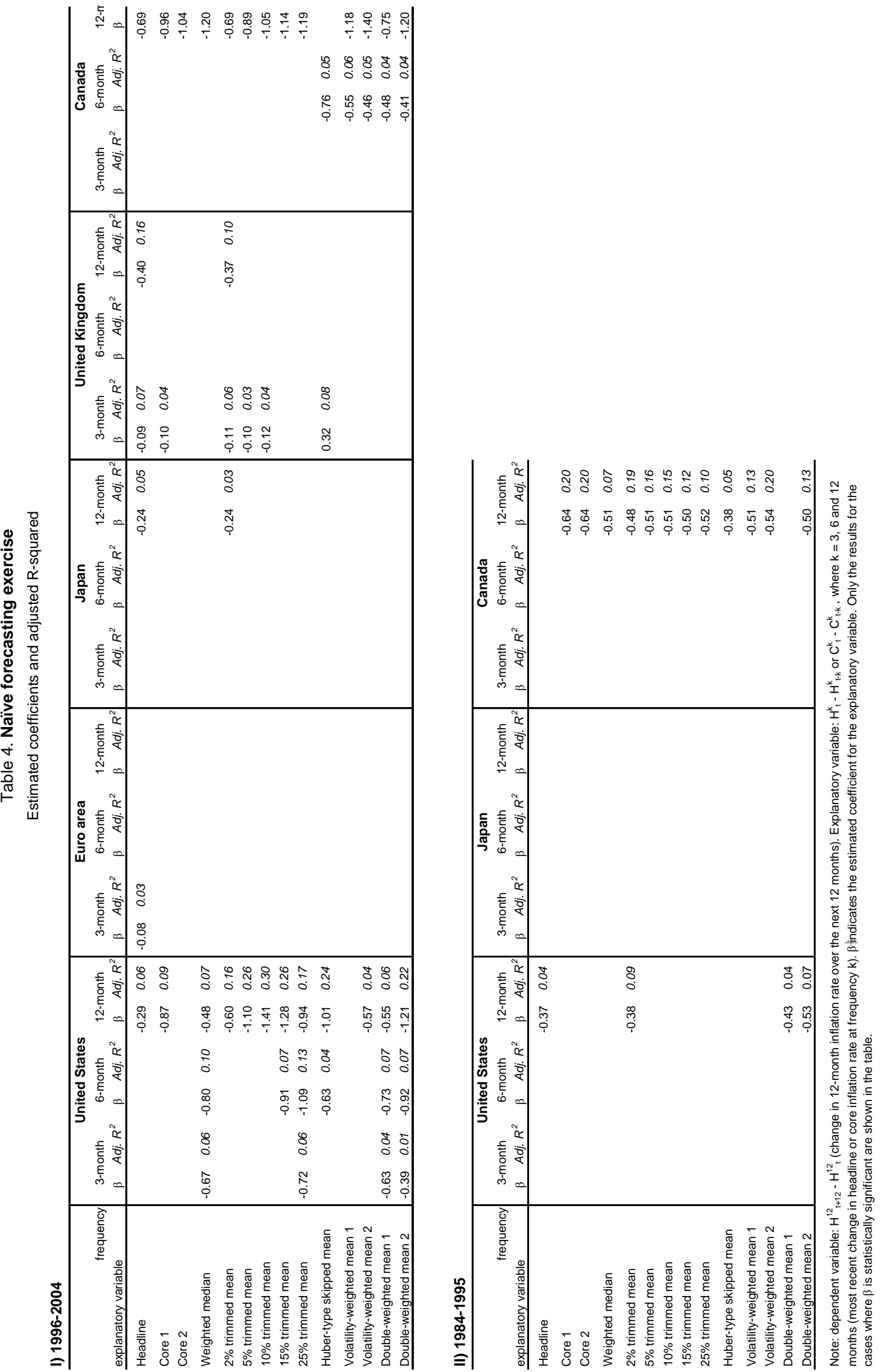
Table 5. Gap model

l) 1996-2004

a) 12-month forecasting horizon

\begin{tabular}{|c|c|c|c|c|c|c|c|c|c|c|}
\hline & \multicolumn{2}{|c|}{ United States } & \multicolumn{2}{|c|}{ Euro area } & \multicolumn{2}{|c|}{ Japan } & \multicolumn{2}{|c|}{ United Kingdom } & \multicolumn{2}{|c|}{ Canada } \\
\hline & $\beta$ & Adj. $R^{2}$ & $\beta$ & Adj. $R^{2}$ & $\beta$ & Adj. $R^{2}$ & $\beta$ & Adj. $R^{2}$ & $\beta$ & Adj. $R^{2}$ \\
\hline Core 1 & 0.78 & 0.24 & & & 1.30 & 0.17 & & & 1.50 & 0.58 \\
\hline Core 2 & 1.06 & 0.44 & & & 0.94 & 0.08 & & & 1.14 & 0.35 \\
\hline Weighted median & 0.60 & 0.23 & 0.65 & 0.11 & 1.12 & 0.18 & 0.90 & 0.28 & 1.68 & 0.67 \\
\hline $2 \%$ trimmed mean & 1.17 & 0.07 & & & 3.05 & 0.30 & 1.50 & 0.10 & 4.38 & 0.16 \\
\hline $5 \%$ trimmed mean & 0.90 & 0.15 & & & 1.82 & 0.27 & 1.34 & 0.22 & 3.06 & 0.41 \\
\hline $10 \%$ trimmed mean & 0.77 & 0.18 & & & 1.54 & 0.24 & 1.00 & 0.28 & 2.38 & 0.61 \\
\hline $15 \%$ trimmed mean & 0.70 & 0.19 & 0.55 & 0.04 & 1.36 & 0.22 & 1.08 & 0.35 & 2.06 & 0.65 \\
\hline $25 \%$ trimmed mean & 0.66 & 0.21 & 0.61 & 0.08 & 1.23 & 0.20 & 1.06 & 0.41 & 1.81 & 0.64 \\
\hline Huber skipped mean & 0.56 & 0.13 & 0.49 & 0.06 & 1.15 & 0.18 & 0.75 & 0.27 & 1.63 & 0.69 \\
\hline Volatility-weighted mean 1 & 1.08 & 0.36 & & & 0.88 & 0.06 & 0.91 & 0.37 & 2.07 & 0.69 \\
\hline Volatility-weighted mean 2 & 1.26 & 0.37 & & & & & 0.90 & 0.32 & 1.96 & 0.64 \\
\hline Double-weighted mean 1 & 0.70 & 0.26 & & & 1.89 & 0.50 & 0.78 & 0.25 & 2.09 & 0.70 \\
\hline Double-weighted mean 2 & 0.78 & 0.22 & & & 2.04 & 0.36 & 0.93 & 0.24 & 2.11 & 0.64 \\
\hline 5 -year average of headline inflation ${ }^{1}$ & 1.02 & 0.42 & & & 0.81 & 0.38 & 0.68 & 0.16 & 1.35 & 0.60 \\
\hline
\end{tabular}

b) 18-month forecasting horizon

\begin{tabular}{|c|c|c|c|c|c|c|c|c|c|c|}
\hline & \multicolumn{2}{|c|}{ United States } & \multicolumn{2}{|c|}{ Euro area } & \multicolumn{2}{|c|}{ Japan } & \multicolumn{2}{|c|}{ United Kingdom } & \multicolumn{2}{|c|}{ Canada } \\
\hline & $\beta$ & Adj. $R^{2}$ & $\beta$ & Adj. $R^{2}$ & $\beta$ & Adj. $R^{2}$ & $\beta$ & Adj. $R^{2}$ & $\beta$ & Adj. $R^{2}$ \\
\hline Core 1 & 1.11 & 0.40 & & & 1.13 & 0.12 & & & 1.42 & 0.55 \\
\hline Core 2 & 1.24 & 0.50 & & & 0.73 & 0.04 & -0.39 & 0.06 & 0.85 & 0.25 \\
\hline Weighted median & 0.87 & 0.40 & 0.68 & 0.09 & 1.30 & 0.22 & 0.38 & 0.05 & 1.19 & 0.46 \\
\hline $2 \%$ trimmed mean & 1.69 & 0.13 & & & 3.60 & 0.38 & & & 1.97 & 0.03 \\
\hline $5 \%$ trimmed mean & 1.17 & 0.22 & & & 1.93 & 0.28 & & & 2.42 & 0.31 \\
\hline $10 \%$ trimmed mean & 1.04 & 0.27 & & & 1.68 & 0.27 & 0.61 & 0.12 & 1.75 & 0.42 \\
\hline $15 \%$ trimmed mean & 0.95 & 0.29 & & & 1.55 & 0.27 & 0.64 & 0.14 & 1.46 & 0.43 \\
\hline $25 \%$ trimmed mean & 0.91 & 0.35 & 0.60 & 0.05 & 1.44 & 0.25 & 0.75 & 0.25 & 1.30 & 0.43 \\
\hline Huber-type skipped mean & 0.79 & 0.23 & 0.52 & 0.05 & 1.33 & 0.23 & 0.40 & 0.08 & 1.21 & 0.51 \\
\hline Volatility-weighted mean 1 & 1.26 & 0.42 & & & 0.89 & 0.06 & 0.68 & 0.26 & 1.71 & 0.60 \\
\hline Volatility-weighted mean 2 & 1.46 & 0.41 & & & & & 0.63 & 0.19 & 1.61 & 0.57 \\
\hline Double-weighted mean 1 & 0.92 & 0.37 & & & 1.99 & 0.52 & 0.50 & 0.11 & 1.62 & 0.53 \\
\hline Double-weighted mean 2 & 1.05 & 0.34 & & & 2.14 & 0.38 & 0.53 & 0.09 & 1.69 & 0.53 \\
\hline 5 -year average of headline inflation ${ }^{1}$ & 1.24 & 0.53 & & & 0.98 & 0.50 & & & 0.97 & 0.40 \\
\hline
\end{tabular}

c) 24-month forecasting horizon

\begin{tabular}{|c|c|c|c|c|c|c|c|c|c|c|}
\hline & \multicolumn{2}{|c|}{ United States } & \multicolumn{2}{|c|}{ Euro area } & \multicolumn{2}{|c|}{ Japan } & \multicolumn{2}{|c|}{ United Kingdom } & \multicolumn{2}{|c|}{ Canada } \\
\hline & $\beta$ & Adj. $R^{2}$ & $\beta$ & Adj. $R^{2}$ & $\beta$ & Adj. $R^{2}$ & $\beta$ & Adj. $R^{2}$ & $\beta$ & Adj. $R^{2}$ \\
\hline Core 1 & 1.58 & 0.64 & 0.46 & 0.07 & 0.78 & 0.05 & & & 1.54 & 0.59 \\
\hline Core 2 & 1.39 & 0.54 & 0.43 & 0.06 & & & & & 0.63 & 0.15 \\
\hline Weighted median & 1.16 & 0.60 & 1.19 & 0.19 & 1.49 & 0.29 & 0.65 & 0.11 & 1.05 & 0.31 \\
\hline $2 \%$ trimmed mean & 2.82 & 0.33 & & & 4.02 & 0.44 & & & 2.16 & 0.05 \\
\hline $5 \%$ trimmed mean & 1.82 & 0.44 & & & 2.10 & 0.32 & 1.09 & 0.12 & 2.00 & 0.23 \\
\hline $10 \%$ trimmed mean & 1.53 & 0.49 & & & 1.85 & 0.32 & 0.82 & 0.16 & 1.43 & 0.27 \\
\hline $15 \%$ trimmed mean & 1.36 & 0.51 & 0.83 & 0.05 & 1.73 & 0.33 & 0.83 & 0.17 & 1.24 & 0.28 \\
\hline $25 \%$ trimmed mean & 1.24 & 0.56 & 1.07 & 0.13 & 1.59 & 0.30 & 0.97 & 0.30 & 1.10 & 0.28 \\
\hline Huber-type skipped mean & 1.19 & 0.44 & 0.96 & 0.14 & 1.63 & 0.35 & 0.45 & 0.07 & 0.98 & 0.29 \\
\hline Volatility-weighted mean 1 & 1.50 & 0.50 & & & & & 0.87 & 0.30 & 1.44 & 0.41 \\
\hline Volatility-weighted mean 2 & 1.84 & 0.54 & 0.63 & 0.06 & & & 0.75 & 0.19 & 1.32 & 0.37 \\
\hline Double-weighted mean 1 & 1.17 & 0.52 & & & 2.04 & 0.54 & 0.84 & 0.24 & 1.36 & 0.36 \\
\hline Double-weighted mean 2 & 1.44 & 0.54 & & & 2.12 & 0.35 & 0.87 & 0.18 & 1.38 & 0.35 \\
\hline 5 -year average of headline inflation ${ }^{1}$ & 1.52 & 0.67 & 0.27 & 0.05 & 1.16 & 0.70 & 0.42 & 0.16 & 0.80 & 0.26 \\
\hline
\end{tabular}

Note: dependent variable: $\mathrm{H}_{\mathrm{t}+\mathrm{h}}^{12}-\mathrm{H}_{\mathrm{t}}^{12}$ (change in 12-month inflation rate over the time horizon $\mathrm{h}$ ). Explanatory variable: $\mathrm{C}^{12}{ }_{\mathrm{t}}-\mathrm{H}^{12}{ }_{\mathrm{t}}(\mathrm{current}$ gap between core and headline inflation rate). $\beta$ efndicates the estimated coefficient for the explanatory variable. Only the results for the cases where $\beta$ is statistically significant are shown.

1) the 5-year average of past headline inflation is a weighted average with geometrically declining weights. The discount factor, selected as the one providing the highest explanatory power, is 0.1 for the United Kingdom, zero for the other four economies. 
ECO/WKP(2005)48

Table 5. Gap model (continued)

II) 1984-1995

a) 12-month forecasting horizon

\begin{tabular}{l|cc|cc|cc}
\hline & \multicolumn{2}{|c|}{ United States } & \multicolumn{2}{c|}{ Japan } & \multicolumn{3}{c}{ Canada } \\
& $\beta$ & Adj. $R^{2}$ & $\beta$ & Adj. $R^{2}$ & $\beta$ & Adj. $R^{2}$ \\
\hline Core 1 & 0.84 & 0.23 & 0.69 & 0.15 & 1.51 & 0.39 \\
Core 2 & 0.92 & 0.39 & 1.02 & 0.13 & 1.00 & 0.25 \\
Weighted median & 1.08 & 0.43 & 0.75 & 0.19 & 1.88 & 0.55 \\
2\% trimmed mean & 3.79 & 0.46 & 2.49 & 0.20 & 3.00 & 0.20 \\
$5 \%$ trimmed mean & 1.77 & 0.50 & 1.46 & 0.24 & 2.05 & 0.30 \\
$10 \%$ trimmed mean & 1.42 & 0.48 & 1.14 & 0.23 & 2.06 & 0.36 \\
15\% trimmed mean & 1.33 & 0.46 & 1.01 & 0.23 & 2.04 & 0.45 \\
$25 \%$ trimmed mean & 1.26 & 0.46 & 0.88 & 0.22 & 1.99 & 0.51 \\
Huber skipped mean & 1.25 & 0.49 & 0.87 & 0.24 & 1.53 & 0.44 \\
Volatility-weighted mean 1 & 1.33 & 0.36 & 0.92 & 0.14 & 2.46 & 0.52 \\
Volatility-weighted mean 2 & 1.38 & 0.36 & 0.95 & 0.14 & 1.75 & 0.24 \\
Double-weighted mean 1 & 1.21 & 0.37 & 0.88 & 0.18 & 2.66 & 0.75 \\
Double-weighted mean 2 & 1.15 & 0.34 & 1.06 & 0.18 & 2.65 & 0.52 \\
& & & & & & \\
5-year average of headline inflation ${ }^{1}$ & 0.61 & 0.10 & 0.15 & 0.02 & 0.53 & 0.21 \\
\hline
\end{tabular}

b) 18-month forecasting horizon

\begin{tabular}{l|cc|cc|cc}
\hline & \multicolumn{2}{|c|}{ United States } & \multicolumn{3}{c|}{ Japan } & \multicolumn{3}{c}{ Canada } \\
& $\beta$ & Adj. $R^{2}$ & $\beta$ & Adj. $R^{2}$ & $\beta$ & Adj. $R^{2}$ \\
\hline Core 1 & 0.81 & 0.19 & 0.82 & 0.15 & 1.08 & 0.27 \\
Core 2 & 0.95 & 0.38 & 0.86 & 0.06 & 1.04 & 0.29 \\
Weighted median & 0.99 & 0.33 & 1.02 & 0.25 & 1.65 & 0.45 \\
$2 \%$ trimmed mean & 3.61 & 0.38 & 3.53 & 0.28 & 2.17 & 0.11 \\
$5 \%$ trimmed mean & 1.70 & 0.42 & 1.82 & 0.26 & 1.72 & 0.23 \\
$10 \%$ trimmed mean & 1.37 & 0.41 & 1.39 & 0.24 & 1.78 & 0.29 \\
$15 \%$ trimmed mean & 1.29 & 0.40 & 1.26 & 0.25 & 1.76 & 0.35 \\
$25 \%$ trimmed mean & 1.22 & 0.39 & 1.15 & 0.27 & 1.74 & 0.42 \\
Huber-type skipped mean & 1.15 & 0.37 & 1.09 & 0.26 & 1.38 & 0.38 \\
Volatility-weighted mean 1 & 1.28 & 0.30 & 0.95 & 0.10 & 2.06 & 0.39 \\
Volatility-weighted mean 2 & 1.35 & 0.31 & 0.92 & 0.09 & 1.46 & 0.18 \\
Double-weighted mean 1 & 1.20 & 0.33 & 1.15 & 0.22 & 2.10 & 0.50 \\
Double-weighted mean 2 & 1.16 & 0.32 & 1.24 & 0.18 & 2.22 & 0.39 \\
& & & & & & \\
5-year average of headline inflation ${ }^{1}$ & 0.45 & 0.04 & 0.19 & 0.03 & 0.47 & 0.18 \\
\hline
\end{tabular}

c) 24-month forecasting horizon

\begin{tabular}{l|cc|cc|cc}
\hline & \multicolumn{2}{|c|}{ United States } & \multicolumn{3}{c|}{ Japan } & \multicolumn{3}{c}{ Canada } \\
& $\beta$ & Adj. $R^{2}$ & $\beta$ & Adj. $R^{2}$ & $\beta$ & Adj. $R^{2}$ \\
\hline Core 1 & 1.03 & 0.25 & 1.12 & 0.19 & 0.99 & 0.25 \\
Core 2 & 1.19 & 0.48 & 0.87 & 0.04 & 1.34 & 0.44 \\
Weighted median & 1.21 & 0.40 & 1.44 & 0.34 & 1.66 & 0.41 \\
$2 \%$ trimmed mean & 4.20 & 0.41 & 4.64 & 0.33 & 2.89 & 0.18 \\
$5 \%$ trimmed mean & 1.96 & 0.45 & 2.40 & 0.31 & 2.11 & 0.31 \\
$10 \%$ trimmed mean & 1.61 & 0.45 & 1.85 & 0.29 & 2.07 & 0.35 \\
$15 \%$ trimmed mean & 1.53 & 0.45 & 1.69 & 0.30 & 1.95 & 0.39 \\
$25 \%$ trimmed mean & 1.44 & 0.44 & 1.57 & 0.33 & 1.87 & 0.43 \\
Huber-type skipped mean & 1.35 & 0.41 & 1.47 & 0.32 & 1.40 & 0.36 \\
Volatility-weighted mean 1 & 1.53 & 0.35 & 1.07 & 0.09 & 2.38 & 0.47 \\
Volatility-weighted mean 2 & 1.68 & 0.39 & 0.96 & 0.06 & 2.09 & 0.34 \\
Double-weighted mean 1 & 1.49 & 0.41 & 1.66 & 0.32 & 1.89 & 0.36 \\
Double-weighted mean 2 & 1.50 & 0.42 & 1.67 & 0.21 & 2.50 & 0.44 \\
& & & & & & \\
5-year average of headline inflation ${ }^{1}$ & 0.53 & 0.05 & 0.36 & 0.08 & 0.52 & 0.20 \\
\hline
\end{tabular}

Note: dependent variable: $\mathrm{H}_{\mathrm{t}+\mathrm{h}}^{12}-\mathrm{H}_{\mathrm{t}}^{12}$ (change in 12-month inflation rate over the time horizon $\mathrm{h}$ ). Explanatory variable: $\mathrm{C}^{12}{ }_{\mathrm{t}}-\mathrm{H}^{12}{ }_{\mathrm{t}}$ (current gap between core and headline inflation rate). $\beta$ indicates the estimated coefficient for the explanatory variable. Only the results for the cases where $\beta$ is statistically significant are show.

1) the 5 -year average of past headline inflation is a weighted average with geometrically declining weights. The discount factor, selected as the one providing the highest explanatory power, is 0.1 for the United States; zero for Japan and Canada. 


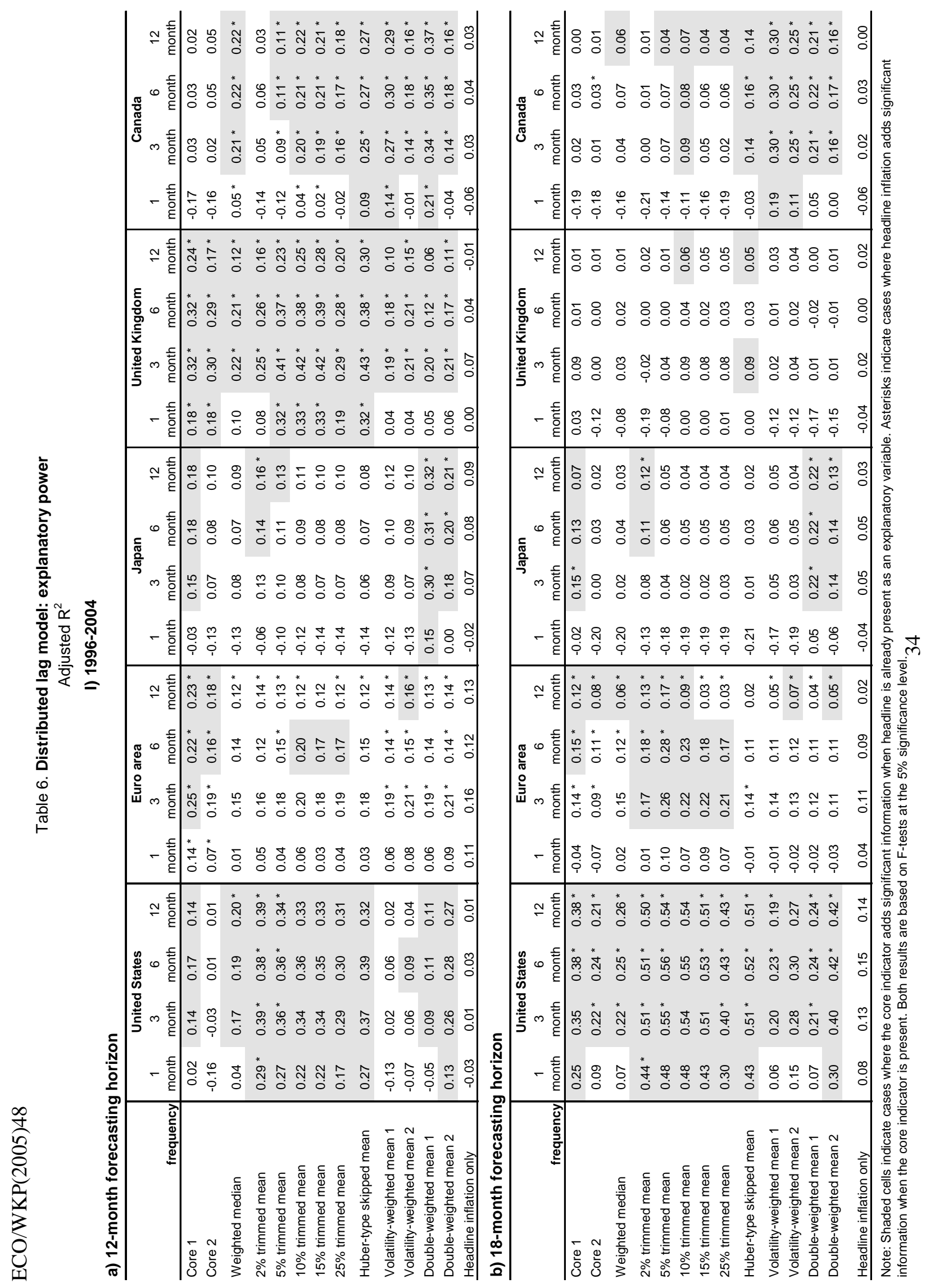




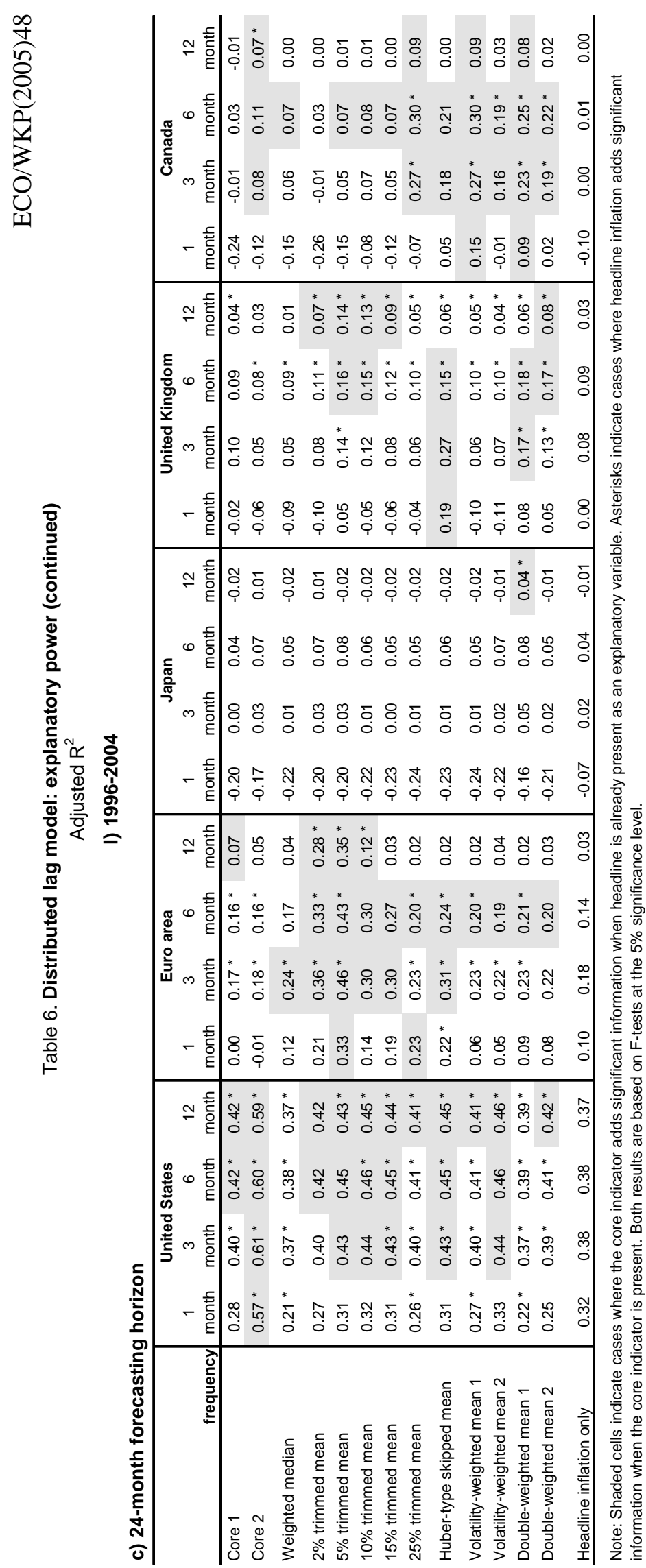


Table 6. Distributed lag model: explanatory power (continued) Adjusted $\mathrm{R}^{2}$

II) $1984-1996$

a) 12-month forecasting horizon

\begin{tabular}{|c|c|c|c|c|c|c|c|c|c|c|c|c|}
\hline \multirow[b]{2}{*}{ frequency } & \multicolumn{4}{|c|}{ United States } & \multicolumn{4}{|c|}{ Japan } & \multicolumn{4}{|c|}{ Canada } \\
\hline & $\begin{array}{c}1 \\
\text { month }\end{array}$ & $\begin{array}{c}3 \\
\text { month }\end{array}$ & $\begin{array}{c}6 \\
\text { month }\end{array}$ & $\begin{array}{c}12 \\
\text { month }\end{array}$ & $\begin{array}{c}1 \\
\text { month }\end{array}$ & $\begin{array}{c}3 \\
\text { month }\end{array}$ & $\begin{array}{c}6 \\
\text { month }\end{array}$ & $\begin{array}{c}12 \\
\text { month }\end{array}$ & $\begin{array}{c}1 \\
\text { month }\end{array}$ & $\begin{array}{c}3 \\
\text { month }\end{array}$ & $\begin{array}{c}6 \\
\text { month }\end{array}$ & $\begin{array}{c}12 \\
\text { month }\end{array}$ \\
\hline Core 1 & -0.01 & 0.09 & 0.11 & 0.09 & 0.16 & 0.24 * & 0.24 * & 0.25 * & 0.59 * & 0.64 * & 0.64 * & $0.63^{*}$ \\
\hline Core 2 & 0.11 & 0.20 & 0.21 & 0.20 & 0.20 & 0.28 & 0.27 & 0.26 & 0.17 & 0.31 & 0.31 & 0.33 \\
\hline Weighted median & 0.18 & 0.24 & 0.25 & 0.22 & 0.17 & 0.25 * & 0.24 * & 0.25 * & 0.62 * & $0.66^{*}$ & 0.63 * & 0.63 * \\
\hline $2 \%$ trimmed mean & 0.18 * & 0.26 * & $0.27^{*}$ & 0.25 * & 0.18 & 0.26 & 0.27 & 0.27 & 0.24 & 0.40 * & 0.40 * & 0.39 * \\
\hline $5 \%$ trimmed mean & $0.27^{*}$ & $0.33^{*}$ & 0.33 * & 0.30 * & 0.21 & 0.28 & 0.28 & 0.29 & 0.22 & 0.38 * & 0.38 * & 0.38 * \\
\hline $10 \%$ trimmed mean & 0.26 & 0.32 * & 0.31 * & 0.27 * & 0.21 & 0.29 & 0.28 & 0.28 & 0.28 & 0.41 * & 0.41 * & 0.41 * \\
\hline $15 \%$ trimmed mean & 0.23 & 0.29 * & 0.29 * & 0.25 * & 0.20 & 0.28 & 0.27 & 0.27 & 0.40 * & 0.50 * & 0.48 * & 0.49 * \\
\hline $25 \%$ trimmed mean & 0.22 & 0.28 & 0.28 & 0.26 & 0.19 & 0.27 & 0.25 & 0.26 & 0.53 * & 0.59 * & $0.57^{*}$ & $0.57^{*}$ \\
\hline Huber-type skipped mean & 0.31 & 0.35 * & 0.33 * & 0.28 * & 0.20 & 0.28 & 0.27 & 0.27 & 0.41 * & 0.51 * & 0.49 * & 0.50 * \\
\hline Volatility-weighted mean 1 & 0.20 & $0.28 *$ & 0.29 * & $0.27^{*}$ & 0.19 & 0.27 & 0.26 & 0.26 & 0.59 * & 0.66 * & 0.64 * & 0.63 * \\
\hline Volatility-weighted mean 2 & 0.19 & 0.26 & 0.28 * & 0.25 * & 0.20 & 0.27 & 0.27 & 0.27 & 0.23 & 0.39 * & 0.38 * & 0.39 * \\
\hline Double-weighted mean 1 & 0.14 & 0.22 & 0.23 & 0.18 & 0.17 & 0.25 & 0.24 & 0.24 * & 0.80 * & 0.82 * & 0.82 * & 0.79 * \\
\hline Double-weighted mean 2 & 0.10 & 0.18 & 0.20 & 0.15 & 0.18 & 0.26 & 0.25 & 0.25 & 0.50 * & 0.58 * & 0.57 * & 0.56 * \\
\hline Headline inflation only & 0.04 & 0.08 & 0.09 & 0.09 & 0.22 & 0.26 & 0.24 & 0.25 & 0.19 & 0.27 & 0.26 & 0.27 \\
\hline
\end{tabular}

\section{b) 18-month forecasting horizon}

\begin{tabular}{|c|c|c|c|c|c|c|c|c|c|c|c|c|}
\hline \multirow[b]{2}{*}{ frequency } & \multicolumn{4}{|c|}{ United States } & \multicolumn{4}{|c|}{ Japan } & \multicolumn{4}{|c|}{ Canada } \\
\hline & $\begin{array}{c}1 \\
\text { month }\end{array}$ & $\begin{array}{c}3 \\
\text { month }\end{array}$ & $\begin{array}{c}6 \\
\text { month }\end{array}$ & $\begin{array}{c}12 \\
\text { month }\end{array}$ & $\begin{array}{c}1 \\
\text { month }\end{array}$ & $\begin{array}{c}3 \\
\text { month }\end{array}$ & $\begin{array}{c}6 \\
\text { month }\end{array}$ & $\begin{array}{c}12 \\
\text { month }\end{array}$ & $\begin{array}{c}1 \\
\text { month }\end{array}$ & $\begin{array}{c}3 \\
\text { month }\end{array}$ & $\begin{array}{c}6 \\
\text { month }\end{array}$ & $\begin{array}{c}12 \\
\text { month }\end{array}$ \\
\hline Core 1 & -0.08 & 0.04 & 0.06 & 0.05 & 0.03 & 0.13 & 0.13 & $0.07^{*}$ & 0.60 * & 0.64 * & 0.65 * & 0.63 * \\
\hline Core 2 & 0.02 & 0.13 & 0.15 & 0.16 & 0.06 & 0.16 & 0.16 & 0.07 & 0.20 & 0.35 & 0.38 & 0.39 \\
\hline Weighted median & 0.00 & 0.10 & 0.12 & 0.09 & 0.02 & 0.12 & 0.12 & 0.07 & $0.49^{*}$ & 0.55 * & 0.54 * & 0.54 * \\
\hline $2 \%$ trimmed mean & 0.03 & $0.13^{*}$ & $0.15^{*}$ & $0.13^{*}$ & 0.12 & 0.18 * & 0.18 * & $0.13^{*}$ & 0.16 & 0.33 & 0.35 & 0.35 * \\
\hline $5 \%$ trimmed mean & 0.13 & 0.22 * & 0.22 * & 0.16 * & 0.06 & 0.16 & 0.16 & 0.10 & 0.17 & 0.33 & 0.36 & 0.37 \\
\hline $10 \%$ trimmed mean & 0.12 & 0.21 & 0.21 * & 0.15 & 0.05 & 0.15 & 0.16 & 0.08 & 0.21 & 0.36 & 0.38 & 0.39 * \\
\hline $15 \%$ trimmed mean & 0.09 & 0.18 & 0.19 & 0.14 & 0.04 & 0.14 & 0.15 & 0.08 & 0.30 & 0.42 * & 0.43 * & $0.43^{*}$ \\
\hline $25 \%$ trimmed mean & 0.08 & 0.17 & 0.18 & 0.14 & 0.04 & 0.14 & 0.14 & 0.08 & 0.41 * & 0.49 * & 0.50 * & 0.50 * \\
\hline Huber-type skipped mean & 0.13 & 0.21 & 0.21 & 0.12 & 0.05 & 0.15 & 0.15 & 0.08 & 0.36 & 0.46 * & $0.47^{*}$ & $0.47^{*}$ \\
\hline Volatility-weighted mean 1 & 0.07 & 0.18 & 0.19 * & 0.18 * & 0.04 & 0.14 & 0.15 & 0.07 & $0.47^{*}$ & 0.55 * & 0.55 * & 0.55 * \\
\hline Volatility-weighted mean 2 & 0.06 & 0.16 & 0.18 & 0.18 * & 0.05 & 0.15 & 0.16 & 0.07 & 0.18 & 0.34 & 0.37 & 0.38 \\
\hline Double-weighted mean 1 & 0.00 & 0.12 & 0.13 & 0.11 & 0.01 & 0.11 & 0.12 & 0.07 & 0.59 * & 0.63 * & 0.62 * & 0.59 * \\
\hline Double-weighted mean 2 & -0.04 & 0.08 & 0.10 & 0.10 & 0.03 & 0.13 & 0.14 & 0.07 & 0.38 & 0.48 * & 0.48 * & 0.48 * \\
\hline Headline inflation only & -0.01 & 0.05 & 0.05 & 0.06 & 0.08 & 0.13 & 0.12 & 0.08 & 0.21 & 0.28 & 0.29 & 0.30 \\
\hline
\end{tabular}

c) 24-month forecasting horizon

\begin{tabular}{|c|c|c|c|c|c|c|c|c|c|c|c|c|}
\hline \multirow[b]{2}{*}{ frequency } & \multicolumn{4}{|c|}{ United States } & \multicolumn{4}{|c|}{ Japan } & \multicolumn{4}{|c|}{ Canada } \\
\hline & $\begin{array}{c}1 \\
\text { month }\end{array}$ & $\begin{array}{c}3 \\
\text { month }\end{array}$ & $\begin{array}{c}6 \\
\text { month }\end{array}$ & $\begin{array}{c}12 \\
\text { month }\end{array}$ & $\begin{array}{c}1 \\
\text { month }\end{array}$ & $\begin{array}{c}3 \\
\text { month }\end{array}$ & $\begin{array}{c}6 \\
\text { month }\end{array}$ & $\begin{array}{c}12 \\
\text { month }\end{array}$ & $\begin{array}{c}1 \\
\text { month }\end{array}$ & $\begin{array}{c}3 \\
\text { month }\end{array}$ & $\begin{array}{c}6 \\
\text { month }\end{array}$ & $\begin{array}{c}12 \\
\text { month }\end{array}$ \\
\hline Core 1 & -0.06 & 0.05 & 0.06 & 0.00 & -0.06 & 0.05 & 0.05 & 0.01 & 0.56 * & $0.62^{*}$ & $0.63^{*}$ & $0.63^{*}$ \\
\hline Core 2 & 0.13 & 0.22 * & 0.21 * & $0.18^{*}$ & 0.03 & 0.13 & 0.12 & $0.04^{*}$ & 0.34 & 0.46 * & 0.48 * & 0.46 * \\
\hline Weighted median & -0.02 & 0.09 * & 0.10 * & 0.05 & -0.08 & 0.04 & 0.04 & -0.01 & 0.37 & 0.46 * & 0.46 * & 0.44 * \\
\hline $2 \%$ trimmed mean & 0.07 & $0.16^{*}$ & $0.14^{*}$ & $0.07^{*}$ & 0.02 & $0.10^{*}$ & 0.09 * & 0.02 * & 0.16 & 0.32 & 0.35 * & 0.36 * \\
\hline $5 \%$ trimmed mean & 0.13 & 0.21 * & 0.20 * & 0.10 * & -0.05 & 0.06 & 0.05 & 0.00 & 0.19 & 0.34 & $0.37^{*}$ & $0.37^{*}$ \\
\hline $10 \%$ trimmed mean & 0.09 & 0.18 * & $0.18^{*}$ & 0.10 * & -0.06 & 0.06 & 0.06 & -0.01 & 0.23 & 0.36 * & 0.39 * & 0.39 * \\
\hline $15 \%$ trimmed mean & 0.06 & 0.16 * & $0.17^{*}$ & 0.10 * & -0.06 & 0.06 & 0.06 & -0.01 & 0.28 & 0.40 * & 0.42 * & $0.41^{*}$ \\
\hline $25 \%$ trimmed mean & 0.03 & 0.25 * & 0.25 * & $0.17^{*}$ & -0.06 & 0.09 & 0.10 & 0.02 & 0.36 & $0.58^{*}$ & 0.58 * & 0.58 * \\
\hline Huber-type skipped mean & 0.01 & 0.12 * & $0.13^{*}$ & 0.07 & -0.06 & 0.05 & 0.05 & -0.01 & 0.24 & 0.37 & 0.39 & 0.38 * \\
\hline Volatility-weighted mean 1 & 0.16 & 0.25 * & 0.25 * & $0.17^{*}$ & -0.03 & 0.09 & 0.10 & 0.02 & 0.51 * & 0.58 * & 0.58 * & $0.58^{*}$ \\
\hline Volatility-weighted mean 2 & $0.17^{*}$ & 0.26 * & 0.26 * & 0.20 * & -0.03 & 0.09 & 0.09 & 0.01 & 0.31 & $0.45^{*}$ & $0.47^{*}$ & $0.45^{*}$ \\
\hline Double-weighted mean 1 & 0.05 & 0.16 * & $0.17^{*}$ & $0.10^{*}$ & -0.07 & 0.04 & 0.05 & 0.00 & 0.49 * & $0.55^{*}$ & 0.53 * & 0.44 * \\
\hline Double-weighted mean 2 & 0.05 & $0.15^{*}$ & $0.16^{*}$ & 0.11 * & -0.05 & 0.06 & 0.07 & 0.01 & 0.36 & $0.46^{*}$ & 0.48 * & $0.48^{*}$ \\
\hline Headline inflation only & -0.01 & 0.05 & 0.00 & 0.00 & -0.01 & 0.04 & 0.00 & 0.00 & 0.18 & 0.25 & 0.00 & 0.25 \\
\hline
\end{tabular}

Note: Shaded cells indicate cases where the core indicator adds significant information when headline is already present as an explanatory variable. Asterisks indicate cases where headline inflation adds significant information when the core indicator is present. Both results are based on F-tests at the $5 \%$ significance level. 
Table 7. Distributed lag model: additional information of higher-frequency data F-test results

I) $1996-2004$

a) 12-month forecasting horizon

\begin{tabular}{|c|c|c|c|c|c|c|c|c|c|c|c|c|c|c|c|}
\hline \multirow[b]{2}{*}{ frequency } & \multicolumn{3}{|c|}{ United States } & \multicolumn{3}{|c|}{ Euro area } & \multicolumn{3}{|c|}{ Japan } & \multicolumn{3}{|c|}{ United Kingdom } & \multicolumn{3}{|c|}{ Canada } \\
\hline & $\begin{array}{c}1 \mathrm{~m} \text { to } \\
3 \mathrm{~m}\end{array}$ & $\begin{array}{c}3 \mathrm{~m} \text { to } \\
6 \mathrm{~m}\end{array}$ & $\begin{array}{c}6 m \text { to } \\
12 m\end{array}$ & $\begin{array}{c}1 \mathrm{~m} \text { to } \\
3 \mathrm{~m}\end{array}$ & $\begin{array}{c}3 \mathrm{~m} \text { to } \\
6 \mathrm{~m}\end{array}$ & $\begin{array}{c}6 m \text { to } \\
12 m\end{array}$ & $\begin{array}{c}1 \mathrm{~m} \text { to } \\
3 \mathrm{~m}\end{array}$ & $\begin{array}{c}3 \mathrm{~m} \text { to } \\
6 \mathrm{~m}\end{array}$ & $\begin{array}{c}6 \mathrm{~m} \text { to } \\
12 \mathrm{~m}\end{array}$ & $\begin{array}{c}1 \mathrm{~m} \text { to } \\
3 \mathrm{~m}\end{array}$ & $\begin{array}{c}3 \mathrm{~m} \text { to } \\
6 \mathrm{~m}\end{array}$ & $\begin{array}{c}6 m \text { to } \\
12 m\end{array}$ & $\begin{array}{c}1 \mathrm{~m} \text { to } \\
3 \mathrm{~m}\end{array}$ & $\begin{array}{c}3 \mathrm{~m} \text { to } \\
6 \mathrm{~m}\end{array}$ & $\begin{array}{c}6 \mathrm{~m} \text { to } \\
12 \mathrm{~m} \\
\end{array}$ \\
\hline Core 1 & & & & & & & & & & & & $x$ & & & \\
\hline Core 2 & & & & & & & & & & & & $\mathrm{x}$ & & & \\
\hline Weighted median & & & & & & & & & & & & $\mathrm{X}$ & & & \\
\hline $2 \%$ trimmed mean & & & & & & & & & & & & $\mathrm{x}$ & & & \\
\hline $5 \%$ trimmed mean & & & & & & & & & & & & $\mathrm{x}$ & & & \\
\hline $10 \%$ trimmed mean & & & $\mathrm{x}$ & & & $\mathrm{X}$ & & & & & & $\mathrm{x}$ & & & \\
\hline $15 \%$ trimmed mean & & & & & & $\mathrm{X}$ & & & & & & $\mathrm{x}$ & & & \\
\hline $25 \%$ trimmed mean & & & & & & $\mathrm{X}$ & & & & & & $\mathrm{x}$ & & & \\
\hline Huber-type skipped mean & & & $\mathrm{x}$ & & & & & & & & $\mathrm{x}$ & $\mathrm{x}$ & & & \\
\hline Volatility-weighted mean 1 & & & & & & & & & & & & $\mathrm{x}$ & & & \\
\hline Volatility-weighted mean 2 & & & $\mathrm{x}$ & & $\mathrm{x}$ & & & & & & & $\mathrm{x}$ & & & \\
\hline Double-weighted mean 1 & & & & & $\mathrm{X}$ & & & & & & $\mathrm{X}$ & $\mathrm{x}$ & & & \\
\hline Double-weighted mean 2 & & & & & $\mathrm{X}$ & & & & & & & $\mathrm{X}$ & & & \\
\hline Headline inflation only & & & & & $\mathrm{X}$ & & & & & & & $\mathrm{x}$ & & & \\
\hline
\end{tabular}

b) 18-month forecasting horizon

\begin{tabular}{|c|c|c|c|c|c|c|c|c|c|c|c|c|c|c|c|}
\hline \multirow[b]{2}{*}{ frequency } & \multicolumn{3}{|c|}{ United States } & \multicolumn{3}{|c|}{ Euro area } & \multicolumn{3}{|c|}{ Japan } & \multicolumn{3}{|c|}{ United Kingdom } & \multicolumn{3}{|c|}{ Canada } \\
\hline & $\begin{array}{c}1 \mathrm{~m} \text { to } \\
3 \mathrm{~m}\end{array}$ & $\begin{array}{c}3 \mathrm{~m} \text { to } \\
6 \mathrm{~m}\end{array}$ & $\begin{array}{c}6 m \text { to } \\
12 m\end{array}$ & $\begin{array}{c}1 \mathrm{~m} \text { to } \\
3 \mathrm{~m}\end{array}$ & $\begin{array}{c}3 \mathrm{~m} \text { to } \\
6 \mathrm{~m}\end{array}$ & $\begin{array}{c}6 m \text { to } \\
12 m\end{array}$ & $\begin{array}{c}1 \mathrm{~m} \text { to } \\
3 \mathrm{~m}\end{array}$ & $\begin{array}{c}3 \mathrm{~m} \text { to } \\
6 \mathrm{~m}\end{array}$ & $\begin{array}{c}6 \mathrm{~m} \text { to } \\
12 \mathrm{~m}\end{array}$ & $\begin{array}{c}1 \mathrm{~m} \text { to } \\
3 \mathrm{~m}\end{array}$ & $\begin{array}{c}3 \mathrm{~m} \text { to } \\
6 \mathrm{~m}\end{array}$ & $\begin{array}{c}6 \mathrm{~m} \text { to } \\
12 \mathrm{~m}\end{array}$ & $\begin{array}{c}1 \mathrm{~m} \text { to } \\
3 \mathrm{~m}\end{array}$ & $\begin{array}{c}3 \mathrm{~m} \text { to } \\
6 \mathrm{~m}\end{array}$ & $\begin{array}{c}6 m \text { to } \\
12 m\end{array}$ \\
\hline Core 1 & & & & & & & & & $x$ & & $\mathrm{x}$ & & & & \\
\hline Core 2 & & & & & & & & & & & & & & & \\
\hline Weighted median & & & & & & $\mathrm{x}$ & & & & & & & & & \\
\hline $2 \%$ trimmed mean & & & & & & $\mathrm{X}$ & & & & & & & & & \\
\hline $5 \%$ trimmed mean & & & & & & $x$ & & & & & & & & & \\
\hline $10 \%$ trimmed mean & & & & & & $x$ & & & & & & & & & \\
\hline $15 \%$ trimmed mean & & & & & & $\mathrm{x}$ & & & & & & & & & \\
\hline $25 \%$ trimmed mean & & & & & & $\mathrm{X}$ & & & & & & & & & \\
\hline Huber-type skipped mean & & & & & & $\mathrm{X}$ & & & & & & & & & \\
\hline Volatility-weighted mean 1 & & & $\mathrm{x}$ & & & $\mathrm{X}$ & & & & & & & & & \\
\hline Volatility-weighted mean 2 & & & $\mathrm{x}$ & & & $\mathrm{X}$ & & & & & & & & & \\
\hline Double-weighted mean 1 & & & & & & $\mathrm{x}$ & & & & & & & & & \\
\hline Double-weighted mean 2 & & & & & & $\mathrm{x}$ & & & & & & & & & \\
\hline Headline inflation only & & & & & & $\mathrm{x}$ & & & & & & & & & \\
\hline
\end{tabular}

c) 24-month forecasting horizon

\begin{tabular}{|c|c|c|c|c|c|c|c|c|c|c|c|c|c|c|c|}
\hline \multirow[b]{2}{*}{ frequency } & \multicolumn{3}{|c|}{ United States } & \multicolumn{3}{|c|}{ Euro area } & \multicolumn{3}{|c|}{ Japan } & \multicolumn{3}{|c|}{ United Kingdom } & \multicolumn{3}{|c|}{ Canada } \\
\hline & $\begin{array}{c}1 \mathrm{~m} \text { to } \\
3 \mathrm{~m}\end{array}$ & $\begin{array}{c}3 \mathrm{~m} \text { to } \\
6 \mathrm{~m}\end{array}$ & $\begin{array}{c}6 m \text { to } \\
12 m\end{array}$ & $\begin{array}{c}1 \mathrm{~m} \text { to } \\
3 \mathrm{~m}\end{array}$ & $\begin{array}{c}3 m \text { to } \\
6 m\end{array}$ & $\begin{array}{c}6 m \text { to } \\
12 m\end{array}$ & $\begin{array}{c}1 \mathrm{~m} \text { to } \\
3 \mathrm{~m}\end{array}$ & $\begin{array}{c}3 \mathrm{~m} \text { to } \\
6 \mathrm{~m}\end{array}$ & $\begin{array}{c}6 \mathrm{~m} \text { to } \\
12 \mathrm{~m}\end{array}$ & $\begin{array}{c}1 \mathrm{~m} \text { to } \\
3 \mathrm{~m}\end{array}$ & $\begin{array}{c}3 \mathrm{~m} \text { to } \\
6 \mathrm{~m}\end{array}$ & $\begin{array}{c}6 m \text { to } \\
12 m\end{array}$ & $\begin{array}{c}1 \mathrm{~m} \text { to } \\
3 \mathrm{~m}\end{array}$ & $\begin{array}{c}3 \mathrm{~m} \text { to } \\
6 \mathrm{~m}\end{array}$ & $\begin{array}{c}6 \mathrm{~m} \text { to } \\
12 \mathrm{~m}\end{array}$ \\
\hline Core 1 & & & & & & $\mathrm{x}$ & & & $x$ & & & & & & \\
\hline Core 2 & $x$ & & & & & $\mathrm{x}$ & & & $\mathrm{x}$ & & & & & & \\
\hline Weighted median & $x$ & & & & $x$ & $\mathrm{x}$ & & & $x$ & & & $x$ & & & $x$ \\
\hline $2 \%$ trimmed mean & & & & & & $x$ & & & $\mathrm{x}$ & & & & & & \\
\hline $5 \%$ trimmed mean & & & & & & $x$ & & & $x$ & & & & & & $x$ \\
\hline $10 \%$ trimmed mean & & & & & & $x$ & & & $x$ & & & & & & $x$ \\
\hline $15 \%$ trimmed mean & & & & & & $x$ & & & $x$ & & & & & & $x$ \\
\hline $25 \%$ trimmed mean & & & & $x$ & & $\mathrm{x}$ & & & $x$ & & & & & & $x$ \\
\hline Huber-type skipped mean & & & & $x$ & $x$ & $x$ & & & $x$ & & $x$ & $\mathrm{x}$ & & & $x$ \\
\hline Volatility-weighted mean 1 & & & & & & $\mathrm{x}$ & & & $x$ & & & & & & $\mathrm{x}$ \\
\hline Volatility-weighted mean 2 & & & & & & $x$ & & & $x$ & & & $x$ & & & $x$ \\
\hline Double-weighted mean 1 & $x$ & & & & & $x$ & & & $\mathrm{x}$ & & & $\mathrm{x}$ & & & $\mathrm{x}$ \\
\hline Double-weighted mean 2 & & & & & & $x$ & & & $x$ & & & $x$ & & & $\mathrm{x}$ \\
\hline Headline inflation only & & & & & & $x$ & & & $\mathrm{x}$ & & & $\mathrm{x}$ & & & $\mathrm{x}$ \\
\hline
\end{tabular}

Note: $\mathrm{X}$ indicates that the restriction on coefficients implied by moving from the higher to the lower frequency is rejected at the $5 \%$ significance level 


\section{ECO/WKP(2005)48}

Table 7. Distributed lag model: additional information of higher-frequency data (continued) F-test results

II) 1984-1995

a) 12-month forecasting horizon

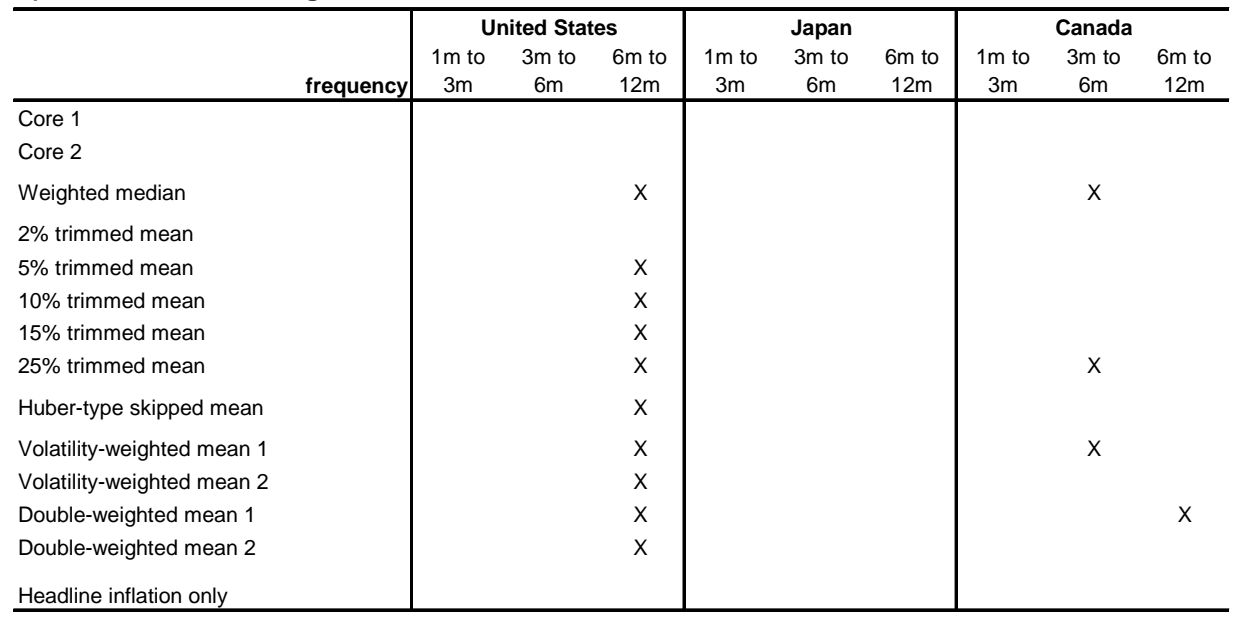

b) 18-month forecasting horizon

\begin{tabular}{|c|c|c|c|c|c|c|c|c|c|c|}
\hline & \multirow[b]{2}{*}{ frequency } & \multicolumn{3}{|c|}{ United States } & \multicolumn{3}{|c|}{ Japan } & \multicolumn{3}{|c|}{ Canada } \\
\hline & & $\begin{array}{c}1 \mathrm{~m} \text { to } \\
3 \mathrm{~m}\end{array}$ & $\begin{array}{c}3 \mathrm{~m} \text { to } \\
6 \mathrm{~m}\end{array}$ & $\begin{array}{c}6 \mathrm{~m} \text { to } \\
12 \mathrm{~m}\end{array}$ & $\begin{array}{c}1 \mathrm{~m} \text { to } \\
3 \mathrm{~m}\end{array}$ & $\begin{array}{c}3 \mathrm{~m} \text { to } \\
6 \mathrm{~m}\end{array}$ & $\begin{array}{c}6 m \text { to } \\
12 m\end{array}$ & $\begin{array}{c}1 \mathrm{~m} \text { to } \\
3 \mathrm{~m}\end{array}$ & $\begin{array}{c}3 \mathrm{~m} \text { to } \\
6 \mathrm{~m}\end{array}$ & $\begin{array}{c}6 \mathrm{~m} \text { to } \\
12 \mathrm{~m}\end{array}$ \\
\hline Core 1 & & & & & & & $x$ & & & $x$ \\
\hline Core 2 & & & & & & & $\mathrm{x}$ & & & \\
\hline Weighted median & & & & $x$ & & & $x$ & & & \\
\hline $2 \%$ trimmed mean & & & & & & & $x$ & & & \\
\hline $5 \%$ trimmed mean & & & & $x$ & & & $x$ & & & \\
\hline $10 \%$ trimmed mean & & & & $x$ & & & $x$ & & & \\
\hline $15 \%$ trimmed mean & & & & $x$ & & & $x$ & & & \\
\hline $25 \%$ trimmed mean & & & & $x$ & & & $x$ & & & \\
\hline Huber-type skipped mean & & & & $\mathrm{x}$ & & & $\mathrm{x}$ & & & \\
\hline Volatility-weighted mean 1 & & & & & & & $x$ & & & \\
\hline Volatility-weighted mean 2 & & & & & & & $x$ & & & \\
\hline Double-weighted mean 1 & & & & & & & $x$ & & & $x$ \\
\hline Double-weighted mean 2 & & & & & & & $x$ & & & \\
\hline Headline inflation only & & & & & & & $\mathrm{x}$ & & & \\
\hline
\end{tabular}

c) 24-month forecasting horizon

\begin{tabular}{|c|c|c|c|c|c|c|c|c|c|c|}
\hline & \multirow[b]{2}{*}{ frequency } & \multicolumn{3}{|c|}{ United States } & \multicolumn{3}{|c|}{ Japan } & \multicolumn{3}{|c|}{ Canada } \\
\hline & & $\begin{array}{c}1 \mathrm{~m} \text { to } \\
3 \mathrm{~m}\end{array}$ & $\begin{array}{c}3 \mathrm{~m} \text { to } \\
6 \mathrm{~m}\end{array}$ & $\begin{array}{c}6 \mathrm{~m} \text { to } \\
12 \mathrm{~m}\end{array}$ & $\begin{array}{c}1 \mathrm{~m} \text { to } \\
3 \mathrm{~m}\end{array}$ & $\begin{array}{c}3 \mathrm{~m} \text { to } \\
6 \mathrm{~m}\end{array}$ & $\begin{array}{c}6 \mathrm{~m} \text { to } \\
12 \mathrm{~m}\end{array}$ & $\begin{array}{c}1 \mathrm{~m} \text { to } \\
3 \mathrm{~m}\end{array}$ & $\begin{array}{c}3 \mathrm{~m} \text { to } \\
6 \mathrm{~m}\end{array}$ & $\begin{array}{c}6 \mathrm{~m} \text { to } \\
12 \mathrm{~m}\end{array}$ \\
\hline Core 1 & & & & $x$ & & & $x$ & & & \\
\hline Core 2 & & & & $\mathrm{x}$ & & & $x$ & & & \\
\hline Weighted median & & & & $x$ & & & $x$ & & & $x$ \\
\hline $2 \%$ trimmed mean & & & & $x$ & & & $\mathrm{X}$ & & & \\
\hline $5 \%$ trimmed mean & & & & $x$ & & & $\mathrm{x}$ & & & \\
\hline $10 \%$ trimmed mean & & & & $x$ & & & $\mathrm{x}$ & & & \\
\hline $15 \%$ trimmed mean & & & & $\mathrm{x}$ & & & $\mathrm{x}$ & & & \\
\hline $25 \%$ trimmed mean & & & & $x$ & & & $\mathrm{x}$ & & & \\
\hline Huber-type skipped mean & & & & $\mathrm{x}$ & & & $\mathrm{x}$ & & & \\
\hline Volatility-weighted mean 1 & & & & $\mathrm{x}$ & & & $\mathrm{x}$ & $\mathrm{x}$ & & \\
\hline Volatility-weighted mean 2 & & & & $\mathrm{x}$ & & & $\mathrm{x}$ & & & \\
\hline Double-weighted mean 1 & & & & $x$ & & & $\mathrm{x}$ & $\mathrm{x}$ & & $\mathrm{x}$ \\
\hline Double-weighted mean 2 & & & & $x$ & & & $x$ & & & \\
\hline Headline inflation only & & & $\mathrm{x}$ & & & $\mathrm{x}$ & & & $\mathrm{x}$ & \\
\hline
\end{tabular}

Note: $\mathrm{X}$ indicates that the restriction on coefficients implied by moving from the higher to the lower frequency is rejected at the $5 \%$ significance level 
ECO/WKP(2005)48

Table 8. Gap model: out-of-sample forecasting performance (12-month forecasting horizon) RMSFE (ratio to RMSFE of random-walk forecast)

\section{A) estimated gap model ${ }^{1}$}

\begin{tabular}{l|cc|c|cc|c|cc}
\hline & \multicolumn{2}{|c|}{ United States } & Euro area & \multicolumn{2}{c|}{ Japan } & $\begin{array}{c}\text { United } \\
\text { Kingdom }\end{array}$ & \multicolumn{2}{c}{ Canada } \\
& $1995-2004$ & $2002-2004$ & $2002-2004$ & $1995-2004$ & $2002-2004$ & $2002-2004$ & $1995-2004$ & $2002-2004$ \\
\hline Core 1 & 1.04 & 1.10 & 1.16 & 1.08 & 1.54 & 1.18 & 1.35 & 1.34 \\
Core 2 & 1.15 & 1.19 & 1.16 & 1.12 & 1.45 & 1.20 & 1.19 & 1.24 \\
Weighted median & 1.04 & 1.13 & 1.20 & 1.05 & 1.17 & 1.33 & 1.48 & 1.49 \\
$2 \%$ trimmed mean & 0.99 & 1.04 & 1.14 & 1.12 & 1.28 & 1.29 & 1.28 & 1.07 \\
5\% trimmed mean & 0.99 & 1.09 & 1.20 & 1.15 & 1.37 & 1.22 & 1.35 & 1.12 \\
10\% trimmed mean & 1.01 & 1.12 & 1.06 & 1.10 & 1.30 & 1.23 & 1.41 & 1.28 \\
15\% trimmed mean & 1.01 & 1.13 & 1.14 & 1.08 & 1.26 & 1.32 & 1.48 & 1.38 \\
$25 \%$ trimmed mean & 1.02 & 1.16 & 1.21 & 1.07 & 1.21 & 1.55 & 1.49 & 1.44 \\
Huber-type skipped mean & 1.01 & 1.12 & 1.21 & 1.06 & 1.18 & 1.29 & 1.41 & 1.45 \\
Volatility-weighted mean 1 & 1.20 & 1.18 & 1.13 & 1.10 & 1.54 & 1.43 & 1.53 & 1.39 \\
Volatility-weighted mean 2 & 1.19 & 1.16 & 1.14 & 1.11 & 1.55 & 1.31 & 1.32 & 1.32 \\
Double-weighted mean 1 $_{\text {Double-weighted mean 2 }}^{1.06}$ & 1.20 & 1.14 & 1.06 & 1.36 & 1.48 & 1.62 & 1.37 \\
5-year average of headline inflation ${ }^{2}$ & 1.00 & 1.10 & 1.15 & 1.08 & 1.41 & 1.47 & 1.52 & 1.40
\end{tabular}

1) model estimated over the period from 1984 to the forecast date for The United States and Japan, from 1986 to the forecast date for Canada, from 1996 to the forecast date for the euro area and from 1997 to the forecast date for the United Kingdom.

2) the 5-year average of past headline inflation is a weighted average with geometrically declining weights. The discount factor, selected on the basis of the lowest RMSFE, is 0.1 for the United States, the euro area and United Kingdom; it is zero for Japan and Canada.

\section{B) "restricted" gap model ${ }^{1}$}

\begin{tabular}{|c|c|c|c|c|c|c|c|c|}
\hline & \multicolumn{2}{|c|}{ United States } & \multirow{2}{*}{$\begin{array}{l}\text { Euro area } \\
2002-2004\end{array}$} & \multicolumn{2}{|c|}{ Japan } & \multirow{2}{*}{$\begin{array}{c}\text { United } \\
\text { Kingdom } \\
2002-2004\end{array}$} & \multicolumn{2}{|c|}{ Canada } \\
\hline & 1995-2004 & 2002-2004 & & $1995-2004$ & 2002-2004 & & $1995-2004$ & 2002-2004 \\
\hline Core 1 & 0.87 & 0.86 & 1.29 & 0.93 & 0.65 & 1.06 & 0.77 & 0.75 \\
\hline Core 2 & 1.04 & 0.79 & 1.18 & 0.94 & 0.74 & 0.89 & 0.75 & 0.63 \\
\hline Weighted median & 1.07 & 1.14 & 0.82 & 0.96 & 0.89 & 1.45 & 0.64 & 0.56 \\
\hline $2 \%$ trimmed mean & 0.96 & 0.88 & 0.87 & 0.90 & 0.94 & 0.91 & 0.92 & 0.97 \\
\hline $5 \%$ trimmed mean & 0.92 & 0.78 & 0.83 & 0.87 & 0.83 & 0.77 & 0.83 & 0.84 \\
\hline $10 \%$ trimmed mean & 0.90 & 0.79 & 0.78 & 0.88 & 0.80 & 0.98 & 0.75 & 0.70 \\
\hline $15 \%$ trimmed mean & 0.91 & 0.82 & 0.78 & 0.90 & 0.82 & 1.15 & 0.71 & 0.63 \\
\hline $25 \%$ trimmed mean & 0.95 & 0.91 & 0.78 & 0.93 & 0.86 & 1.45 & 0.67 & 0.59 \\
\hline Huber-type skipped mean & 0.97 & 0.88 & 0.84 & 0.93 & 0.91 & 1.65 & 0.70 & 0.56 \\
\hline Volatility-weighted mean 1 & 0.82 & 0.78 & 1.14 & 0.93 & 1.23 & 2.26 & 0.71 & 0.66 \\
\hline Volatility-weighted mean 2 & 0.86 & 0.73 & 1.06 & 0.96 & 1.32 & 1.25 & 0.70 & 0.65 \\
\hline Double-weighted mean 1 & 0.96 & 1.06 & 1.05 & 0.89 & 0.73 & 3.19 & 0.80 & 0.69 \\
\hline Double-weighted mean 2 & 0.90 & 0.86 & 0.92 & 0.89 & 0.69 & 1.92 & 0.75 & 0.68 \\
\hline 5 -year average of headline inflation ${ }^{2}$ & 0.86 & 0.57 & 0.71 & 1.00 & 0.93 & 0.54 & 0.63 & 0.55 \\
\hline
\end{tabular}

1) the forecast headline inflation at the horizon indicated is assumed to be equal to the core inflation rate at the time the forecast is made. This is equivalent to a forecast using a gap model restricted to have a unit coefficient for the gap and a zero constant term.

2) the 5-year average of past headline inflation is a weighted average with geometrically declining weights. The discount factor, selected on the basis of the lowest RMSFE, is 0.1 for the euro area and Japan, 0.03 for United Kingdom and Canada, and zero for the United States. 


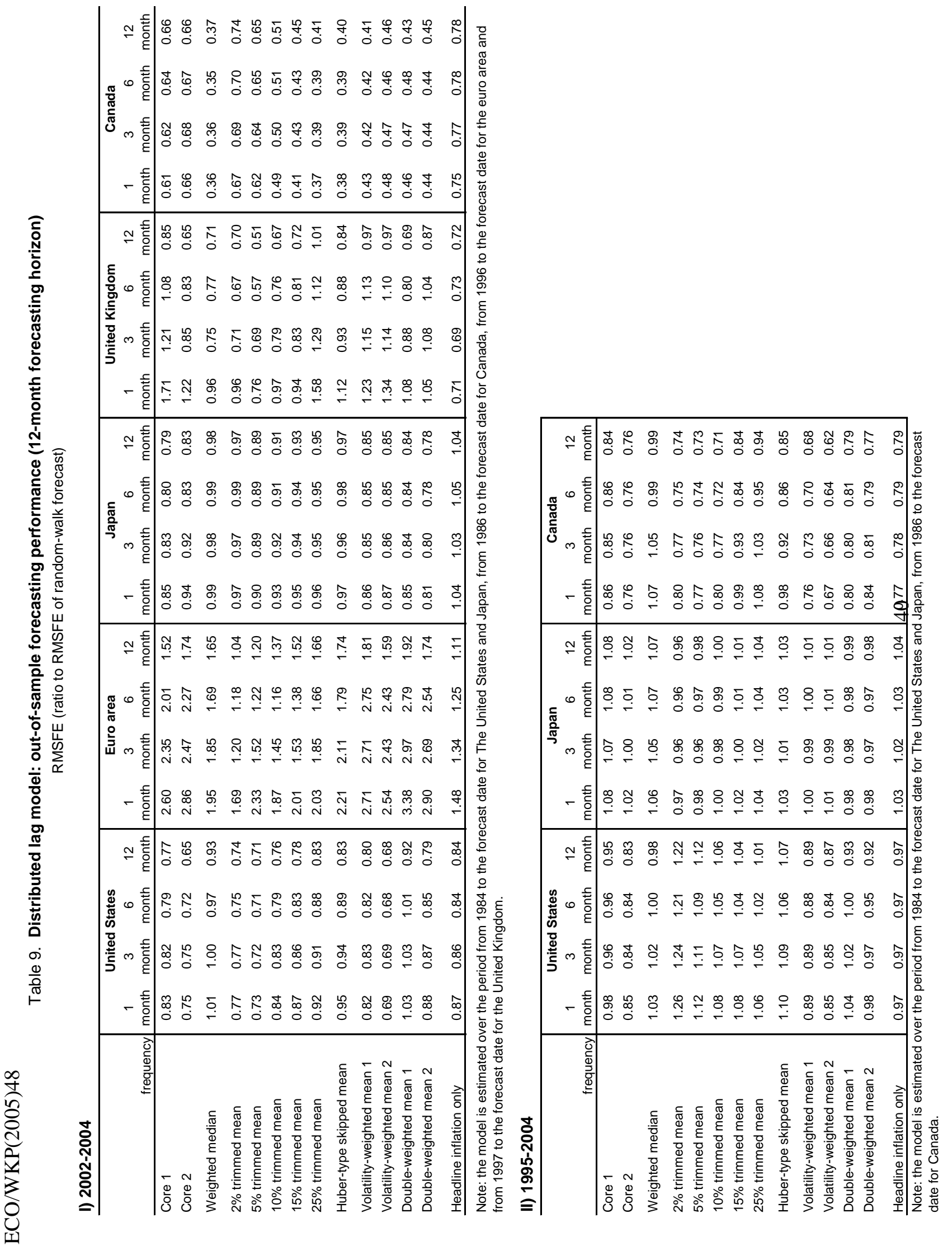


Figure 1a. United States : indicators of core inflation year-on-year \% change
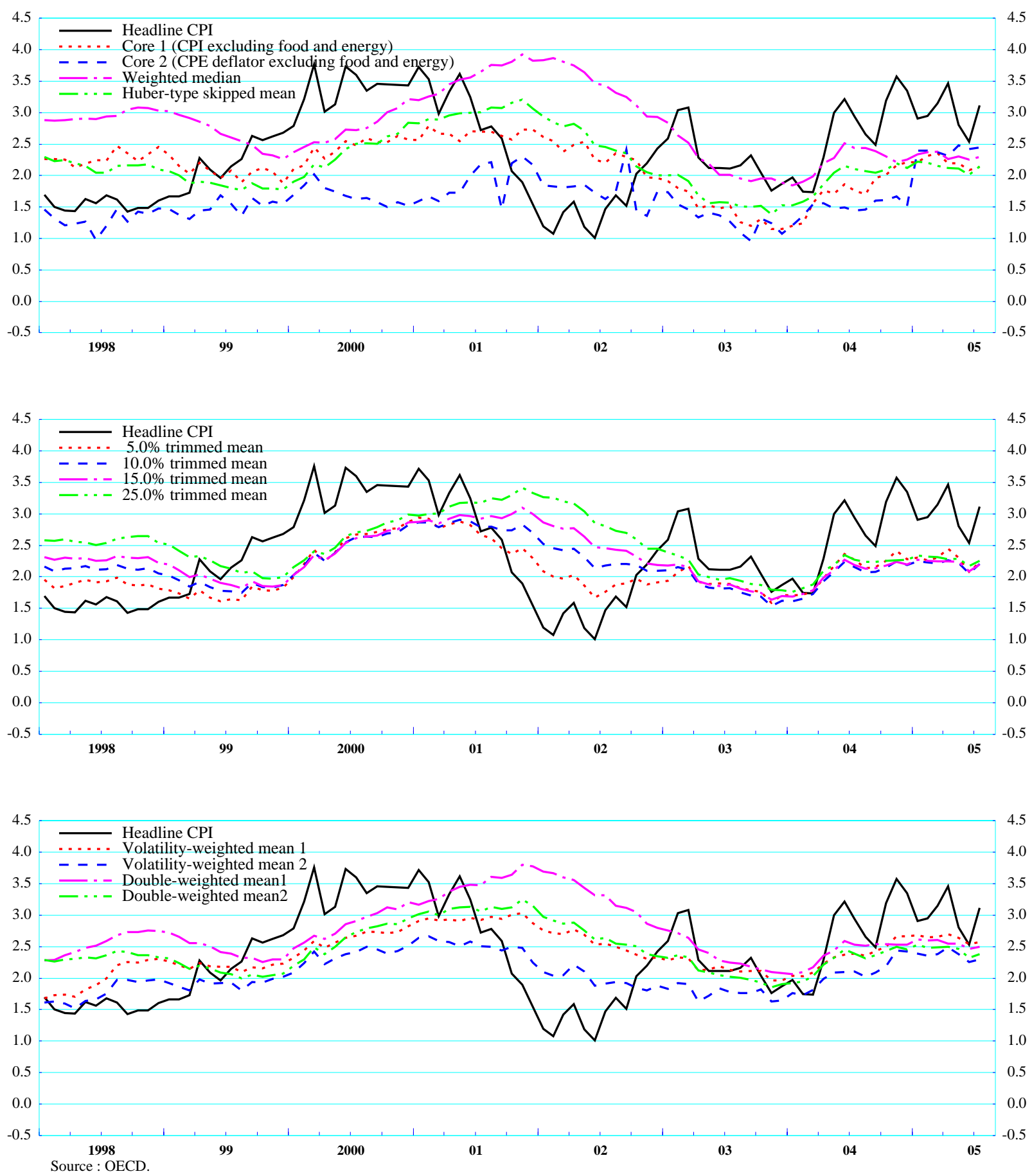
Figure 1b. Euro area : indicators of core inflation year-on-year \% change
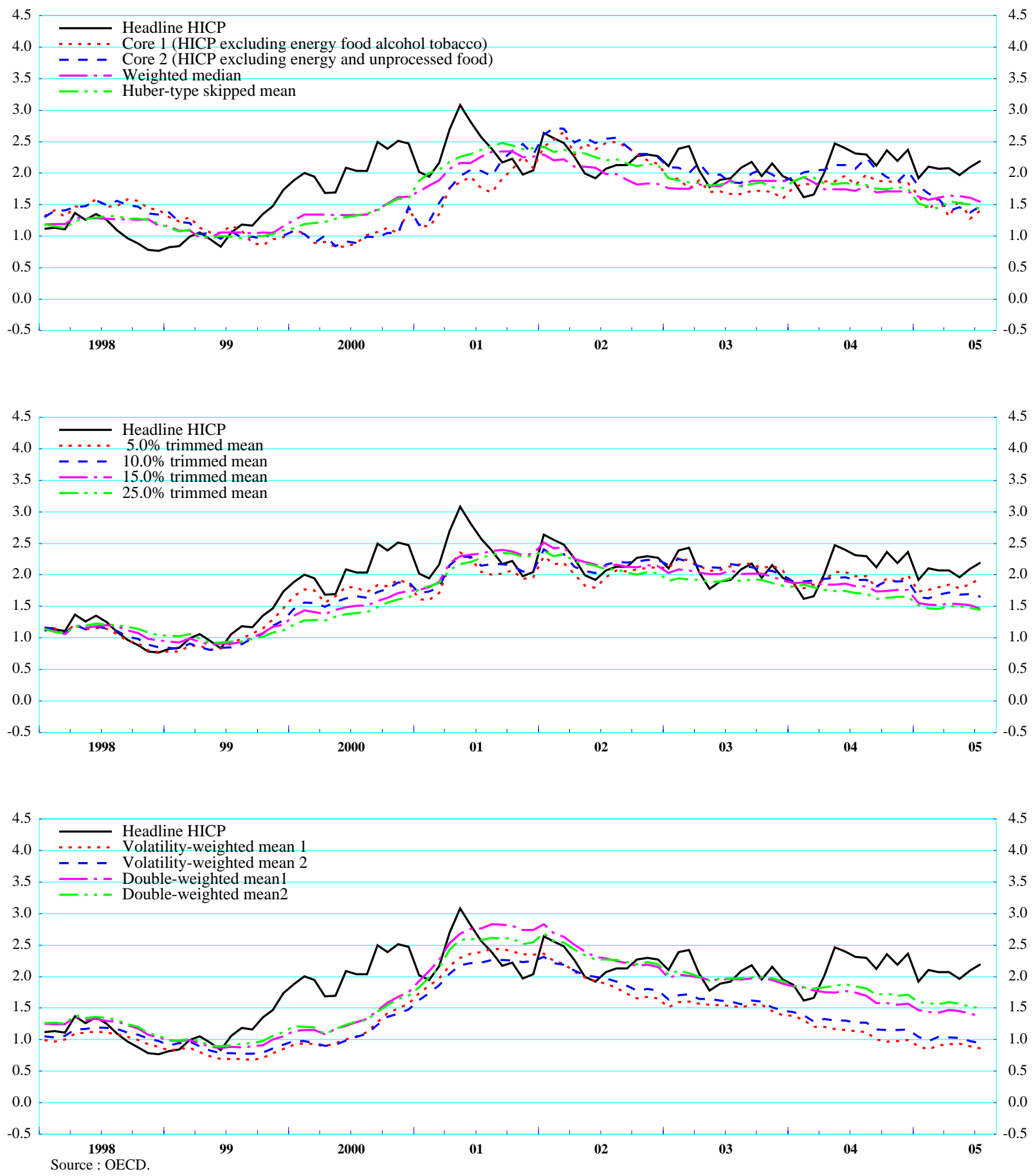
Figure 1c. Japan : indicators of core inflation year-on-year \% change
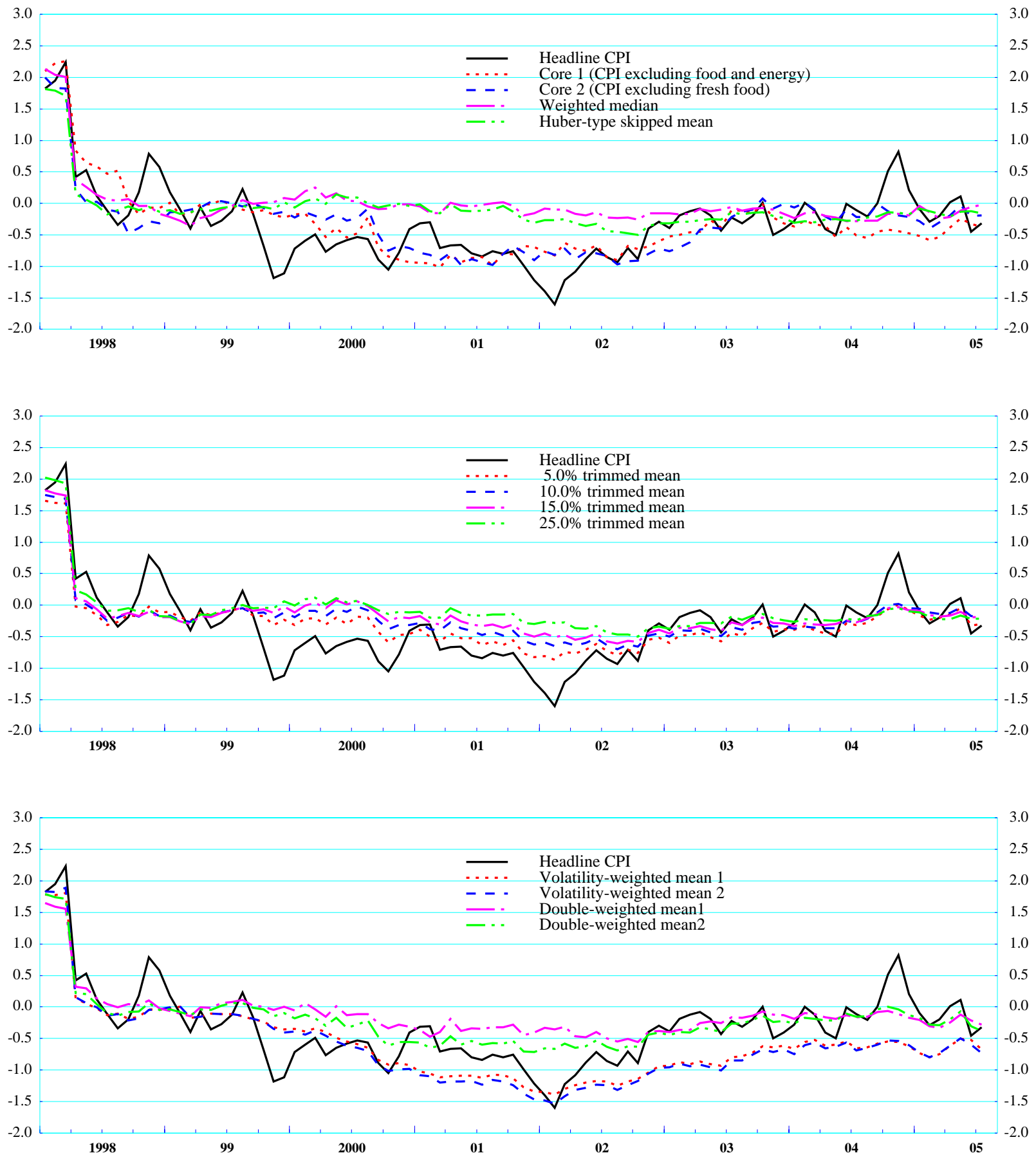

Source : OECD 
Figure 1d. United Kingdom : indicators of core inflation year-on-year \% change
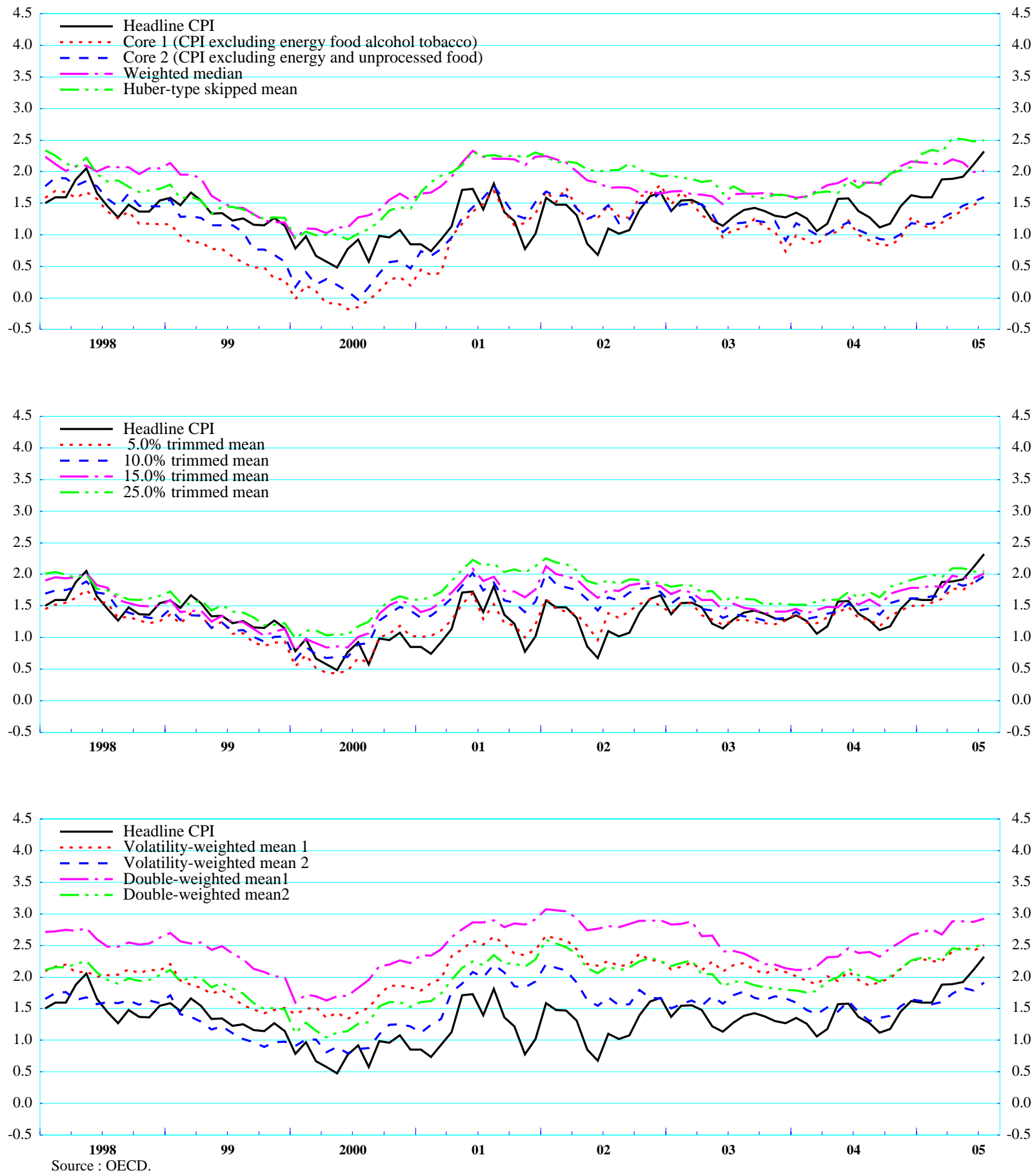
Figure 1e. Canada: indicators of core inflation year-on-year \% change
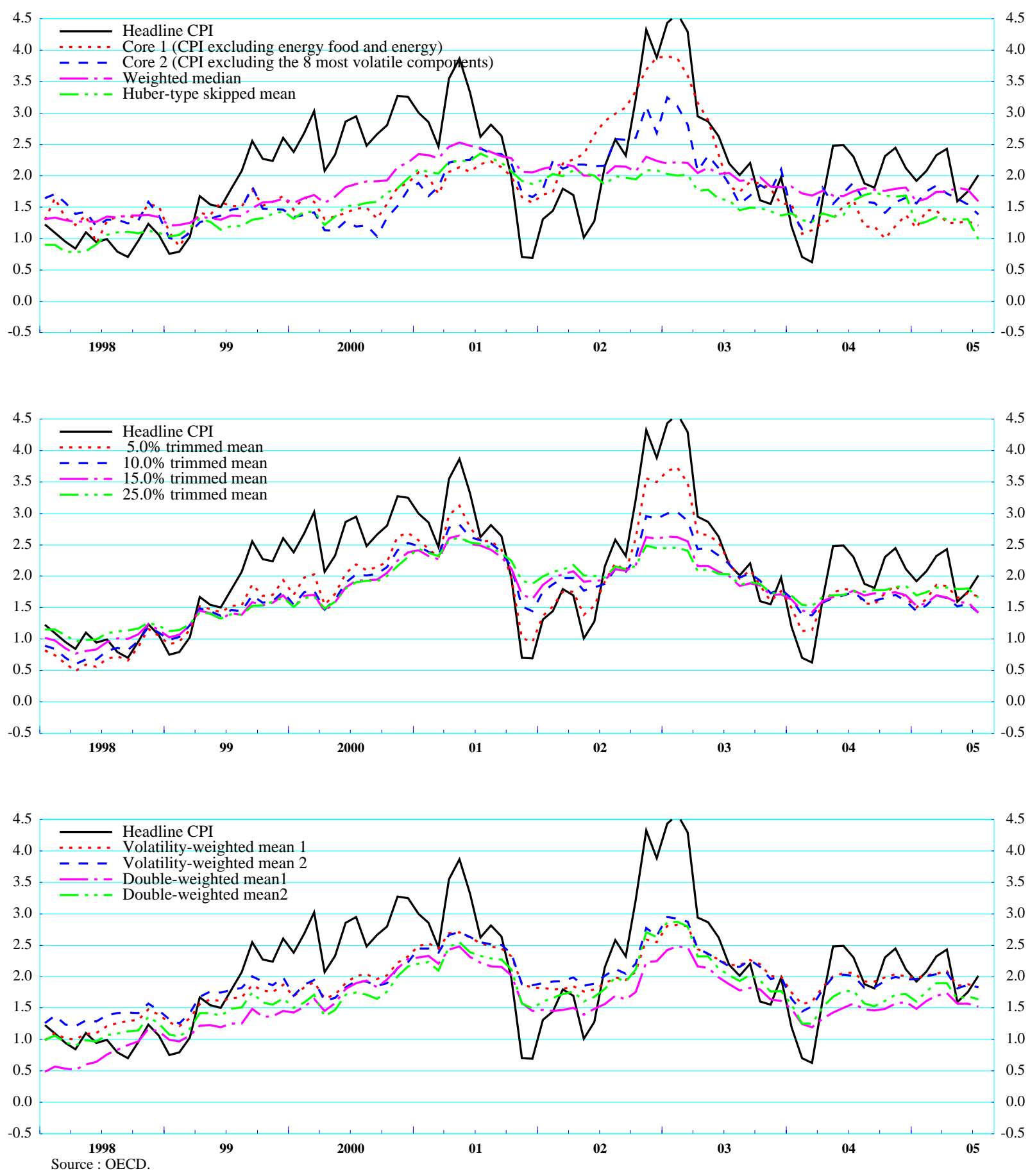
Figure 2. Main components of core inflation year-on-year \% change

All-items CPI

$\begin{array}{ll}\ldots . . & \text { Goods less food \& energy } \\ & 1\end{array}$
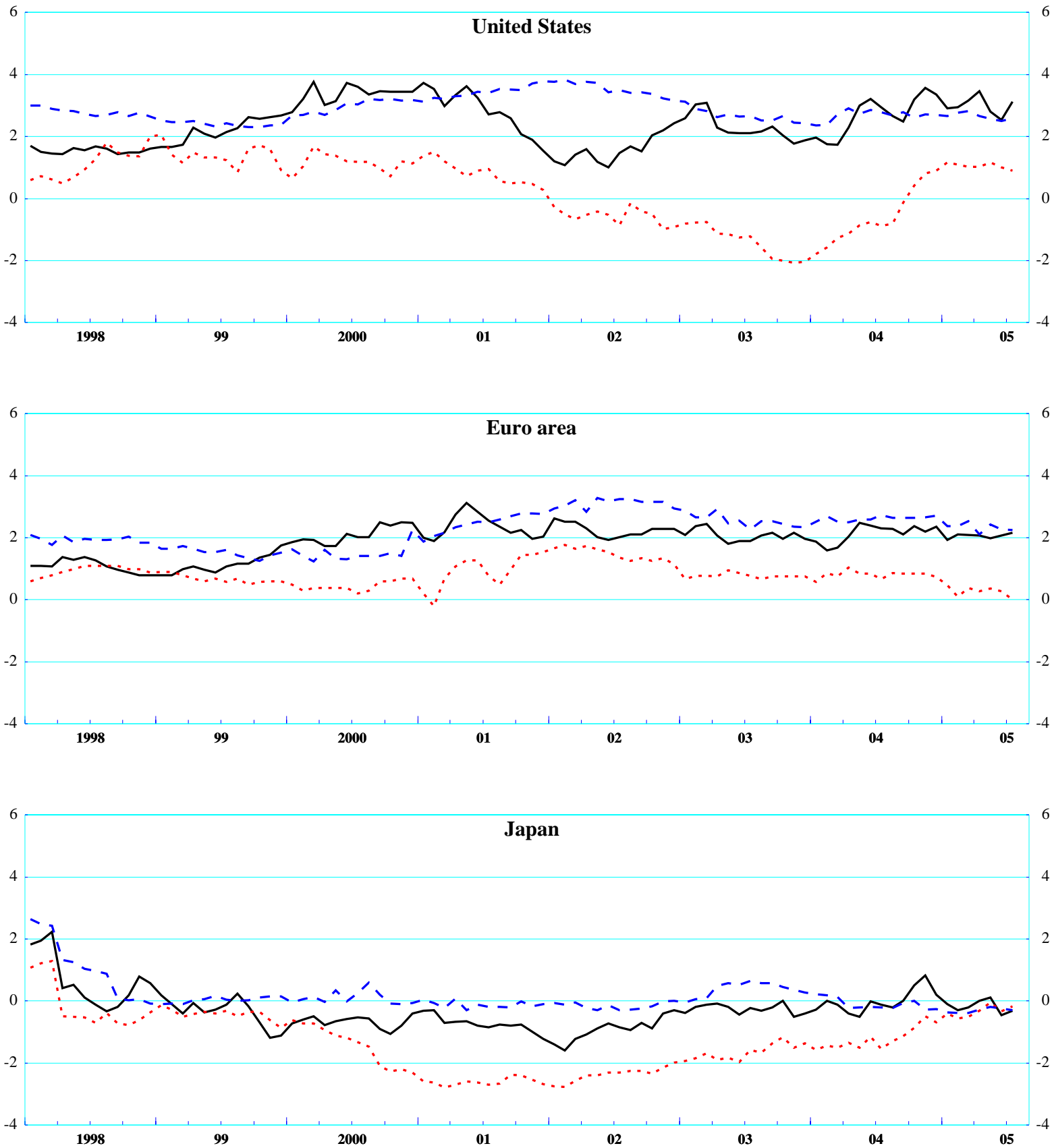

1. Goods excluding fresh food and petroleum products for Japan; non-energy industrial goods for the euro area. 2. Services less energy services for the United States.

Source : US Bureau of Labor Statistics, Eurostat, Datastream. 
Figure 2(cont.). Main components of core inflation year-on-year \% change
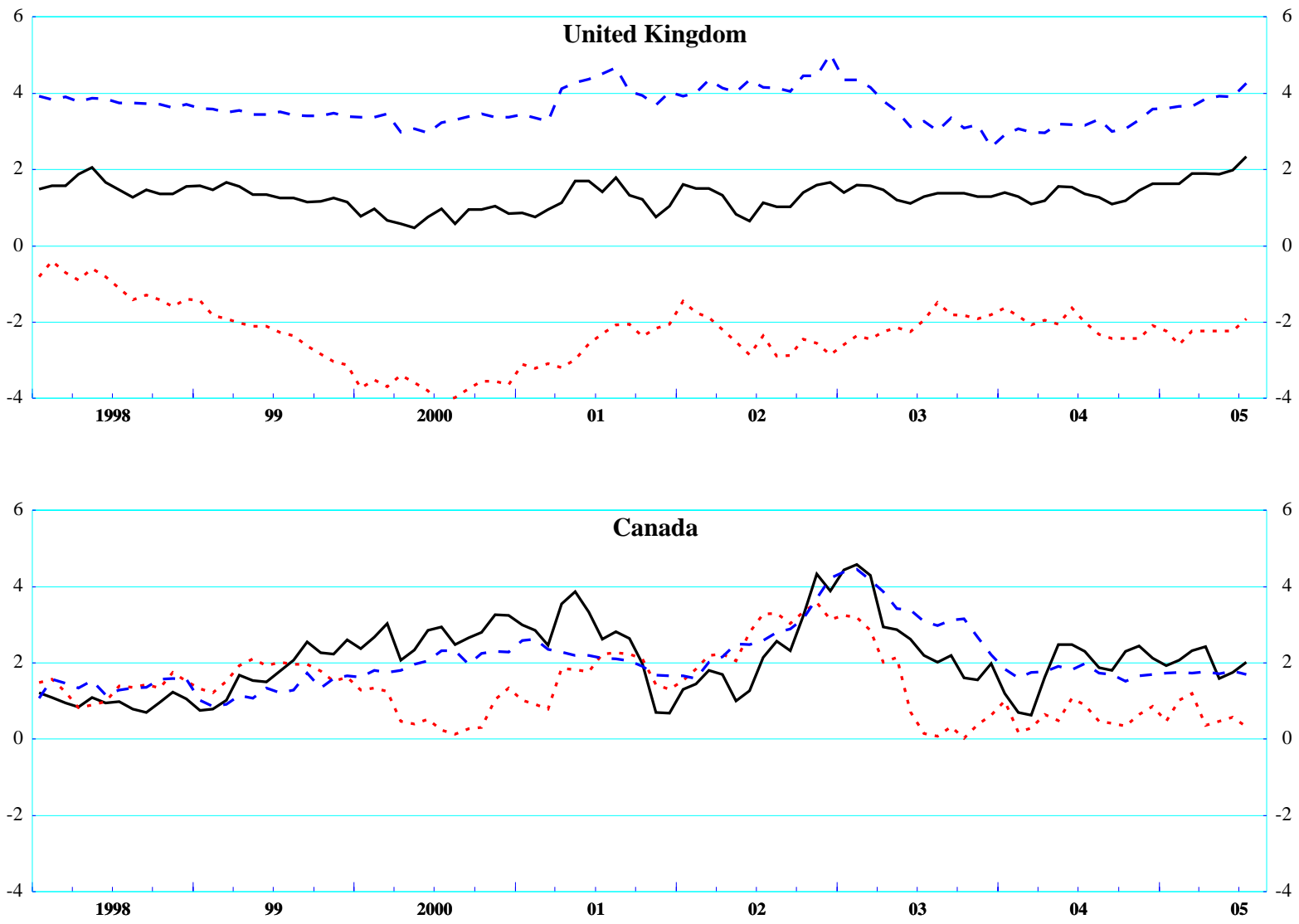

1. Non-energy industrial goods for the United Kingdom; goods excluding food purchased from stores and energy for Canada. Source : Datastream, Statistics Canada. 
Figure 3a. United States : headline inflation rate and selected indicators of core inflation 3-month \% change
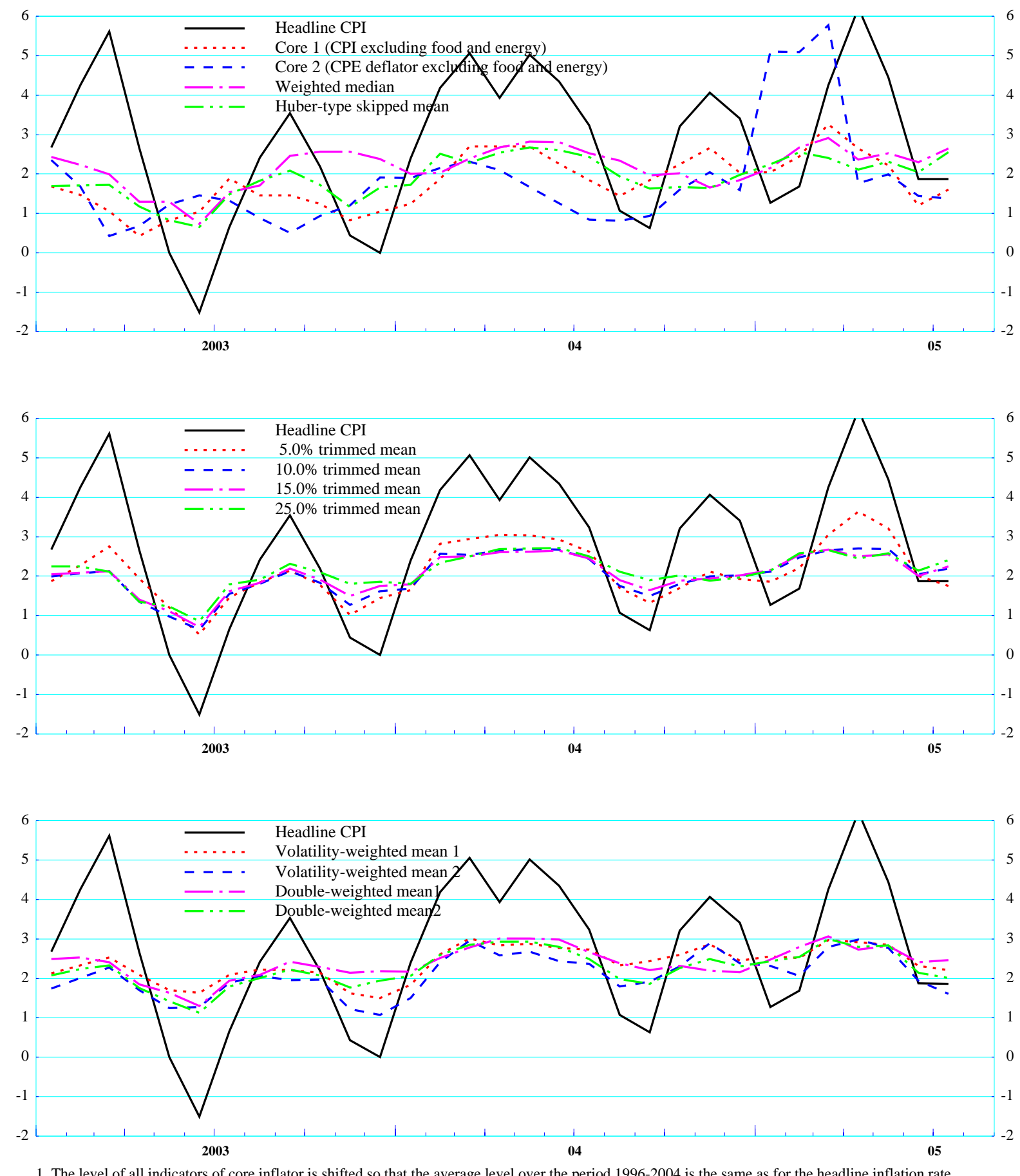

of all indicators of core inflator is shifted so that the average level over the period 1996-2004 is the same as for the headline inflation rate. Source : OECD. 
Figure 3b. Euro area : headline inflation rate and selected indicators of core inflation 3-month \% change
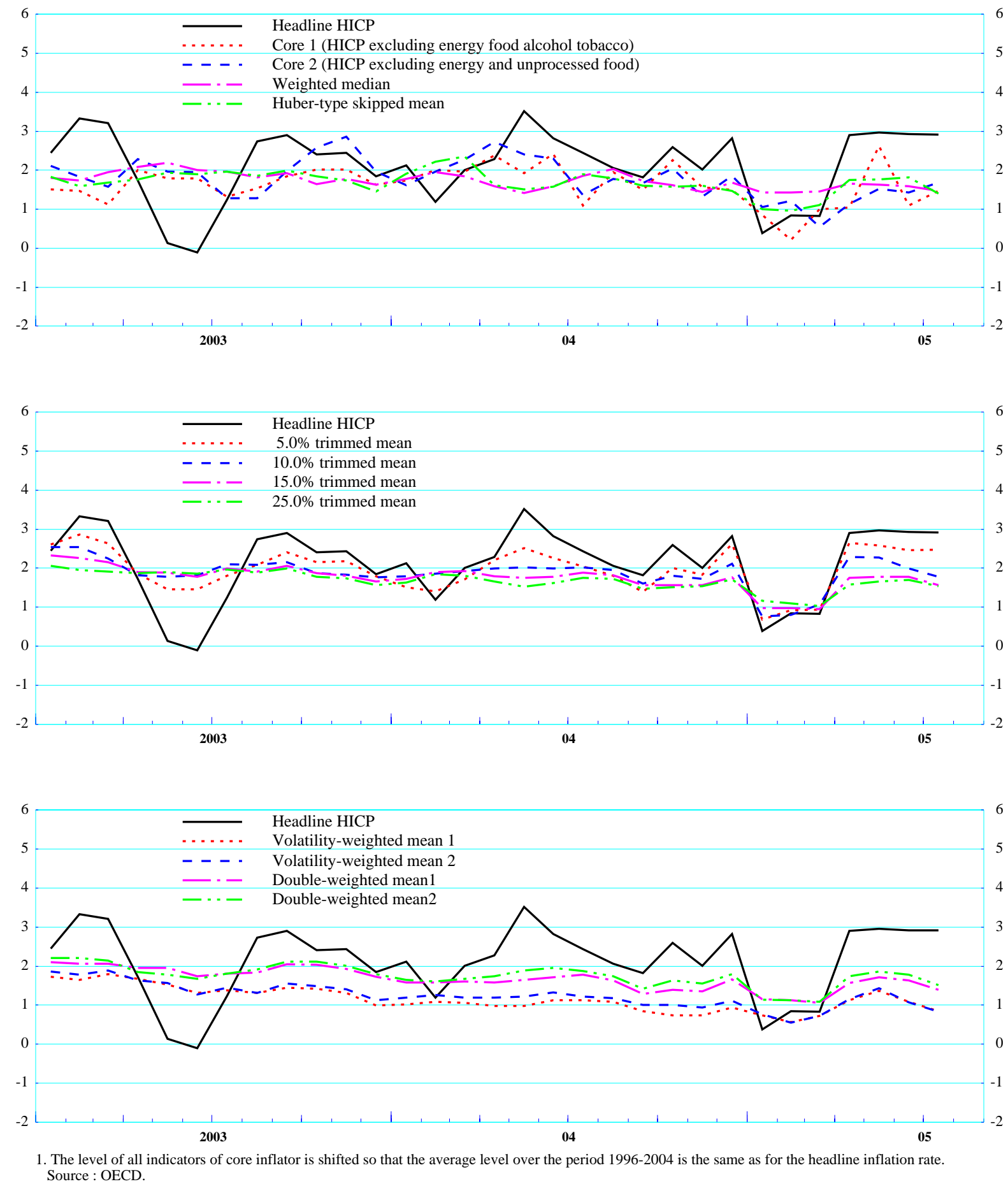
Figure 3c. Japan : headline inflation rate and selected indicators of core inflation 3-month \% change
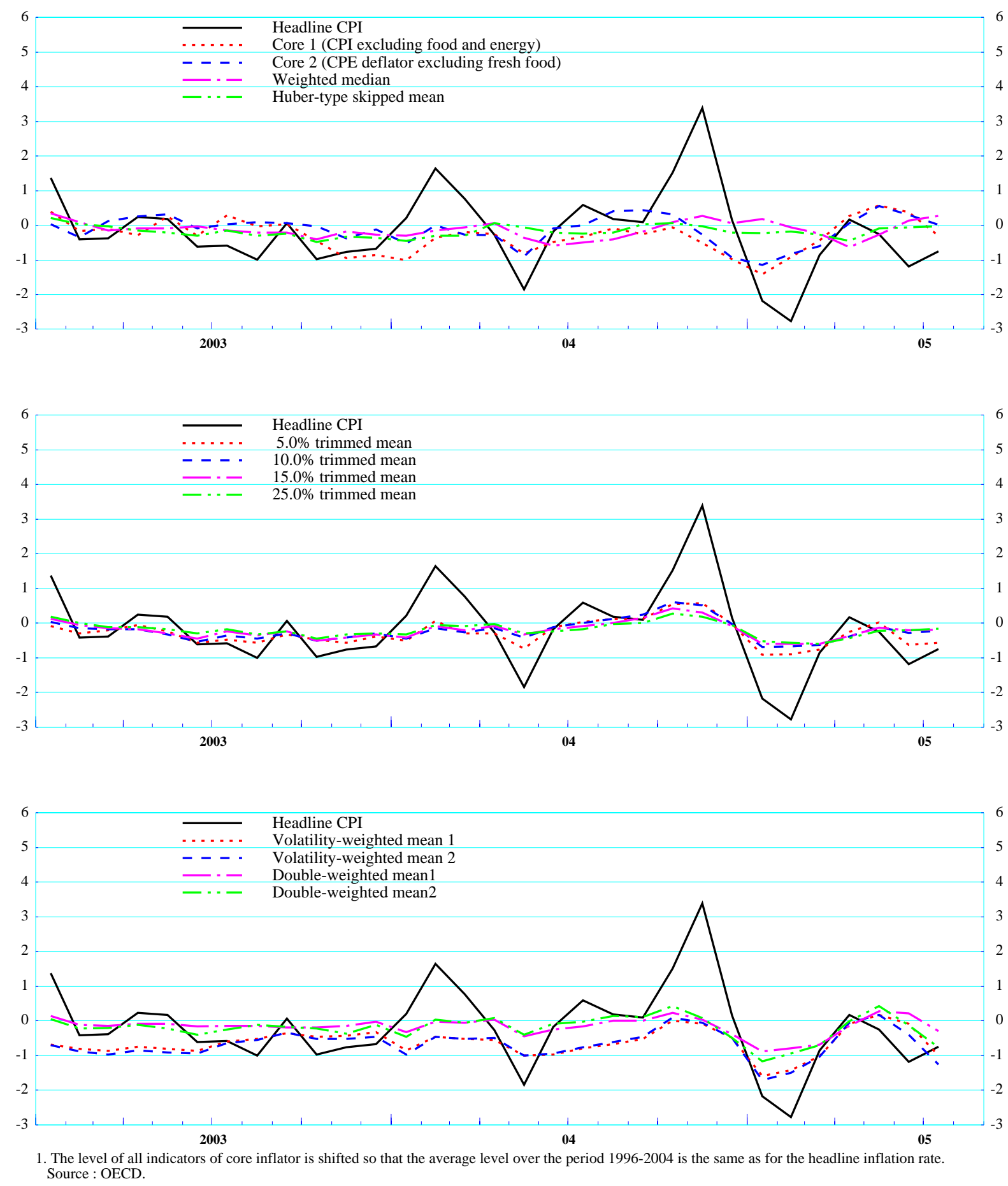
Figure 3d. United Kingdom : headline inflation rate and selected indicators of core inflation 3-month \% change
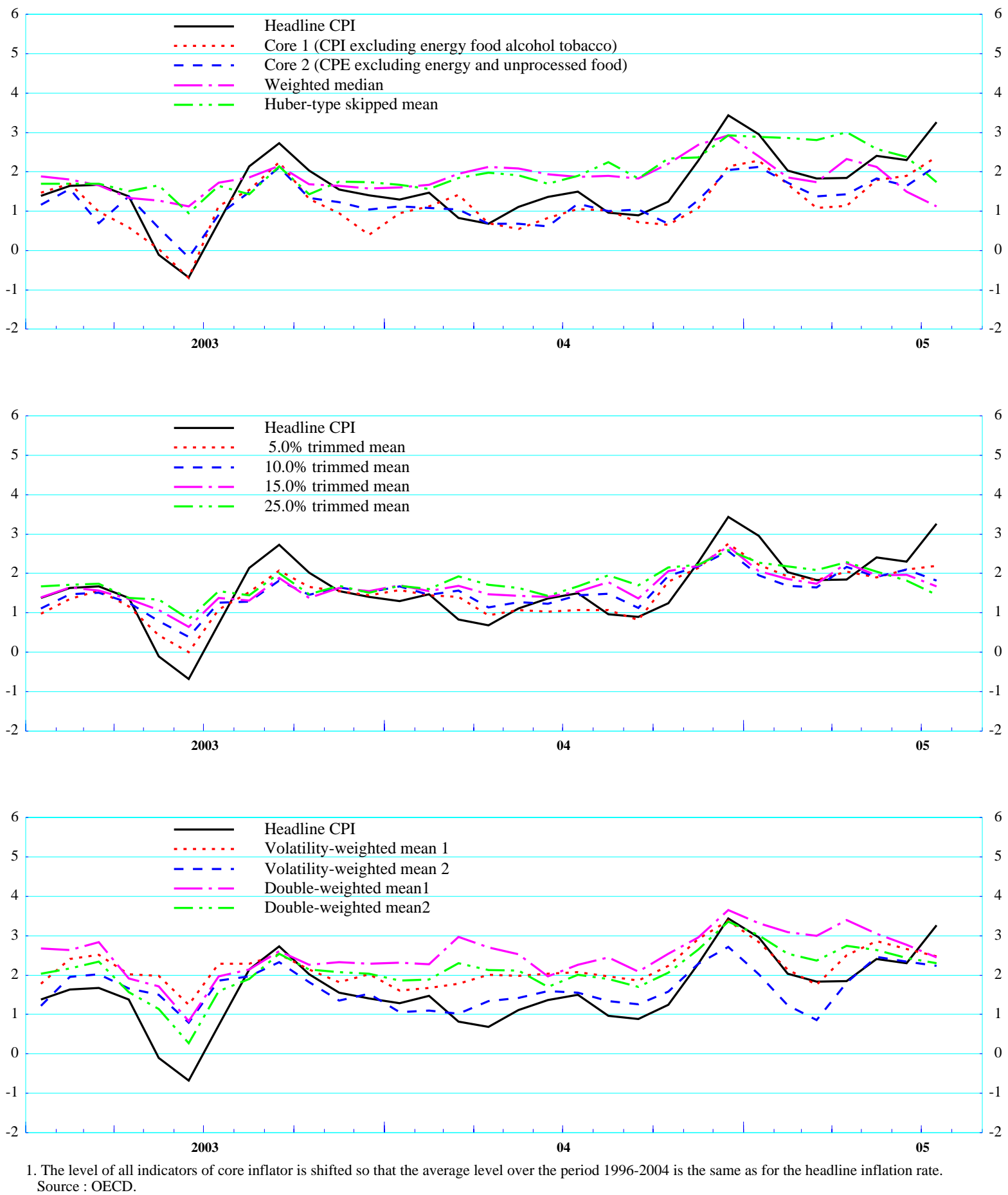
Figure 3e. Canada : headline inflation rate and selected indicators of core inflation 3-month \% change
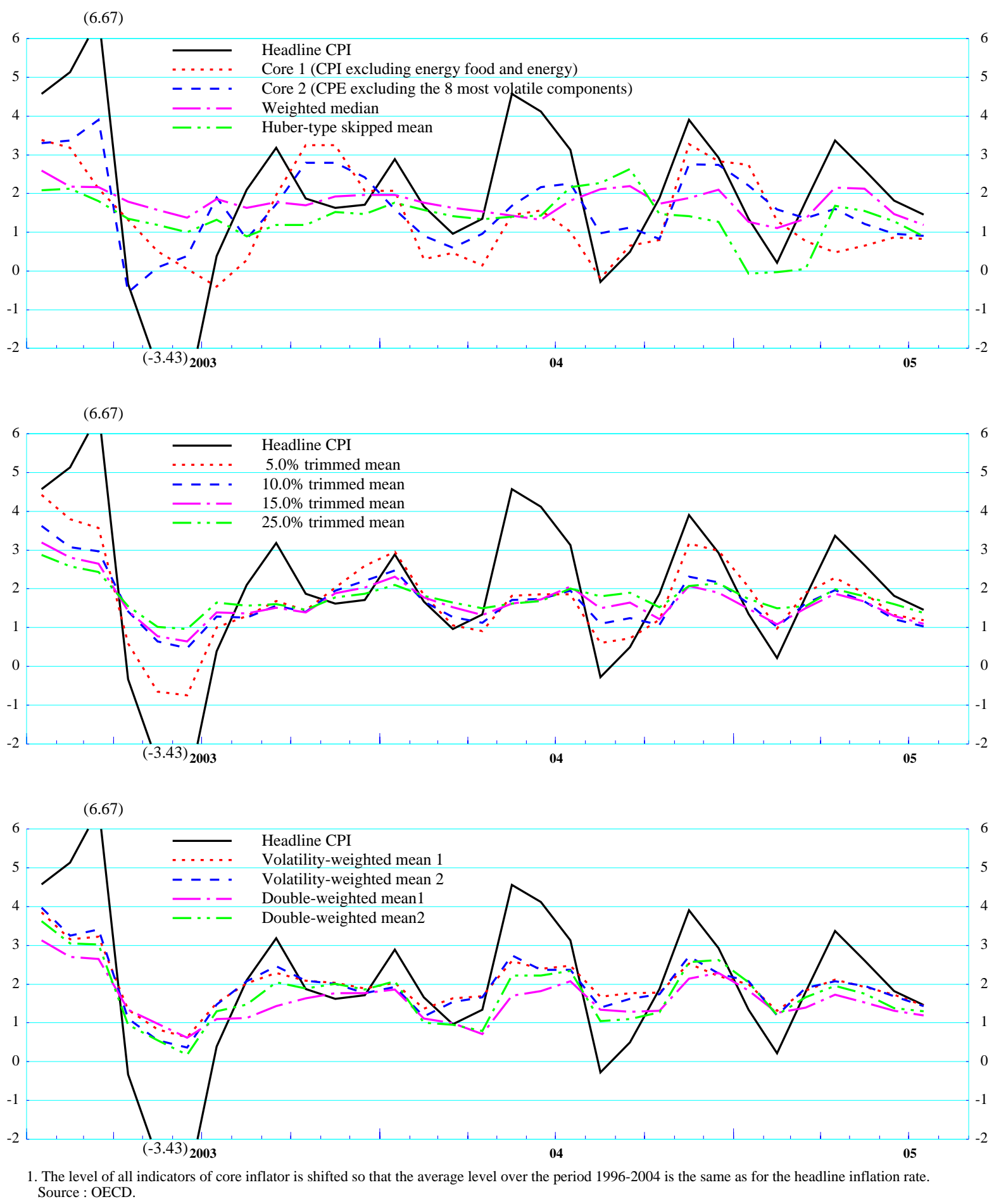
ECO/WKP(2005)48

\section{ANNEX 1. TECHNICAL DETAILS ON THE CONSTRUCTION OF CORE INFLATION INDICATORS}

46. This annex provides technical details on the calculation of the core inflation indicators used in the study and on data sources. With the exception of the two standard core inflation indicators named Core 1 and Core 2, which are regularly by statistical agencies, all indicators were calculated on the basis of disaggregated consumer price data, using month-on-month price changes. Three-, six- and twelve-month inflation rates were then calculated by compounding the indicator's monthly rate of change.

\section{A.1 Data}

47. For Core 1 and Core 2 published data were used. In cases were seasonally adjusted data were not available, data were seasonally adjusted using X12. All the remaining core inflation indicators were calculated from the distribution of monthly price changes of CPI components (HICP for the euro area). ${ }^{23}$ The component breakdown used consists of 42 items for the United States (36 before 1998); 94 for the euro area (but varying between 81 and 93 before 2001); 40 for Japan; 84 for the United Kingdom (between 78 and 83 in 1996-2000) and 54 for Canada. ${ }^{24}$ For the euro area, aggregated area-wide data are used rather than country-level data. For reasons of data availability, the period for which the indicators were calculated is 1967-2004 for the United States; 1995-2000 for the euro area; 1980-2004 for Japan; 1996-2004 for the United Kingdom and 1985-2004 for Canada. ${ }^{25}$

48. The indicators are constructed from seasonally adjusted data for the United States, Japan and Canada. For the United States the officially published seasonally-adjusted CPI data were used. For Japan and Canada, the published raw CPI data were seasonally adjusted using X12. On the other hand, for the euro area and the United Kingdom, where the lower-level data series available are too short to allow reliable seasonal adjustment, the indicators were computed from unadjusted data, and the resulting indicator series were then seasonally adjusted using X12.

23. Data sources are as follows. United States: Bureau of Labor Statistics, except Core 2 data, which are from the Bureau of Economic Analysis. Euro area and United Kingdom: Eurostat. Japan: Statistics Bureau (via Datastream), except Core 1 data, which are from the OECD's Main Economic Indicators. Canada: Statistics Canada's CANSIM database. CPI/HICP weights are from the same sources. Kind help from the Bank of Canada and from the Federal Reserve Bank of Cleveland in identifying the set of CPI components and reconstructing some data series is gratefully acknowledged.

24. Results can vary depending on the level of aggregation of the CPI data used (Bryan et al., 1997; Aucremanne, 2000). For the euro area, the most disaggregated publicly available area-wide data were used. Vega and Wynne (2001) show that results can be different if country-level data are used. The same level of aggregation was used for the United Kingdom. For the United States, Japan and Canada, intermediate levels of aggregation were preferred for reasons of data availability and computational simplicity. For the United States, the CPI component breakdown used is the same adopted by Clark (2001).

25. These dates refer to 1-month inflation rates. Series for 12-month inflation rates are one year shorter. 


\section{A.2 Trimmed means}

49. Trimmed means are weighted means calculated excluding - that is, assigning a zero weight to the largest and the smallest price increments realised in each particular month. The (symmetric) trimming percentage $\alpha$ indicates how much (in terms of CPI weights) of the "tails" of the distribution of price changes is to be excluded. To identify the excluded items, all CPI components' price changes are arranged in ascending order. Then the corresponding weights are added up until their cumulative sum reaches the threshold $\alpha$ and then again the threshold 1- $\alpha$. The items outside the interval between the two thresholds are excluded. The two marginal items (i.e. those whose weights lie across the thresholds) are given a reduced weight to ensure that the trimmed percentage on each side is exactly $\alpha$. The weights are then re-scaled so that they add up to one.

50. The formal calculation of the weights is as follows. We indicate with $\Pi_{t}=\left\{\pi_{t}^{i}\right\}$ the vector of monthly price changes of all CPI components (indexed by $i$ ) at time $\mathrm{t}$, and with $W_{t}=\left\{w_{t}^{i}\right\}$ the vector of corresponding CPI weights. $\tilde{\Pi}_{t}=A_{t} \Pi_{t}$ indicates a linear transformation of $\Pi_{t}$ where its components are simply rearranged in ascending order, and $V_{t}=\left\{v_{t}^{i}\right\}=A_{t} W_{t}$ the corresponding rearrangement of the weights vector. This procedure is repeated each period, so the transformation matrix $A_{t}$ is different each period. The weights $z_{t}^{i}$ for the calculation of the trimmed mean with trimming percentage $\alpha$ are:

$$
\begin{aligned}
& z_{t}^{i}=\quad 0 \quad \text { if } \sum_{j=0}^{i} v_{t}^{j} \leq \alpha \\
& 0 \\
& \text { if } \sum_{j=0}^{i-1} v_{t}^{j} \geq 1-\alpha \\
& \frac{1}{1-2 \alpha} v_{t}^{i} \quad \text { if } \sum_{j=0}^{i-1} v_{t}^{j} \geq \alpha \text { and } \sum_{j=0}^{i} v_{t}^{j} \leq 1-\alpha \\
& \frac{1}{1-2 \alpha}\left[(1-\alpha)-\sum_{j=0}^{i-1} v_{t}^{j}\right] \quad \text { if } \sum_{j=0}^{i-1} v_{t}^{j}<1-\alpha<\sum_{j=0}^{i} v_{t}^{j} \\
& \frac{1}{1-2 \alpha}\left[\sum_{j=0}^{i} v_{t}^{j}-\alpha\right] \quad \text { if } \sum_{j=0}^{i-1} v_{t}^{j}<\alpha<\sum_{j=0}^{i} v_{t}^{j}
\end{aligned}
$$

51. The trimmed mean of inflation in month $t$ is then calculated by multiplying the vector of weights $Z_{t}=\left\{z_{t}^{i}\right\}$ by the vector of rearranged price changes $\tilde{\Pi}_{t}$ :

$$
T M_{t}^{\alpha}=\sum_{i=1}^{n} z_{t}^{i} \tilde{\pi}_{t}^{i}
$$

52. Trimmed means can be calculated for any trimming percentage $\alpha$ between zero and 50. The limiting case for $\alpha=0$ is the standard weighted mean, while setting $\alpha=50$ yields the weighted median. In this paper it was chosen to use, for illustrative purposes, five different trimmed means, the $2 \%, 5 \%, 10 \%$, $15 \%$ and $25 \%$ trimmed mean, as well as the weighted median (see below). 


\section{A.3 Weighted median}

53. The weighted median can be seen as the limiting case of a trimmed mean where the trimming percentage on each side is 50 per cent. In this case, only the component whose price change lies at the centre of the distribution, leaving 50 per cent of the weights on each side, is considered. It is called weighted median because the identification of this element is based on weights (in an unweighted median it would be the element that leaves half of the total number of components - regardless of weights - on each side).

54. Using the same notation as above, the expression for the weights $z_{t}^{i}$ of the weighted median reduces to:

$$
\begin{aligned}
& z_{t}^{i}=\quad 1 \quad \text { if } \sum_{j=0}^{i-1} v_{t}^{j} \leq 0.5 \leq \sum_{j=0}^{i} v_{t}^{j} \\
& 0 \quad \text { otherwise }
\end{aligned}
$$

\section{A.4 The one-step Huber-type skipped mean}

55. As in trimmed means, also in the Huber skipped mean a varying number of components identified on the basis of the size of the realised price changes - are excluded from the calculation of mean inflation each month. However, here the excluded components are those whose price changes are determined to be "outliers" with respect to a standardisation of the sample distribution of price changes that is robust to non-normality. Unlike in the case of trimmed means, the total weight of excluded elements each period depends on how many price changes are "outliers" and therefore will be time-varying. Moreover, it is not necessarily the same from each of the two tails.

56. If the cross-section distribution of price changes were approximately normal, the criterion for identifying outliers could be defined simply in terms of whether the distance from the mean price change exceeds 2.5 standard deviations. However, the normality condition is usually not met as price distributions tend to exhibit excess kurtosis. Therefore, a standardisation robust to non-normality has to be used. In the one used here - following Aucremanne (2000) - a price change is excluded if the difference between its price change and the median price change exceeds, in absolute value, $\mathrm{X}$ times the median absolute price deviation from the median. $\mathrm{X}$ is set equal to 2.5 , multiplied by a correction factor (1.4826) in order to make this condition equivalent to using a threshold of 2.5 standard deviations in the case of a normal distribution.

57. In formal terms, the standardisation of the monthly price changes $\pi_{t}^{i}$ is obtained by defining:

$$
\hat{\pi}_{t}^{i}=\frac{\pi_{t}^{i}-\operatorname{med}\left(\pi_{t}^{i}\right)}{1.4826 \cdot \operatorname{med}\left|\pi_{t}^{i}-\operatorname{med}\left(\pi_{t}^{i}\right)\right|}
$$

58. and the weights $z_{t}^{i}$ are then obtained by setting:

$$
z_{t}^{i}=0 \quad \text { if }\left|\hat{\pi}_{t}^{i}\right| \geq 2.5
$$




$$
\frac{w_{t}^{i}}{1-\sum_{\forall j \text { s.t. }\left|\hat{\pi}_{t}^{i}\right| \geq 2.5} w_{t}^{j}} \text { otherwise }
$$

\section{A.5 Volatility-weighted and double-weighted means}

59. The volatility-weighted mean is calculated by replacing the CPI weights (which are based on expenditure shares) with weights that are inversely proportional to the volatility of each component's price. The double-weighted mean can be regarded as a hybrid between the standard CPI mean inflation calculated with expenditure weights and the volatility-weighted mean: the CPI weights are not disregarded as in the volatility-weighted mean, but re-weighted by being divided by each item's price volatility.

60. The formulas for the weights of the volatility-weighted and the double-weighted means are, respectively:

Volatility-weighted mean: $z_{t}^{i}=\frac{1 / V^{i}}{\sum_{j=1}^{n}\left(1 / V^{j}\right)}$

Double-weighted mean: $z_{t}^{i}=\frac{w_{t}^{i} / V^{i}}{\sum_{j=1}^{n}\left(w_{t}^{j} / V^{j}\right)}$

61. In this paper, two alternative measures of price volatility are used:

1. The standard deviation of the difference between each item's monthly price change and the overall CPI's monthly change. It is an indicator of the volatility of the item's relative price.

2. The standard deviation of the second difference of the item's price index (that is, of the monthly price change at time $t$ minus the monthly price change at time $t-1)$. It is an indicator of highfrequency price volatility, which will be higher if price changes are subject to frequent reversals.

62. The corresponding formulas are:

$$
\begin{aligned}
& V 1^{i}=\operatorname{STD}\left(\pi_{t}^{i}-\bar{\pi}_{t}\right) \\
& V 2^{i}=\operatorname{STD}\left(\pi_{t}^{i}-\pi_{t-1}^{i}\right),
\end{aligned}
$$

63. For each country, these measures of price volatility were calculated over the whole period for which data are available: 1967-1997 and 1998-2004 for the United States (the split period is due the fact that the same component breakdown is not available under the new and the old data series); 1995-2004 for the euro area; 1980-2004 for Japan; 1996-2004 for the United Kingdom; and 1995-2004 for Canada. ${ }^{26}$ As a

26. In principle it would have been desirable to use rolling time intervals covering only the past (in order to subsequently allow a proper comparison of out-of-sample forecasting performance). However, in the case of the euro area and the United Kingdom only short price data series are available. Setting a sufficiently 
consequence, the weights for the volatility-weighted mean are constant over the whole period (or-subperiod in the case of the United States), while the weights of the double-weighted mean vary only as a result of the changes in the CPI weights.

\section{A.6 The influence of individual CPI components on the different core indicators}

64. To complement the above description of the rules for the computation of indicators of core inflation, this annex also includes a number of statistics illustrating the influence of CPI components on the different types of indicators, which is the result of how, in each economy, those computation rules interact with the behaviour of individual prices. The purpose is to shed some light on the differences and similarities between alternative ways of "filtering out" the more volatile components of inflation. Tables A1.1-A1.5 present, for each economy, the list of CPI components used in the construction of indicators. Indicated next to each item are: the standard CPI (expenditure-based) weights; whether the item is excluded from the Core 1 and the Core 2 indicators; the two measures of volatility used for the construction of volatility-weighted and double-weighted means; and the frequency of exclusion from two trimmed means (the 5\% and the 15\% trimmed mean) and from the one-step Huber-type skipped mean. In addition, the ratio between the percentage of months the item is the median item in the weighted median and the CPI weight is an indicator of whether an item is more frequently than others at the centre of the distribution. At the bottom of each table, the corresponding weighted average statistics are presented for four standard groupings of CPI items: food; energy; non-food non-energy goods; and services.

65. A number of observations emerge on the basis of these tables. First, some of the items excluded from the traditional core measures (food and energy items, or a subset of them) are indeed among the most volatile and also tend to be more frequently excluded or down-weighted in other indicators; but some food items are not particularly volatile, and there are other non-excluded items that are as volatile as the traditionally excluded ones. Second, service prices are everywhere among the least volatile. As a result, they are more frequently found in the central part of the distribution of price changes, where the median is, and are on average less frequently trimmed out of trimmed means and the Huber-type skipped mean. Thus, their effective weight in the determination of most core indicators is likely to exceed their CPI weight. Third, while energy items are by far the most volatile group, the average volatility of food items is not very different from that of non-food non-energy goods. In fact both groups include both very volatile and lowvolatility items. The relative volatility of these two groups can differ depending on which measure of volatility is used, and their effective weight in indicators can also vary according to the type of indicator (for example, in trimmed means it can depend on the trimming percentage).

long past interval for the calculation of volatilities would therefore have entailed a further shortening of indicator time series, making it more difficult to carry out meaningful comparisons. 
Table A1.1a. United States: CPI component breakdown and selected statistics (1985-1997)

\begin{tabular}{|c|c|c|c|c|c|c|c|c|}
\hline CPI components & $\begin{array}{c}\text { Average } \\
\text { weight }\end{array}$ & $\begin{array}{c}\text { Items } \\
\text { excluded } \\
\text { from Core } \\
1 \text {, Core } 2 \\
1\end{array}$ & $\begin{array}{l}\text { Volatility } \\
\text { STDEV of } \\
\text { relative } \\
\text { price } \\
\text { change }\end{array}$ & $\begin{array}{l}\text { STDEV of } \\
\text { price 2nd } \\
\text { difference }\end{array}$ & $\begin{array}{c}15 \% \\
\text { trimmed } \\
\text { mean }\end{array}$ & $\begin{array}{c}5 \% \\
\text { trimmed } \\
\text { mean }\end{array}$ & $\begin{array}{l}\text { Huber-type } \\
\text { skipped } \\
\text { mean }\end{array}$ & $\begin{array}{c}\text { Frequency } \\
\text { median item } \\
\text { / weight }^{2}\end{array}$ \\
\hline All items CPI & 100.00 & .. & .. & 0.19 & .. & .. & .. & \\
\hline Cereals and bakery products & 1.48 & ${ }^{*} \#$ & 0.30 & 0.41 & 28.9 & 4.4 & 3.8 & 0.87 \\
\hline Meats, poultry, fish, and eggs & 3.16 & ${ }^{*} \#$ & 0.57 & 0.66 & 51.6 & 9.9 & 9.0 & 0.41 \\
\hline Dairy products & 1.28 & ${ }^{*} \#$ & 0.60 & 0.58 & 56.0 & 23.4 & 13.5 & 0.00 \\
\hline Fruits and vegetables & 1.87 & ${ }^{*} \#$ & 1.89 & 2.82 & 82.7 & 58.0 & 53.8 & 0.34 \\
\hline Other food at home & 2.54 & ${ }^{*} \#$ & 0.39 & 0.43 & 24.2 & 5.1 & 2.6 & 0.50 \\
\hline Food away from home & 6.07 & ${ }^{*} \#$ & 0.19 & 0.12 & 1.2 & 0.0 & 0.0 & 1.06 \\
\hline Alcoholic beverages & 1.51 & & 0.52 & 0.62 & 13.8 & 3.1 & 1.9 & 0.00 \\
\hline Shelter & 27.14 & & 0.22 & 0.23 & 2.8 & 0.4 & 0.6 & 2.27 \\
\hline Fuel oil and other household fuel commodities & 0.52 & ${ }^{*} \#$ & 3.61 & 4.71 & 85.9 & 60.3 & 54.5 & 0.00 \\
\hline Gas (piped) and electricity (energy services) & 3.77 & ${ }^{*} \#$ & 0.62 & 0.96 & 54.4 & 17.4 & 16.0 & 0.17 \\
\hline Other utilities and public services & 3.14 & & 0.42 & 0.61 & 31.9 & 7.6 & 5.1 & 0.41 \\
\hline Housefurnishings & 3.76 & & 0.34 & 0.45 & 45.8 & 6.5 & 3.8 & 0.34 \\
\hline Housekeeping supplies & 1.22 & & 0.36 & 0.50 & 35.3 & 5.8 & 1.9 & 1.58 \\
\hline Housekeeping services & 1.59 & & 0.44 & 0.59 & 22.2 & 3.3 & 1.9 & 0.81 \\
\hline Men's and boys' apparel & 1.41 & & 0.48 & 0.71 & 49.1 & 14.4 & 10.3 & 0.45 \\
\hline Women's and girls' apparel & 2.29 & & 0.91 & 1.37 & 77.6 & 29.7 & 27.6 & 0.00 \\
\hline Infants' and toddlers' apparel & 0.20 & & 1.77 & 2.46 & 82.1 & 61.9 & 58.3 & 0.00 \\
\hline Footwear & 0.77 & & 0.59 & 0.87 & 60.9 & 21.6 & 12.8 & 0.84 \\
\hline Other apparel commodities & 0.54 & & 1.12 & 1.70 & 71.9 & 40.8 & 44.2 & 0.00 \\
\hline Apparel services & 0.60 & & 0.27 & 0.33 & 22.6 & 3.8 & 0.6 & 2.15 \\
\hline New vehicles & 4.94 & & 0.29 & 0.25 & 21.4 & 1.1 & 1.3 & 0.39 \\
\hline Used cars & 1.70 & & 0.77 & 0.55 & 71.4 & 31.7 & 22.4 & 0.00 \\
\hline Motor fuel & 3.46 & ${ }^{*} \#$ & 2.78 & 3.12 & 85.4 & 63.8 & 59.0 & 0.37 \\
\hline Maintenance and repairs & 1.55 & & 0.24 & 0.26 & 12.5 & 1.0 & 0.0 & 0.00 \\
\hline Other private transportation commodities & 0.66 & & 0.42 & 0.63 & 52.6 & 11.6 & 7.7 & 0.00 \\
\hline Other private transportation services & 3.85 & & 0.43 & 0.54 & 36.3 & 9.6 & 8.3 & 0.83 \\
\hline Public transportation & 1.54 & & 1.20 & 1.66 & 71.1 & 46.0 & 40.4 & 0.00 \\
\hline Medical care commodities & 1.20 & & 0.28 & 0.25 & 29.8 & 5.8 & 0.0 & 1.60 \\
\hline Medical care services & 5.44 & & 0.23 & 0.13 & 35.8 & 1.9 & 0.0 & 1.18 \\
\hline Entertainment commodities & 2.08 & & 0.28 & 0.36 & 23.2 & 3.6 & 0.0 & 0.62 \\
\hline Entertainment services & 2.26 & & 0.33 & 0.41 & 32.9 & 4.8 & 1.3 & 0.28 \\
\hline Tobacco and smoking products & 1.55 & & 0.92 & 1.12 & 51.9 & 24.3 & 20.5 & 0.00 \\
\hline Toilet goods and personal care appliances & 0.67 & & 0.48 & 0.67 & 46.6 & 17.8 & 5.8 & 0.96 \\
\hline Personal care services & 0.63 & & 0.28 & 0.38 & 20.9 & 3.3 & 0.6 & 1.02 \\
\hline School books and supplies & 0.25 & & 0.36 & 0.48 & 41.0 & 8.0 & 3.8 & 0.00 \\
\hline Personal and educational services & 3.39 & & 0.29 & 0.35 & 45.2 & 8.0 & 1.9 & 0.19 \\
\hline Main commodity groups ${ }^{3}$ & \multicolumn{8}{|c|}{ (weighted averages) $^{4}$} \\
\hline Food & 16.39 & & 0.31 & 0.24 & 30.53 & 11.54 & 9.67 & 0.67 \\
\hline Energy & 7.75 & & 1.04 & 1.51 & 70.32 & 40.94 & 37.76 & 0.25 \\
\hline Goods excl. food and energy & 24.75 & & 0.40 & 0.44 & 42.55 & 12.46 & 9.24 & 0.41 \\
\hline Services & 51.12 & & 0.26 & 0.25 & 18.19 & 3.94 & 2.76 & 1.50 \\
\hline
\end{tabular}

1) * indicates items excluded from Core1 (CPI excl. food and energy); \# indicates items excluded from Core 2 (CPE deflator excl. food and energy).

2) Ratio between the percentage of months where the item is the weighted median item and the CPI weight.

3) Based on standard national definitions. Food includes food away from home, but excludes alcoholic beverages.

4) Weighted averages are calculated using the average weights in the left column. For volatility measures, the harmonic weighted mean is used. 
ECO/WKP(2005)48

Table A1.1b. United States: CPI component breakdown and selected statistics (1998-2004)

\begin{tabular}{|c|c|c|c|c|c|c|c|c|}
\hline \multirow[b]{2}{*}{ CPI components } & \multirow[b]{2}{*}{$\begin{array}{c}\text { Average } \\
\text { weight }\end{array}$} & \multirow{2}{*}{$\begin{array}{c}\text { Items } \\
\text { excluded } \\
\text { from Core } \\
1 \text {, Core } 2 \\
1\end{array}$} & \multicolumn{2}{|c|}{ Volatility measures } & \multicolumn{3}{|c|}{ Frequency of exclusion from } & \multirow{2}{*}{$\begin{array}{c}\text { Frequency } \\
\text { median } \\
\text { item / } \\
\text { weight }^{2} \\
\end{array}$} \\
\hline & & & $\begin{array}{c}\text { STDEV of } \\
\text { relative price } \\
\text { change }\end{array}$ & $\begin{array}{l}\text { STDEV of } \\
\text { price 2nd } \\
\text { difference }\end{array}$ & $\begin{array}{c}15 \% \\
\text { trimmed } \\
\text { mean }\end{array}$ & $\begin{array}{c}5 \% \\
\text { trimmed } \\
\text { mean } \\
\end{array}$ & $\begin{array}{c}\text { Huber-type } \\
\text { skipped } \\
\text { mean }\end{array}$ & \\
\hline All items CPI & 100.00 & & .. & 0.28 & & & & \\
\hline Cereals and bakery products & 1.42 & ${ }^{*} \#$ & 0.36 & 0.53 & 20.0 & 2.5 & 3.6 & 2.52 \\
\hline Meats, poultry, fish, and eggs & 2.46 & ${ }^{*} \#$ & 0.63 & 0.72 & 60.3 & 11.7 & 7.1 & 0.00 \\
\hline Dairy and related products & 0.99 & ${ }^{*} \#$ & 1.14 & 1.27 & 62.7 & 28.6 & 20.2 & 0.00 \\
\hline fresh fruits and vegetables & 1.05 & ${ }^{*} \#$ & 1.68 & 2.45 & 73.8 & 47.2 & 40.5 & 0.00 \\
\hline processed fruits and vegetables & 0.30 & ${ }^{\star} \#$ & 0.61 & 0.99 & 51.2 & 15.9 & 8.3 & 0.00 \\
\hline Nonalcoholic beverages and beverage materials & 1.00 & ${ }^{*} \#$ & 0.54 & 0.83 & 47.5 & 7.2 & 7.1 & 0.00 \\
\hline Other food at home & 1.89 & ${ }^{*} \#$ & 0.42 & 0.67 & 42.5 & 7.0 & 1.2 & 0.00 \\
\hline Food away from home & 5.93 & ${ }^{*} \#$ & 0.23 & 0.13 & 4.2 & 0.0 & 0.0 & 1.20 \\
\hline Alcoholic beverages & 1.00 & & 0.24 & 0.28 & 11.0 & 1.2 & 0.0 & 1.19 \\
\hline Rent of primary residence & 6.78 & & 0.22 & 0.09 & 2.8 & 0.0 & 0.0 & 1.58 \\
\hline Lodging away from home & 2.54 & & 1.07 & 1.68 & 76.2 & 34.8 & 31.0 & 0.00 \\
\hline Owners' equivalent rent of primary residence & 21.47 & & 0.23 & 0.09 & 1.1 & 0.0 & 0.0 & 2.71 \\
\hline Tenants' and household insurance & 0.37 & & 0.47 & 0.57 & 31.0 & 7.8 & 4.8 & 0.00 \\
\hline Fuel oil and other fuels & 0.26 & ${ }^{*} \#$ & 4.54 & 6.06 & 95.2 & 70.2 & 66.7 & 0.00 \\
\hline Gas (piped) and electricity & 3.65 & ${ }^{*} \#$ & 1.24 & 1.58 & 66.1 & 15.4 & 25.0 & 0.00 \\
\hline Water and sewer and trash collection services & 0.91 & & 0.25 & 0.20 & 20.2 & 2.2 & 0.0 & 1.30 \\
\hline Household furnishings and operations & 4.67 & & 0.26 & 0.28 & 16.7 & 0.0 & 0.0 & 0.51 \\
\hline Men's and boys' apparel & 1.20 & & 0.54 & 0.80 & 69.8 & 17.0 & 10.7 & 0.00 \\
\hline Women's and girls' apparel & 1.81 & & 0.70 & 1.01 & 66.0 & 19.7 & 17.9 & 0.00 \\
\hline Footwear & 0.83 & & 0.77 & 1.08 & 63.1 & 29.8 & 19.0 & 0.00 \\
\hline Infants' and toddlers' apparel & 0.23 & & 0.88 & 1.21 & 71.4 & 32.1 & 28.6 & 0.00 \\
\hline jewelry and watches & 0.36 & & 1.10 & 1.75 & 79.8 & 43.9 & 31.0 & 0.00 \\
\hline New vehicles & 4.85 & & 0.32 & 0.32 & 31.9 & 1.3 & 0.0 & 0.00 \\
\hline Used cars and trucks & 1.95 & & 0.86 & 0.62 & 65.1 & 27.8 & 19.0 & 0.00 \\
\hline Leased cars and trucks & 0.41 & & 0.53 & 0.54 & 43.8 & 15.2 & 9.5 & 0.00 \\
\hline car and truck rental & 0.13 & & 1.30 & 1.52 & 82.1 & 54.8 & 46.4 & 0.00 \\
\hline Motor fuel & 3.21 & ${ }^{*} \#$ & 4.88 & 6.54 & 95.0 & 82.2 & 79.8 & 0.00 \\
\hline Motor vehicle parts and equipment & 0.48 & & 0.34 & 0.45 & 30.9 & 5.6 & 0.0 & 0.00 \\
\hline Motor vehicle maintenance and repair & 1.53 & & 0.26 & 0.23 & 15.8 & 1.2 & 0.0 & 0.78 \\
\hline Motor vehicle insurance & 2.47 & & 0.43 & 0.34 & 40.8 & 9.6 & 0.0 & 0.96 \\
\hline Motor vehicle fees & 0.60 & & 0.85 & 1.21 & 24.6 & 11.9 & 4.8 & 0.00 \\
\hline Public transportation & 1.28 & & 1.08 & 1.61 & 79.0 & 37.5 & 36.9 & 0.00 \\
\hline Medical care commodities & 1.33 & & 0.24 & 0.23 & 19.2 & 1.3 & 0.0 & 0.89 \\
\hline Medical care services & 4.55 & & 0.23 & 0.16 & 23.9 & 0.6 & 0.0 & 0.52 \\
\hline Recreation & 6.00 & & 0.24 & 0.22 & 5.0 & 0.4 & 0.0 & 0.20 \\
\hline Education & 2.80 & & 0.25 & 0.20 & 65.6 & 6.2 & 0.0 & 0.00 \\
\hline Communication & 2.81 & & 0.59 & 0.79 & 65.3 & 14.8 & 14.3 & 0.42 \\
\hline Tobacco and smoking products & 1.09 & & 3.07 & 4.93 & 80.0 & 62.0 & 60.7 & 0.00 \\
\hline Personal care products & 0.72 & & 0.49 & 0.66 & 41.9 & 11.3 & 2.4 & 0.00 \\
\hline Personal care services & 0.91 & & 0.27 & 0.30 & 19.0 & 3.0 & 0.0 & 1.31 \\
\hline Miscellaneous personal services & 1.52 & & 0.27 & 0.17 & 19.6 & 2.4 & 0.0 & 3.13 \\
\hline Miscellaneous personal goods & 0.23 & & 0.61 & 0.86 & 59.5 & 20.2 & 15.5 & 0.00 \\
\hline Main commodity groups ${ }^{3}$ & & & & (weig & ted averag & & & \\
\hline Food & 15.04 & & 0.36 & 0.27 & 32.21 & 9.01 & 6.45 & 0.71 \\
\hline Energy & 7.12 & & 1.94 & 2.51 & 80.19 & 47.58 & 51.23 & 0.00 \\
\hline Goods excl. food and energy & 22.59 & & 0.37 & 0.39 & 38.79 & 11.61 & 8.65 & 0.22 \\
\hline Services & 55.25 & & 0.26 & 0.13 & 19.11 & 4.47 & 3.12 & 1.53 \\
\hline
\end{tabular}

1) * indicates items excluded from Core1 (CPI excl. food and energy); \# indicates items excluded from Core 2 (CPE deflator excl. food and energy).

2) Ratio between the percentage of months where the item is the weighted median item and the CPI weight.

3) Based on standard national definitions. Food includes food away from home, but excludes alcoholic beverages. The items "recreation" and "communication" include both goods and services, and are therefore attributed proportionately to the two groups according to the weights of the respective sub-components.

4) Weighted averages are calculated using the average weights in the left column. For volatility measures, the harmonic weighted mean is used. 
Table A1.2. Euro area: HICP component breakdown and selected statistics (1995-2004)

\begin{tabular}{|c|c|c|c|c|c|c|c|c|}
\hline HICP components & $\begin{array}{l}\text { Average } \\
\text { weight }^{1}\end{array}$ & $\begin{array}{c}\text { Items } \\
\text { excluded } \\
\text { from Core } \\
1 \text {, Core } 2 \\
2\end{array}$ & \begin{tabular}{|c} 
Volatility \\
STDEV of \\
relative \\
price \\
change \\
\end{tabular} & $\begin{array}{l}\text { measures } \\
\text { STDEV of } \\
\text { price 2nd } \\
\text { difference } \\
\end{array}$ & $\begin{array}{c}15 \% \\
\text { trimmed } \\
\text { mean } \\
\end{array}$ & $\begin{array}{c}5 \% \\
\text { trimmed } \\
\text { mean } \\
\end{array}$ & $\begin{array}{c}\text { Huber-type } \\
\text { skipped } \\
\text { mean }\end{array}$ & $\begin{array}{c}\text { Frequency } \\
\text { median } \\
\text { item / } \\
\text { weight }^{3} \\
\end{array}$ \\
\hline All-items HICP & 100.00 & & & 0.26 & & & & \\
\hline Bread and cereals & 2.52 & * & 0.23 & 0.13 & 5.9 & 0.0 & 0.0 & 3.00 \\
\hline Meat & 3.90 & * & 0.37 & 0.29 & 26.1 & 0.4 & 10.1 & 0.22 \\
\hline Fish and seafood & 1.14 & ${ }^{*} \#$ & 1.00 & 1.35 & 64.0 & 23.9 & 47.9 & 0.00 \\
\hline Milk, cheese and eggs & 2.23 & ${ }^{*} \#$ & 0.26 & 0.14 & 11.6 & 0.0 & 0.8 & 1.13 \\
\hline Oils and fats & 0.55 & * & 0.59 & 0.35 & 48.6 & 14.1 & 28.6 & 0.00 \\
\hline Fruit & 1.16 & ${ }^{*} \#$ & 2.04 & 2.18 & 86.2 & 46.3 & 77.3 & 0.00 \\
\hline Vegetables & 1.55 & ${ }^{*} \#$ & 3.01 & 3.61 & 84.1 & 57.8 & 82.4 & 0.00 \\
\hline Sugar, jam, honey, chocolate and confectionery & 0.98 & * & 0.23 & 0.14 & 6.8 & 0.0 & 0.0 & 0.85 \\
\hline Food products n.e.c. & 0.39 & * & 0.26 & 0.16 & 12.6 & 0.8 & 1.7 & 0.00 \\
\hline Coffee, tea and cocoa & 0.40 & * & 0.62 & 0.38 & 58.8 & 17.4 & 28.6 & 0.00 \\
\hline Mineral waters, soft drinks, fruit and vegetable juices & 0.88 & * & 0.25 & 0.18 & 11.6 & 0.0 & 0.0 & 1.92 \\
\hline Spirits & 0.32 & * & 0.39 & 0.39 & 13.1 & 0.8 & 1.7 & 0.00 \\
\hline Wine & 0.69 & * & 0.26 & 0.18 & 4.9 & 0.0 & 0.0 & 1.21 \\
\hline Beer & 0.56 & * & 0.29 & 0.30 & 22.4 & 0.8 & 4.2 & 1.49 \\
\hline Tobacco & 2.36 & * & 0.88 & 1.19 & 25.9 & 7.9 & 16.8 & 0.00 \\
\hline Clothing materials & 0.03 & & 1.67 & 2.44 & 74.8 & 23.6 & 64.5 & 0.00 \\
\hline Garments & 5.49 & & 2.09 & 2.79 & 76.1 & 25.5 & 62.2 & 0.78 \\
\hline Other articles of clothing and clothing accessories & 0.23 & & 1.24 & 1.88 & 47.9 & 2.5 & 42.0 & 0.00 \\
\hline Cleaning, repair and hire of clothing & 0.19 & & 0.29 & 0.31 & 13.4 & 1.7 & 3.4 & 8.85 \\
\hline Footwear including repair & 1.56 & & 1.90 & 2.51 & 73.6 & 15.1 & 58.0 & 0.00 \\
\hline Actual rentals for housing & 6.46 & & 0.26 & 0.18 & 4.8 & 0.6 & 2.5 & 2.21 \\
\hline Materials for the maintenance and repair of the dwelling & 0.62 & & 0.22 & 0.17 & 5.0 & 0.3 & 1.7 & 2.72 \\
\hline Services for the maintenance and repair of the dwelling & 0.93 & & 0.28 & 0.25 & 10.4 & 0.8 & 1.7 & 1.80 \\
\hline Water supply & 0.80 & & 0.37 & 0.39 & 11.4 & 0.1 & 3.4 & 1.05 \\
\hline Refuse collection & 0.54 & & 0.53 & 0.58 & 23.6 & 4.6 & 13.4 & 0.00 \\
\hline Sewerage collection & 0.46 & & 0.51 & 0.60 & 19.6 & 3.2 & 8.4 & 0.00 \\
\hline Other services relating to the dwelling n.e.c. & 0.72 & & 0.35 & 0.37 & 17.8 & 0.3 & 4.2 & 1.16 \\
\hline Electricity & 2.02 & *\# & 0.58 & 0.73 & 28.7 & 4.9 & 10.1 & 0.83 \\
\hline Gas & 1.38 & ${ }^{*} \#$ & 0.93 & 1.05 & 47.2 & 14.5 & 36.1 & 0.00 \\
\hline Liquid fuels & 0.70 & ${ }^{*} \#$ & 4.56 & 6.11 & 92.3 & 69.6 & 86.6 & 0.00 \\
\hline Solid fuels & 0.08 & ${ }^{*} \#$ & 0.56 & 0.50 & 37.8 & 14.5 & 24.4 & 0.00 \\
\hline Heat energy & 0.46 & ${ }^{\star} \#$ & 0.71 & 0.28 & 63.6 & 16.2 & 39.5 & 0.00 \\
\hline Furniture and furnishings & 2.75 & & 0.21 & 0.26 & 7.2 & 0.0 & 0.0 & 1.22 \\
\hline Carpets and other floor coverings & 0.27 & & 0.26 & 0.36 & 14.1 & 2.2 & 4.2 & 3.15 \\
\hline Repair of furniture, furnishings and floor coverings & 0.12 & & 0.30 & 0.32 & 17.6 & 0.8 & 5.9 & 0.00 \\
\hline Household textiles & 0.62 & & 0.59 & 0.92 & 39.4 & 1.8 & 32.8 & 0.00 \\
\hline Household appliances & 1.04 & & 0.19 & 0.16 & 26.1 & 0.0 & 0.0 & 0.81 \\
\hline Repair of household appliances & 0.13 & & 0.32 & 0.35 & 11.8 & 1.7 & 4.2 & 0.00 \\
\hline Glassware, tableware and household utensils & 0.61 & & 0.20 & 0.30 & 6.7 & 0.8 & 0.8 & 0.00 \\
\hline Tools and equipment for house and garden & 0.45 & & 0.19 & 0.12 & 5.9 & 0.0 & 0.0 & 3.78 \\
\hline Non-durable household goods & 1.02 & & 0.21 & 0.11 & 6.2 & 0.0 & 0.0 & 0.00 \\
\hline Domestic services and household services & 0.88 & & 0.44 & 0.52 & 16.0 & 4.8 & 10.1 & 0.00 \\
\hline Pharmaceutical products & 1.20 & & 0.70 & 0.96 & 27.1 & 5.0 & 8.4 & 0.00 \\
\hline Other medical products & 0.54 & & 1.27 & 1.73 & 12.6 & 3.4 & 2.5 & 0.00 \\
\hline Medical services; paramedical services & 0.94 & & 1.02 & 1.34 & 24.6 & 3.4 & 5.0 & 0.00 \\
\hline Dental services & 0.63 & & 0.65 & 0.79 & 37.3 & 4.5 & 6.7 & 0.00 \\
\hline Hospital services & 0.67 & & 1.16 & 1.58 & 13.6 & 2.1 & 23.4 & 0.00 \\
\hline Motor cycles, bicycles and animal drawn vehicles & 0.38 & & 0.25 & 0.21 & 9.6 & 0.0 & 1.7 & 0.00 \\
\hline Motor cars & 4.50 & & 0.31 & 0.36 & 15.2 & 0.2 & 3.4 & 1.12 \\
\hline Spares parts and accessories for personal transport equipment & 1.01 & & 0.31 & 0.29 & 17.6 & 0.8 & 4.2 & 0.84 \\
\hline Fuels and lubricants for personal transport equipment & 3.74 & ${ }^{*} \#$ & 1.74 & 2.35 & 80.0 & 31.6 & 67.5 & 0.00 \\
\hline Maintenance and repair of personal transport equipment & 2.52 & & 0.28 & 0.27 & 10.4 & 0.3 & 1.7 & 1.33 \\
\hline Other services in respect of personal transport equipment & 1.00 & & 0.28 & 0.32 & 8.7 & 0.0 & 5.1 & 2.51 \\
\hline Passenger transport by railway & 0.41 & & 0.53 & 0.65 & 21.8 & 5.9 & 9.2 & 0.00 \\
\hline Passenger transport by road & 0.51 & & 0.33 & 0.41 & 14.3 & 0.7 & 6.0 & 4.94 \\
\hline Passenger transport by air & 0.50 & & 3.01 & 4.62 & 84.9 & 65.2 & 82.9 & 0.00 \\
\hline Passenger transport by sea and inland waterway & 0.10 & & 3.44 & 4.38 & 68.5 & 53.4 & 63.2 & 0.00 \\
\hline Combined passenger transport & 0.54 & & 0.37 & 0.42 & 16.0 & 0.0 & 6.0 & 0.00 \\
\hline Other purchased transport services & 0.07 & & 0.61 & 0.74 & 47.8 & 9.2 & 29.1 & 0.00 \\
\hline
\end{tabular}


ECO/WKP(2005)48

Table A1.2. Euro area: HICP component breakdown and selected statistics (1995-2004) continued

\begin{tabular}{|c|c|c|c|c|c|c|c|c|}
\hline HICP components & $\begin{array}{l}\text { Average } \\
\text { weight }^{1} \\
\end{array}$ & $\begin{array}{c}\text { Items } \\
\text { excluded } \\
\text { from Core } \\
1 \text {, Core } 2 \\
2\end{array}$ & \begin{tabular}{|c} 
Volatility \\
STDEV of \\
relative \\
price \\
change \\
\end{tabular} & $\begin{array}{l}\text { measures } \\
\text { STDEV of } \\
\text { price 2nd } \\
\text { difference } \\
\end{array}$ & $\begin{array}{c}15 \% \\
\text { trimmed } \\
\text { mean }\end{array}$ & $\begin{array}{c}5 \% \\
\text { trimmed } \\
\text { mean }\end{array}$ & $\begin{array}{c}\text { Huber-type } \\
\text { skipped } \\
\text { mean }\end{array}$ & $\begin{array}{c}\text { Frequency } \\
\text { median } \\
\text { item / } \\
\text { weight }^{3} \\
\end{array}$ \\
\hline Postal services & 0.20 & & 0.69 & 0.94 & 30.3 & 11.8 & 18.5 & 0.00 \\
\hline Telephone and telefax equipment & 0.26 & & 1.11 & 1.34 & 70.8 & 29.4 & 42.0 & 0.00 \\
\hline Telephone and telefax services & 2.29 & & 0.64 & 0.80 & 45.1 & 11.5 & 24.4 & 0.00 \\
\hline Equipment for the reception, rec. and repr. of sound and pictures & 0.59 & & 0.26 & 0.26 & 77.8 & 12.8 & 42.0 & 0.00 \\
\hline Photo and cinematographic equipment and optical instruments & 0.16 & & 0.35 & 0.30 & 71.4 & 17.2 & 35.3 & 0.00 \\
\hline Information processing equipment & 0.36 & & 0.81 & 0.66 & 94.9 & 54.7 & 86.6 & 0.00 \\
\hline Recording media & 0.42 & & 0.27 & 0.29 & 32.6 & 1.6 & 4.2 & 0.00 \\
\hline Repair of audio-visual, photo and information processing equipment & 0.10 & & 0.25 & 0.21 & 8.8 & 0.8 & 1.7 & 0.00 \\
\hline Major durables for recreation incl. musical instruments & 0.26 & & 0.32 & 0.37 & 8.4 & 1.7 & 2.5 & 6.50 \\
\hline Maintenance and repair of durables for recreation and culture & 0.00 & & 0.75 & 0.99 & 33.6 & 5.9 & 19.3 & 0.00 \\
\hline Games, toys and hobbies & 0.43 & & 0.29 & 0.28 & 20.2 & 1.7 & 10.1 & 1.93 \\
\hline Equipment for sport, camping and open-air recreation & 0.27 & & 0.38 & 0.47 & 30.6 & 5.3 & 11.8 & 0.00 \\
\hline Gardens, plants and flowers & 0.61 & & 1.56 & 1.88 & 89.4 & 50.3 & 81.5 & 0.00 \\
\hline Pets and related products and services & 0.48 & & 0.26 & 0.20 & 9.4 & 1.4 & 0.8 & 3.52 \\
\hline Recreational and sporting services & 1.05 & & 0.45 & 0.64 & 31.2 & 7.0 & 15.1 & 0.00 \\
\hline Cultural services & 1.44 & & 0.51 & 0.66 & 10.3 & 1.2 & 6.7 & 0.58 \\
\hline Books & 0.67 & & 0.32 & 0.35 & 12.7 & 2.0 & 5.9 & 3.75 \\
\hline Newspapers and periodicals & 0.99 & & 0.32 & 0.27 & 7.9 & 0.0 & 1.7 & 1.70 \\
\hline Miscellaneous printed matter & 0.32 & & 0.26 & 0.23 & 17.4 & 1.6 & 7.6 & 2.67 \\
\hline Package holidays & 1.48 & & 6.59 & 10.71 & 95.3 & 88.3 & 95.8 & 0.00 \\
\hline Education & 0.95 & & 0.42 & 0.47 & 19.3 & 1.6 & 16.0 & 0.00 \\
\hline Restaurants, cafés and the like & 6.83 & & 0.23 & 0.18 & 2.5 & 0.0 & 0.0 & 1.60 \\
\hline Canteens & 0.79 & & 0.30 & 0.30 & 7.0 & 0.0 & 1.9 & 0.00 \\
\hline Accommodation services & 1.73 & & 2.51 & 3.69 & 86.6 & 49.0 & 84.0 & 0.49 \\
\hline Hairdressing salons and personal grooming establishments & 1.10 & & 0.24 & 0.18 & 3.9 & 0.0 & 0.0 & 2.29 \\
\hline Electrical and other appliances and products for personal care & 1.52 & & 0.21 & 0.15 & 3.4 & 0.0 & 0.0 & 1.11 \\
\hline Jewellery, clocks and watches & 0.55 & & 0.22 & 0.27 & 15.6 & 0.0 & 1.7 & 0.00 \\
\hline Other personal effects & 0.58 & & 0.55 & 0.83 & 24.9 & 1.7 & 18.5 & 1.46 \\
\hline Social protection & 0.86 & & 0.36 & 0.45 & 10.4 & 0.0 & 1.7 & 2.40 \\
\hline Insurance connected with the dwelling & 0.23 & & 0.62 & 0.83 & 8.4 & 0.8 & 1.7 & 3.66 \\
\hline Insurance connected with health & 0.58 & & 0.62 & 1.01 & 12.5 & 2.3 & 6.8 & 3.54 \\
\hline Insurance connected with transport & 0.73 & & 0.79 & 1.04 & 24.5 & 9.2 & 13.4 & 3.47 \\
\hline Other insurance & 0.26 & & 0.56 & 0.90 & 19.9 & 4.2 & 11.9 & 0.00 \\
\hline Financial services n.e.c. & 0.52 & & 0.90 & 1.24 & 20.3 & 8.4 & 11.8 & 0.00 \\
\hline Other services n.e.c. & 0.93 & & 0.36 & 0.40 & 9.2 & 1.9 & 4.2 & 2.70 \\
\hline \multicolumn{3}{|l|}{ Main commodity groups ${ }^{4}$} & \multicolumn{5}{|c|}{ (weighted averages) $^{5}$} & \\
\hline Food & 19.63 & & 0.38 & 0.26 & 30.5 & 10.5 & 19.5 & 0.77 \\
\hline Energy & 8.39 & & 1.04 & 1.10 & 62.0 & 24.5 & 48.1 & 0.20 \\
\hline Goods excl. food and energy & 31.32 & & 0.36 & 0.34 & 32.2 & 7.8 & 20.5 & 1.00 \\
\hline Services & 40.66 & & 0.36 & 0.32 & 20.6 & 8.4 & 13.9 & 1.28 \\
\hline
\end{tabular}

1) Average 2001-2004. Before 2001 some of the HICP items listed here are either not available or are available at a higher level of aggregation.

2) * indicates items excluded from Core1 (HICP excl. energy, food, alcohol and tobacco); \# indicates items excluded from Core 2 (HICP excl. energy and unprocessed food'

3) Ratio between the percentage of months where the item is the weighted median item and the CPI weight.

4) Based on standard Eurostat definitions. Food also includes alcoholic beverages and tobacco, but excludes food away from home ("restaurants and cafés" and "canteens

5) Weighted averages are calculated using the average weights in the left column. For volatility measures, the harmonic weighted mean is used. 
Table A1.3. Japan: CPI component breakdown and selected statistics (1985-2004)

\begin{tabular}{|c|c|c|c|c|c|c|c|c|}
\hline \multirow[b]{2}{*}{ CPI components } & \multirow[b]{2}{*}{$\begin{array}{l}\text { Average } \\
\text { weights }\end{array}$} & \multirow{2}{*}{$\begin{array}{c}\text { Items } \\
\text { excluded } \\
\text { from } \\
\text { Core } 1, \\
\text { Core } 2{ }^{1} \\
\end{array}$} & \multicolumn{2}{|c|}{ Volatility measures } & \multicolumn{3}{|c|}{ Frequency of exclusion from } & \multirow{2}{*}{$\begin{array}{c}\text { Frequency } \\
\text { median } \\
\text { item } / \\
\text { weight }^{2} \\
\end{array}$} \\
\hline & & & $\begin{array}{c}\text { STDEV of } \\
\text { relative price } \\
\text { change }\end{array}$ & $\begin{array}{l}\text { STDEV of } \\
\text { price 2nd } \\
\text { difference } \\
\end{array}$ & $\begin{array}{c}15 \% \\
\text { trimmed } \\
\text { mean }\end{array}$ & $\begin{array}{c}5 \% \\
\text { trimmed } \\
\text { mean } \\
\end{array}$ & $\begin{array}{c}\text { Huber-type } \\
\text { skipped } \\
\text { mean }\end{array}$ & \\
\hline All items CPI & 100.00 & & & 0.36 & & & & \\
\hline Cereals & 2.91 & * & 0.73 & 0.70 & 33.8 & 11.7 & 12.1 & 1.29 \\
\hline Fish and shellfish & 3.37 & ${ }^{*}(\#)^{3}$ & 0.82 & 1.31 & 68.8 & 25.4 & 40.0 & 0.49 \\
\hline Meat & 2.43 & * & 0.33 & 0.39 & 27.1 & 6.3 & 2.9 & 1.03 \\
\hline Dairy products and eggs & 1.17 & * & 1.13 & 1.72 & 71.3 & 32.9 & 45.8 & 0.00 \\
\hline Vegetables and seaweeds & 3.26 & ${ }^{*}(\#)^{3}$ & 4.68 & 7.00 & 93.3 & 82.5 & 89.6 & 0.00 \\
\hline Fruits & 1.31 & ${ }^{*}(\#)^{3}$ & 4.12 & 6.46 & 96.3 & 80.8 & 90.4 & 0.00 \\
\hline Oils fats and seasonings & 1.05 & * & 0.40 & 0.54 & 40.8 & 7.9 & 10.0 & 0.00 \\
\hline Cakes and candies & 2.34 & * & 0.29 & 0.39 & 15.4 & 0.8 & 1.3 & 1.42 \\
\hline Cooked food & 2.31 & * & 0.33 & 0.49 & 16.3 & 4.6 & 1.7 & 1.44 \\
\hline Beverages & 1.28 & * & 0.37 & 0.43 & 34.6 & 7.1 & 3.3 & 0.32 \\
\hline Alcoholic beverages & 1.51 & * & 0.43 & 0.50 & 7.9 & 2.1 & 1.7 & 1.38 \\
\hline Eating out & 7.07 & * & 0.36 & 0.55 & 13.3 & 4.2 & 4.2 & 1.47 \\
\hline Rent & 14.90 & & 0.27 & 0.17 & 14.2 & 2.5 & 0.4 & 1.93 \\
\hline Repairs and maintenance & 2.48 & & 0.28 & 0.30 & 14.2 & 2.5 & 0.8 & 1.68 \\
\hline Electricity & 2.54 & * & 0.81 & 1.14 & 30.8 & 7.1 & 7.5 & 0.49 \\
\hline Gas & 1.74 & * & 0.52 & 0.54 & 23.8 & 5.4 & 7.1 & 0.48 \\
\hline Other fuel and light & 0.43 & * & 2.14 & 2.13 & 72.1 & 40.8 & 51.3 & 0.00 \\
\hline Water and sewerage charges & 1.22 & & 0.34 & 0.35 & 26.3 & 5.8 & 4.2 & 1.02 \\
\hline Household durables & 1.34 & & 0.36 & 0.38 & 61.7 & 14.2 & 25.8 & 0.62 \\
\hline Interior furnishings & 0.48 & & 0.33 & 0.49 & 27.1 & 7.5 & 3.3 & 0.00 \\
\hline Bedding & 0.38 & & 0.38 & 0.50 & 40.8 & 12.9 & 9.6 & 0.00 \\
\hline Domestic utensils & 0.87 & & 0.27 & 0.34 & 14.6 & 2.1 & 0.4 & 0.48 \\
\hline Domestic non-durables & 0.67 & & 0.32 & 0.41 & 37.5 & 7.5 & 5.4 & 0.00 \\
\hline Domestic services & 0.34 & & 0.44 & 0.58 & 15.4 & 3.8 & 1.3 & 0.00 \\
\hline Japanese clothing & 0.44 & & 0.38 & 0.56 & 37.5 & 9.6 & 9.2 & 2.85 \\
\hline Clothing & 2.96 & & 0.82 & 1.27 & 48.3 & 17.1 & 23.3 & 0.42 \\
\hline Shirts and sweaters & 1.36 & & 0.69 & 1.12 & 55.4 & 17.9 & 25.4 & 0.92 \\
\hline Underwear & 0.59 & & 0.36 & 0.48 & 23.3 & 6.3 & 2.1 & 0.71 \\
\hline Footwear & 0.74 & & 0.29 & 0.39 & 20.8 & 1.7 & 2.1 & 0.57 \\
\hline Cloth and thread & 0.20 & & 0.43 & 0.55 & 32.9 & 9.2 & 10.0 & 0.00 \\
\hline Other clothing & 0.54 & & 0.34 & 0.46 & 27.5 & 5.8 & 5.4 & 1.56 \\
\hline Services related to clothing & 0.52 & & 0.24 & 0.21 & 5.4 & 0.4 & 0.0 & 2.42 \\
\hline Medicines and health fortifications & 0.93 & & 0.27 & 0.33 & 5.8 & 0.4 & 0.4 & 1.34 \\
\hline Medical supplies and appliances & 0.61 & & 0.41 & 0.55 & 30.4 & 5.0 & 3.3 & 0.68 \\
\hline Medical services & 1.76 & & 1.65 & 2.38 & 33.3 & 9.6 & 8.8 & 2.13 \\
\hline Public transportation & 3.31 & & 0.50 & 0.74 & 21.3 & 8.8 & 7.9 & 0.50 \\
\hline Private transportation & 6.39 & $\left({ }^{*}\right)^{3}$ & 0.41 & 0.48 & 22.1 & 3.8 & 8.8 & 1.04 \\
\hline Communication & 2.25 & & 0.71 & 1.05 & 20.4 & 5.4 & 8.8 & 0.92 \\
\hline School fees & 3.31 & & 0.30 & 0.22 & 41.7 & 6.7 & 2.1 & 0.25 \\
\hline School textbooks and reference books for study & 0.16 & & 0.73 & 1.03 & 15.4 & 3.8 & 2.9 & 0.00 \\
\hline Tutorial fees & 1.05 & & 0.42 & 0.54 & 31.7 & 8.3 & 5.8 & 0.40 \\
\hline Recreational durables & 0.97 & & 0.84 & 0.98 & 79.6 & 41.3 & 57.1 & 0.00 \\
\hline Recreational goods & 2.60 & & 0.75 & 1.36 & 63.8 & 15.4 & 36.3 & 0.48 \\
\hline Books and other reading materials & 1.67 & & 0.64 & 0.87 & 21.7 & 7.1 & 5.8 & 0.75 \\
\hline Recreational services & 5.78 & & 0.44 & 0.76 & 30.4 & 5.4 & 11.7 & 0.79 \\
\hline Personal care services & 1.25 & & 0.25 & 0.21 & 9.6 & 0.0 & 0.0 & 1.00 \\
\hline Toilet articles & 1.18 & & 0.27 & 0.30 & 17.1 & 0.8 & 1.7 & 1.41 \\
\hline Personal effects & 0.91 & & 0.37 & 0.46 & 24.6 & 8.3 & 7.5 & 0.92 \\
\hline Cigarettes & 0.89 & & 1.04 & 1.46 & 22.1 & 2.5 & 1.7 & 0.00 \\
\hline Other & 0.19 & & 1.16 & 1.63 & 33.8 & 8.8 & 5.8 & 0.00 \\
\hline \multicolumn{3}{|l|}{ Main commodity groups ${ }^{4}$} & \multicolumn{5}{|c|}{ (weighted averages) ${ }^{5}$} & \\
\hline Food & 30.02 & & 0.48 & 0.66 & 39.21 & 20.36 & 23.16 & 0.92 \\
\hline Energy & 6.82 & & 0.58 & 0.68 & 28.92 & 7.76 & 10.54 & 0.63 \\
\hline Goods excl. food and energy & 22.63 & & 0.46 & 0.59 & 37.55 & 10.53 & 15.49 & 0.69 \\
\hline Services & 40.49 & & 0.34 & 0.28 & 21.58 & 4.49 & 4.33 & 1.29 \\
\hline
\end{tabular}

1) * indicates items excluded from Core1 (CPI excl. food and energy); \# indicates items excluded from Core 2 (CPE deflator excl. food and energy).

2) Ratio between the percentage of months where the item is the weighted median item and the CPI weight.

3) Fuel (which is excluded from the Core 1 indicator) is part of "private transportation" in this classification. Fresh food (which is excluded from the Core 2 indicator) includes the fresh sub-components of the "fish", "fruit" and "vegetables" items in this list.

4) Based on standard national definitions. Food includes both alcoholic beverages and food away from home ("eating out"). The item "private transportation" includes energy goods (fuel), non-energy goods (vehicles and parts) and services (repair, fees, insurance), and is therefore attributed proportionately to the three groups according to the weights of the respective sub-components.

5) Weighted averages are calculated using the average weights in the left column. For volatility measures, the harmonic weighted mean is used. 
ECO/WKP(2005)48

Table A1.4. United Kingdom: HICP component breakdown and selected statistics (1996-2004)

\begin{tabular}{|c|c|c|c|c|c|c|c|c|}
\hline \multirow[b]{2}{*}{ HICP components } & \multirow[b]{2}{*}{$\begin{array}{l}\text { Average } \\
\text { weight }^{1}\end{array}$} & \multirow{2}{*}{\begin{tabular}{|c} 
Items \\
exclude \\
d from \\
Core 1, \\
Core $2{ }^{2}$ \\
\end{tabular}} & \multicolumn{2}{|c|}{ Volatility measures } & \multicolumn{3}{|c|}{ Frequency of exclusion from } & \multirow{2}{*}{$\begin{array}{c}\text { Frequency } \\
\text { median } \\
\text { item / } \\
\text { weight }^{3} \\
\end{array}$} \\
\hline & & & $\begin{array}{c}\text { STDEV of } \\
\text { relative price } \\
\text { change }\end{array}$ & $\begin{array}{l}\text { STDEV of } \\
\text { price 2nd } \\
\text { difference }\end{array}$ & $\begin{array}{c}15 \% \\
\text { trimmed } \\
\text { mean }\end{array}$ & $\begin{array}{c}5 \% \\
\text { trimmed } \\
\text { mean } \\
\end{array}$ & $\begin{array}{c}\text { Huber-type } \\
\text { skipped } \\
\text { mean }\end{array}$ & \\
\hline All-items HICP & 100.00 & & & 0.52 & & & & \\
\hline Bread and cereals & 1.65 & * & 0.57 & 0.74 & 24.4 & 2.4 & 6.5 & 0.00 \\
\hline Meat & 2.34 & * & 0.94 & 1.27 & 42.2 & 8.5 & 12.1 & 0.41 \\
\hline Fish and seafood & 0.42 & ${ }^{*} \#$ & 1.32 & 1.99 & 62.6 & 31.5 & 35.5 & 2.34 \\
\hline Milk, cheese and eggs & 1.38 & ${ }^{*} \#$ & 0.58 & 0.71 & 23.6 & 3.6 & 4.7 & 0.00 \\
\hline Oils and fats & 0.20 & * & 0.89 & 1.28 & 37.4 & 10.7 & 11.2 & 0.00 \\
\hline Fruit & 0.82 & ${ }^{*} \#$ & 2.79 & 4.32 & 75.4 & 40.2 & 57.9 & 0.00 \\
\hline Vegetables & 1.62 & ${ }^{*} \#$ & 3.47 & 5.10 & 77.3 & 52.6 & 62.6 & 0.00 \\
\hline Sugar, jam, honey, chocolate and confectionery & 1.21 & * & 0.57 & 0.50 & 15.3 & 3.9 & 1.9 & 4.43 \\
\hline Food products n.e.c. & 0.27 & * & 0.66 & 0.93 & 23.2 & 5.6 & 5.6 & 0.00 \\
\hline Coffee, tea and cocoa & 0.27 & * & 1.02 & 1.38 & 48.6 & 18.8 & 21.5 & 0.00 \\
\hline Mineral waters, soft drinks, fruit and vegetable juices & 0.92 & * & 0.81 & 1.04 & 29.0 & 8.4 & 10.3 & 1.01 \\
\hline Spirits & 0.50 & * & 1.33 & 1.65 & 48.6 & 16.7 & 24.3 & 0.00 \\
\hline Wine & 0.90 & * & 0.97 & 1.32 & 39.0 & 9.0 & 16.8 & 1.03 \\
\hline Beer & 0.54 & * & 1.33 & 1.87 & 64.5 & 27.1 & 32.7 & 1.69 \\
\hline Tobacco & 2.88 & * & 0.96 & 1.26 & 19.7 & 6.1 & 9.3 & 1.26 \\
\hline Garments & 4.91 & & 2.84 & 4.56 & 67.5 & 26.4 & 51.4 & 0.20 \\
\hline Other articles of clothing and clothing accessories & 0.27 & & 1.89 & 3.16 & 55.0 & 9.3 & 38.3 & 0.00 \\
\hline Cleaning, repair and hire of clothing & 0.13 & & 0.50 & 0.37 & 6.5 & 0.0 & 0.9 & 0.00 \\
\hline Footwear including repair & 0.81 & & 1.73 & 2.75 & 51.0 & 5.6 & 41.1 & 2.41 \\
\hline Actual rentals for housing & 5.05 & & 0.52 & 0.71 & 7.8 & 0.6 & 1.9 & 1.87 \\
\hline Materials for the maintenance and repair of the dwelling & 1.07 & & 0.57 & 0.84 & 18.0 & 2.6 & 6.5 & 1.71 \\
\hline Services for the maintenance and repair of the dwelling & 0.84 & & 0.77 & 0.89 & 19.4 & 4.7 & 2.8 & 1.17 \\
\hline Water supply & 0.46 & & 1.20 & 1.75 & 13.1 & 5.7 & 7.5 & 2.05 \\
\hline Sewerage collection & 0.51 & & 1.91 & 2.75 & 14.0 & 7.0 & 8.4 & 0.00 \\
\hline Electricity & 1.41 & *\# & 0.64 & 0.50 & 18.0 & 5.6 & 9.3 & 0.67 \\
\hline Gas & 1.18 & ${ }^{*} \#$ & 0.93 & 1.00 & 11.3 & 7.4 & 7.5 & 0.77 \\
\hline Liquid fuels & 0.12 & ${ }^{*} \#$ & 7.19 & 9.77 & 87.9 & 76.5 & 83.2 & 8.73 \\
\hline Solid fuels & 0.10 & ${ }^{*} \#$ & 1.33 & 1.41 & 35.5 & 17.8 & 22.4 & 0.00 \\
\hline Furniture and furnishings & 2.27 & & 2.66 & 4.72 & 73.5 & 32.6 & 56.1 & 0.00 \\
\hline Carpets and other floor coverings & 0.73 & & 2.17 & 3.93 & 79.4 & 33.0 & 59.8 & 0.00 \\
\hline Household textiles & 0.82 & & 2.28 & 4.18 & 89.9 & 41.1 & 79.4 & 0.00 \\
\hline Major household appliances and small electric appliances & 0.86 & & 1.05 & 1.92 & 39.7 & 10.3 & 21.5 & 0.00 \\
\hline Repair of household appliances & 0.10 & & 1.03 & 1.37 & 15.0 & 3.7 & 3.7 & 0.00 \\
\hline Glassware, tableware and household utensils & 0.79 & & 1.34 & 2.54 & 56.7 & 15.0 & 41.1 & 0.00 \\
\hline Tools and equipment for house and garden & 0.52 & & 0.71 & 0.86 & 24.7 & 6.8 & 10.3 & 0.00 \\
\hline Non-durable household goods & 0.54 & & 0.77 & 1.01 & 39.2 & 8.0 & 12.1 & 0.00 \\
\hline Domestic services and household services & 0.59 & & 0.64 & 0.55 & 18.8 & 2.8 & 0.0 & 1.59 \\
\hline Pharmaceutical products & 0.52 & & 0.69 & 0.90 & 25.1 & 4.7 & 4.7 & 0.00 \\
\hline Other medical products - therapeutic appliances and equipment & 0.53 & & 0.81 & 1.27 & 21.4 & 7.6 & 12.1 & 0.00 \\
\hline Medical services - paramedical services & 0.23 & & 1.37 & 2.07 & 32.7 & 10.8 & 13.6 & 7.48 \\
\hline Dental services & 0.20 & & 0.96 & 1.26 & 18.6 & 10.2 & 8.5 & 0.00 \\
\hline Hospital services & 0.87 & & 0.72 & 0.81 & 27.7 & 6.4 & 2.1 & 0.00 \\
\hline Motor cycles, bicycles and animal drawn vehicles & 0.30 & & 0.96 & 1.26 & 28.0 & 12.5 & 14.0 & 0.00 \\
\hline Motor cars & 4.60 & & 0.69 & 0.75 & 22.2 & 3.0 & 7.5 & 1.21 \\
\hline Spares parts and accessories for personal transport equipment & 0.52 & & 0.41 & 0.39 & 5.6 & 0.0 & 0.0 & 3.74 \\
\hline Fuels and lubricants for personal transport equipment & 2.92 & ${ }^{*} \#$ & 1.92 & 2.58 & 64.7 & 24.2 & 37.4 & 0.33 \\
\hline Maintenance and repair of personal transport equipment & 2.46 & & 0.67 & 0.66 & 13.8 & 2.7 & 1.9 & 0.38 \\
\hline Other services in respect of personal transport equipment & 0.71 & & 0.63 & 0.68 & 11.6 & 2.3 & 1.9 & 1.31 \\
\hline Passenger transport by railway & 0.83 & & 0.88 & 0.97 & 23.2 & 4.7 & 2.8 & 1.12 \\
\hline Passenger transport by road & 1.44 & & 0.53 & 0.55 & 15.2 & 3.7 & 0.0 & 1.93 \\
\hline Passenger transport by air & 0.78 & & 10.99 & 17.77 & 49.5 & 40.2 & 43.0 & 1.32 \\
\hline Passenger transport by sea and inland waterway & 0.13 & & 6.69 & 8.44 & 74.8 & 59.8 & 66.4 & 0.00 \\
\hline Postal services & 0.18 & & 0.72 & 0.84 & 6.5 & 3.7 & 3.7 & 0.00 \\
\hline Telephone and telefax equipment and services & 2.29 & & 0.69 & 0.84 & 24.6 & 8.7 & 12.1 & 1.23 \\
\hline
\end{tabular}




\section{$\mathrm{ECO} / \mathrm{WKP}(2005) 48$}

Table A1.4. United Kingdom: HICP component breakdown and selected statistics (1996-2004) continued

\begin{tabular}{|c|c|c|c|c|c|c|c|c|}
\hline \multirow[b]{2}{*}{ HICP components } & \multirow[b]{2}{*}{$\begin{array}{l}\text { Average } \\
\text { weight }^{1}\end{array}$} & \multirow{2}{*}{\begin{tabular}{|c|} 
Items \\
exclude \\
d from \\
Core 1, \\
Core $2^{2}$ \\
\end{tabular}} & \multicolumn{2}{|c|}{ Volatility measures } & \multicolumn{3}{|c|}{ Frequency of exclusion from } & \multirow{2}{*}{$\begin{array}{c}\text { Frequency } \\
\text { median } \\
\text { item / } \\
\text { weight }^{3} \\
\end{array}$} \\
\hline & & & $\begin{array}{c}\text { STDEV of } \\
\text { relative price } \\
\text { change }\end{array}$ & $\begin{array}{l}\text { STDEV of } \\
\text { price } 2 \text { nd } \\
\text { difference }\end{array}$ & $\begin{array}{c}15 \% \\
\text { trimmed } \\
\text { mean }\end{array}$ & $\begin{array}{c}5 \% \\
\text { trimmed } \\
\text { mean }\end{array}$ & $\begin{array}{c}\text { Huber-type } \\
\text { skipped } \\
\text { mean }\end{array}$ & \\
\hline Equipment for the reception, rec. and repr. of sound and pictures & 0.67 & & 0.69 & 1.27 & 68.2 & 21.1 & 30.8 & 0.00 \\
\hline Photo and cinematographic equipment and optical instruments & 0.43 & & 0.96 & 1.48 & 55.1 & 22.5 & 31.8 & 0.00 \\
\hline Information processing equipment & 0.52 & & 2.30 & 3.20 & 82.2 & 59.1 & 74.8 & 0.00 \\
\hline Recording media & 0.91 & & 1.08 & 1.68 & 42.1 & 14.3 & 20.6 & 0.91 \\
\hline Repair of audio-visual, photo and information processing equipment & 0.10 & & 0.97 & 1.31 & 12.1 & 2.8 & 0.9 & 0.00 \\
\hline Major durables for recreation incl. musical instruments & 0.80 & & 0.62 & 0.79 & 15.3 & 7.0 & 91.1 & 0.00 \\
\hline Games, toys and hobbies & 1.67 & & 0.89 & 1.45 & 50.0 & 9.9 & 15.0 & 0.00 \\
\hline Equipment for sport, camping and open-air recreation & 0.44 & & 0.73 & 1.16 & 34.0 & 7.5 & 9.3 & 0.00 \\
\hline Gardens, plants and flowers & 0.62 & & 1.50 & 2.20 & 66.4 & 26.9 & 34.6 & 0.00 \\
\hline Pets and related products - veterinary and other services for pets & 0.73 & & 0.53 & 0.51 & 11.9 & 0.9 & 0.9 & 1.33 \\
\hline Recreational and sporting services & 1.06 & & 0.53 & 0.59 & 10.3 & 0.0 & 1.9 & 0.00 \\
\hline Cultural services & 2.36 & & 0.86 & 1.24 & 26.3 & 4.2 & 4.7 & 0.38 \\
\hline Books & 0.50 & & 0.85 & 1.27 & 39.3 & 9.3 & 14.0 & 0.00 \\
\hline Newspapers and periodicals & 0.89 & & 0.84 & 1.13 & 14.1 & 5.9 & 7.5 & 2.20 \\
\hline Miscellaneous printed matter, stationery and drawing materials & 0.77 & & 0.57 & 0.90 & 22.6 & 2.8 & 5.6 & 1.30 \\
\hline Package holidays & 3.23 & & 0.59 & 0.38 & 20.0 & 4.1 & 4.7 & 2.00 \\
\hline Education & 1.66 & & 1.25 & 1.74 & 13.1 & 5.8 & 11.2 & 1.06 \\
\hline Restaurants, cafés and the like & 11.14 & & 0.37 & 0.16 & 1.3 & 0.0 & 0.0 & 2.25 \\
\hline Canteens & 1.04 & & 0.51 & 0.50 & 8.4 & 1.9 & 0.9 & 0.00 \\
\hline Accommodation services & 1.77 & & 0.49 & 0.33 & 10.7 & 1.9 & 1.9 & 1.01 \\
\hline Hairdressing salons and personal grooming establishments & 0.76 & & 0.38 & 0.29 & 10.3 & 1.4 & 0.0 & 0.00 \\
\hline Electrical and other appliances for personal care & 1.90 & & 0.67 & 0.81 & 27.4 & 4.5 & 8.4 & 1.00 \\
\hline Jewellery, clocks and watches & 0.65 & & 0.60 & 1.26 & 19.7 & 4.7 & 6.5 & 1.45 \\
\hline Other personal effects & 0.25 & & 0.98 & 1.88 & 45.3 & 12.0 & 26.2 & 0.00 \\
\hline Social protection & 1.35 & & 0.51 & 0.42 & 19.3 & 0.0 & 0.0 & 0.00 \\
\hline Insurance connected with the dwelling & 0.13 & & 1.11 & 1.41 & 20.9 & 8.4 & 10.3 & 0.00 \\
\hline Insurance connected with health & 0.23 & & 1.36 & 1.87 & 25.4 & 15.3 & 15.3 & 14.49 \\
\hline Insurance connected with transport & 0.25 & & 1.57 & 2.12 & 29.0 & 14.0 & 18.7 & 0.00 \\
\hline Financial services n.e.c. & 1.76 & & 2.67 & 3.88 & 28.5 & 12.5 & 18.7 & 0.00 \\
\hline Other services n.e.c. & 1.95 & & 0.75 & 0.83 & 25.2 & 5.0 & 0.9 & 0.83 \\
\hline Main commodity groups ${ }^{4}$ & & & & (weigh & ed averag & & & \\
\hline Food & 15.92 & & 0.90 & 1.12 & 38.19 & 14.46 & 19.03 & 0.86 \\
\hline Energy & 5.73 & & 1.13 & 1.09 & 42.20 & 17.18 & 25.05 & 0.68 \\
\hline Goods excl. food and energy & 32.24 & & 0.95 & 1.28 & 43.35 & 14.36 & 28.33 & 0.65 \\
\hline Services & 46.12 & & 0.56 & 0.38 & 14.14 & 3.88 & 4.27 & 1.38 \\
\hline
\end{tabular}

1) Average 2001-2004. Before 2001 some of the HICP items listed here are either not available or are available at a higher level of aggregation.

2) * indicates items excluded from Core1 (HICP excl. energy, food, alcohol and tobacco); \# indicates items excluded from Core 2 (HICP excl. energy and unprocessed food).

3) Ratio between the percentage of months where the item is the weighted median item and the CPI weight.

4) Based on standard Eurostat definitions. Food also includes alcoholic beverages and tobacco, but excludes food away from home ("restaurants and cafés" and "canteens").

5) Weighted averages are calculated using the average weights in the left column. For volatility measures, the harmonic weighted mean is used. 
ECO/WKP(2005)48

Table A1.5. Canada: CPI component breakdown and selected statistics (1985-2004)

\begin{tabular}{|c|c|c|c|c|c|c|c|c|}
\hline CPI components & $\begin{array}{l}\text { Average } \\
\text { weights }\end{array}$ & $\begin{array}{c}\text { Items } \\
\text { excluded } \\
\text { from } \\
\text { Core } 1, \\
\text { Core } 2{ }^{1} \\
\end{array}$ & $\begin{array}{l}\text { Volatility } \\
\text { STDEV of } \\
\text { relative } \\
\text { price } \\
\text { change } \\
\end{array}$ & $\begin{array}{l}\text { measures } \\
\text { STDEV of } \\
\text { price 2nd } \\
\text { difference }\end{array}$ & $\begin{array}{c}15 \% \\
\text { trimmed } \\
\text { mean }\end{array}$ & $\begin{array}{c}5 \% \\
\text { trimmed } \\
\text { mean }\end{array}$ & $\begin{array}{l}\text { sion from } \\
\text { Huber- } \\
\text { type } \\
\text { skipped } \\
\text { mean }\end{array}$ & $\begin{array}{c}\text { Frequency } \\
\text { median } \\
\text { item / } \\
\text { weight }^{2} \\
\end{array}$ \\
\hline All-items CPI & 100.00 & & .. & 0.36 & & & & \\
\hline Meat & 3.22 & * & 0.90 & 1.17 & 51.6 & 15.1 & 21.3 & 0.13 \\
\hline Fish and other seafood & 0.44 & * & 0.57 & 0.68 & 35.4 & 5.2 & 7.1 & 0.94 \\
\hline Dairy products and eggs & 2.12 & * & 0.48 & 0.67 & 16.5 & 2.6 & 3.3 & 1.97 \\
\hline Bakery and other cereal products & 1.81 & * & 0.55 & 0.77 & 31.6 & 5.4 & 7.9 & 1.39 \\
\hline Fruit, fruit preparations and nuts & 1.35 & ${ }^{*} \#$ & 1.60 & 2.38 & 76.2 & 39.6 & 50.6 & 0.31 \\
\hline Vegetables and vegetable preparations & 1.19 & ${ }^{*} \#$ & 4.34 & 6.56 & 86.0 & 63.7 & 75.3 & 0.00 \\
\hline Other food products & 2.52 & * & 0.58 & 0.92 & 31.7 & 7.8 & 9.2 & 0.17 \\
\hline Food purchased from restaurants & 5.19 & * & 0.38 & 0.63 & 2.1 & 0.0 & 0.0 & 1.86 \\
\hline Rented accommodation & 7.32 & & 0.27 & 0.11 & 0.0 & 0.0 & 0.0 & 2.97 \\
\hline Mortgage interest cost & 5.21 & \# & 0.45 & 0.23 & 34.6 & 2.1 & 5.4 & 0.48 \\
\hline Replacement cost & 3.00 & & 0.53 & 0.38 & 21.7 & 3.8 & 4.6 & 1.53 \\
\hline Property taxes (including special charges) & 3.20 & & 0.51 & 0.69 & 9.2 & 2.3 & 3.8 & 2.22 \\
\hline Homeowners' insurance premiums & 0.84 & & 0.67 & 0.72 & 32.3 & 6.2 & 9.2 & 0.00 \\
\hline Homeowners' maintenance and repairs & 1.43 & & 1.20 & 2.02 & 55.0 & 22.2 & 28.9 & 0.29 \\
\hline Other owned accommodation expenses & 1.15 & & 0.34 & 0.32 & 7.5 & 0.4 & 0.4 & 1.09 \\
\hline Electricity & 2.36 & * & 2.16 & 3.67 & 25.4 & 9.3 & 15.5 & 1.77 \\
\hline Water & 0.41 & & 0.48 & 0.65 & 18.3 & 3.8 & 4.2 & 0.00 \\
\hline Natural gas & 0.98 & ${ }^{*} \#$ & 3.53 & 5.15 & 70.0 & 41.2 & 47.3 & 0.00 \\
\hline Fuel oil and other fuel & 0.61 & ${ }^{*} \#$ & 3.53 & 4.47 & 72.3 & 45.7 & 51.5 & 0.69 \\
\hline Communications & 1.98 & & 0.80 & 1.16 & 26.0 & 6.9 & 8.4 & 0.85 \\
\hline Child care and domestic services & 1.10 & & 0.45 & 0.54 & 10.8 & 3.6 & 3.8 & 0.00 \\
\hline Household chemical products & 0.73 & & 0.57 & 0.90 & 33.5 & 5.6 & 8.4 & 0.57 \\
\hline Paper, plastic and foil supplies & 0.81 & & 0.67 & 0.96 & 34.5 & 8.0 & 10.0 & 0.52 \\
\hline Other household goods and services & 1.33 & & 0.42 & 0.63 & 20.8 & 2.6 & 2.9 & 1.25 \\
\hline Furniture & 1.55 & & 0.86 & 1.30 & 41.0 & 16.4 & 18.4 & 1.08 \\
\hline Household textiles & 0.62 & & 1.30 & 2.25 & 69.5 & 32.9 & 41.8 & 0.00 \\
\hline Household equipment & 1.72 & & 0.46 & 0.64 & 24.5 & 3.3 & 5.9 & 1.21 \\
\hline Services related to household furnishings & 0.30 & & 0.53 & 0.84 & 15.9 & 2.9 & 4.2 & 1.41 \\
\hline Clothing & 4.81 & & 0.69 & 1.16 & 37.5 & 7.7 & 14.6 & 0.78 \\
\hline Footwear & 0.95 & & 0.83 & 1.37 & 49.8 & 14.8 & 18.8 & 0.89 \\
\hline Clothing accessories and jewellery & 0.70 & & 0.83 & 1.22 & 50.2 & 18.5 & 21.3 & 1.19 \\
\hline Clothing material, notions and services & 0.74 & & 0.42 & 0.58 & 17.5 & 3.1 & 1.3 & 0.57 \\
\hline Purchase of automotive vehicles & 6.62 & & 0.81 & 1.06 & 28.7 & 6.2 & 13.4 & 0.44 \\
\hline Leasing and renting of automobiles & 0.56 & & 1.18 & 1.71 & 42.5 & 17.2 & 20.9 & 1.50 \\
\hline Gasoline & 3.81 & ${ }^{*} \#$ & 2.90 & 3.90 & 77.6 & 51.8 & 63.6 & 0.11 \\
\hline Automotive vehicle parts, maintenance and repairs & 2.01 & & 0.40 & 0.63 & 10.1 & 2.5 & 2.1 & 1.25 \\
\hline Other automotive vehicle operating expenses & 3.26 & & 0.93 & 1.27 & 32.7 & 7.6 & 11.3 & 0.64 \\
\hline Local and commuter transportation & 0.72 & & 0.55 & 0.81 & 12.4 & 2.9 & 3.3 & 2.89 \\
\hline Inter-city transportation & 1.10 & $\#$ & 3.24 & 5.08 & 79.2 & 56.3 & 65.7 & 0.38 \\
\hline Health care goods & 0.67 & & 0.41 & 0.48 & 15.2 & 1.5 & 1.3 & 0.62 \\
\hline Health care services & 1.13 & & 0.32 & 0.31 & 5.0 & 0.8 & 0.4 & 2.58 \\
\hline Personal care supplies and equipment & 1.51 & & 0.62 & 1.00 & 37.3 & 7.9 & 10.5 & 0.00 \\
\hline Personal care services & 0.97 & & 0.47 & 0.69 & 8.7 & 3.0 & 1.7 & 2.59 \\
\hline Recreational equipment and services (excl. vehicles) & 1.67 & & 0.55 & 0.74 & 33.8 & 7.6 & 12.6 & 0.25 \\
\hline Purchase of recreational vehicles & 0.70 & & 0.63 & 0.82 & 22.7 & 7.6 & 7.5 & 0.60 \\
\hline Operation of recreational vehicles & 0.38 & & 0.71 & 1.15 & 37.1 & 2.9 & 20.1 & 0.00 \\
\hline Home entertainment equipment and services & 1.26 & & 0.43 & 0.64 & 25.3 & 4.0 & 4.2 & 0.66 \\
\hline Travel services & 1.73 & & 1.34 & 2.16 & 49.1 & 18.9 & 26.4 & 0.24 \\
\hline Other recreational services & 2.17 & & 0.46 & 0.57 & 17.7 & 3.5 & 3.3 & 0.58 \\
\hline Education & 1.69 & & 0.66 & 0.87 & 32.6 & 5.1 & 3.8 & 0.25 \\
\hline Reading material and other print matter (excl. textbooks) & 0.84 & & 0.59 & 0.95 & 23.8 & 3.0 & 7.5 & 1.00 \\
\hline Served alcoholic beverages & 1.11 & & 0.43 & 0.69 & 9.3 & 1.5 & 2.1 & 0.75 \\
\hline Alcoholic beverages purchased from stores & 2.07 & & 0.44 & 0.49 & 15.4 & 2.6 & 2.9 & 1.22 \\
\hline Tobacco products and smokers' supplies & 2.31 & \# & 3.20 & 4.51 & 55.2 & 17.4 & 26.4 & 0.18 \\
\hline \multicolumn{4}{|l|}{ Main commodity groups ${ }^{3}$} & \multicolumn{4}{|c|}{ (weighted averages) ${ }^{4}$} & \\
\hline Food & 17.85 & & 0.57 & 0.86 & 31.94 & 12.07 & 15.40 & 1.01 \\
\hline Energy & 7.76 & & 2.72 & 3.98 & 60.33 & 37.06 & 45.94 & 0.65 \\
\hline Goods excl. food and energy & 31.59 & & 0.64 & 0.92 & 31.95 & 7.84 & 12.24 & 0.72 \\
\hline Services & 42.80 & & 0.48 & 0.33 & 22.53 & 5.97 & 7.85 & 1.27 \\
\hline
\end{tabular}

1) * indicates items excluded from Core1 (CPI excl. food and energy); \# indicates items excluded from Core 2 (CPE deflator excl. food and energy). 2) Ratio between the percentage of months where the item is the weighted median item and the CPI weight.

3) Based on standard national definitions. Food includes food away from home ("food purchased from restaurants"), but excludes alcoholic beverages. 4) Weighted averages are calculated using average weights. For volatility measures, the harmonic weighted mean is used. 


\section{ANNEX 2. CHARACTERISTICS OF THE CROSS-SECTION DISTRIBUTION OF PRICE CHANGES IN THE FIVE MAJOR ECONOMIC AREAS}

66. A number of studies have found that the cross-section distribution of CPI price changes often departs from a normal distribution. ${ }^{27}$ This fact is sometimes cited as a reason for replacing the mean with limited-influence estimators such as the median or trimmed means as a measure of the "central tendency" of inflation. In fact, if a distribution is not normal, the sample mean is not necessarily the most efficient estimator of the "true" mean. This Annex presents some evidence in this regard for the five economies covered in this study.

67. The economic literature has found that the cross-section distribution of CPI price changes tends to depart from normality in two important ways: it tends to have much higher kurtosis than a normal distribution, which means that it is both more "pointed" in the middle part and has "fatter" tails relative to the bell-shaped normal distribution; and it tends to be positively skewed on average, instead of symmetric as would be a normal distribution, although both the absolute size and the sign of skewness can vary a lot from month to month. ${ }^{28}$ In combination, these two characteristics tend to make the sample mean an inefficient estimator. If the distribution has fat tails a larger portion of the overall probability mass will be found in the tails as compared with a normal distribution with the same standard deviation. If in addition it is asymmetric, these outliers will not be distributed equally on both sides of the mean, and therefore will tend to distort the sample mean in any particular month.

68. Table A2.1 presents a number of average statistics on the cross-section distribution of CPI price changes in the United States, the euro area, Japan, the United Kingdom and Canada. The statistics refer to month-on-month price changes calculated on seasonally adjusted data; for the euro area and the United Kingdom also the corresponding statistics based on unadjusted data are reported. ${ }^{29}$ For each economy, the

27. See in particular Bryan et al. (1997) for the United States, Vega and Wynne (2001) for the euro area, Bryan and Cecchetti (1999) for Japan, Bakhshi and Yates (1999) for the United Kingdom and Hogan et al. (2001) for Canada.

28. The skewness and the kurtosis of a distribution are defined as, respectively, its scaled third and fourth central moment. In the case of the cross-distribution of CPI price changes, the weighted moments are usually considered, calculated using the CPI weights. The formulas for the two statistics are:

Skew $_{t}=\frac{\sum_{i=1}^{n} w_{t}^{i}\left(\pi_{t}^{i}-\bar{\pi}_{t}\right)^{3}}{S T D^{3}} ;$ Kurt $_{t}=\frac{\sum_{i=1}^{n} w_{t}^{i}\left(\pi_{t}^{i}-\bar{\pi}_{t}\right)^{4}}{S T D^{4}}$,

where $\pi_{t}^{i}$ and $w_{t}^{i}$ indicate the monthly inflation rates and the weights of CPI components, $\bar{\pi}_{t}$ is the weighted average monthly inflation rate at time $\mathrm{t}$ and $S T D_{t}=\left(\sum_{i=1}^{n} w_{t}^{i}\left(\pi_{t}^{i}-\bar{\pi}_{t}\right)^{2}\right)^{1 / 2}$ is the (weighted) standard deviation of CPI components' inflation rates at time t.

29. For the euro area and the United Kingdom, where HICP data cover only ten years or less, core inflation indicators were computed on the basis of unadjusted data (see Annex 1). 
CPI component breakdown is the same that was used for computing the core inflation indicators (see Annex 1), ${ }^{30}$ The following conclusions emerge from the table:

- The cross-section distribution is everywhere highly kurtotic: in each of the five economies the weighted kurtosis was around 20 on average in 1995-2004 (it would be 3 for a normal distribution); its monthly values exceed 3 every single month and they exceed 10 in about 75 per cent of the months.

- The distribution also tends to be rather skewed, although the sign changes often. On average there seems to be a prevalence of positive skewness (a heavier positive tail), ${ }^{31}$ but the monthly skewness statistic varies considerably over time. Its average absolute value, a measure of how skewed monthly distributions are regardless of sign, everywhere exceeds 2 .

- Over time, the absolute value of skewness is strongly correlated with kurtosis: when there is a high proportion of outliers these are likely to be asymmetrically distributed. At the same time, the skewness's algebraic value is positively correlated with the sample mean, which reflects the fact that when there are more outliers at one end of the distribution this tends to affect average CPI inflation in the same direction. On the other hand, the mean does not seem to be strongly correlated with the standard deviation, indicating that greater dispersion of relative price changes is not necessarily associated with a higher measured inflation rate. ${ }^{32}$

- A summary measure of the distribution's departure from normality is the Jarque-Bera statistic. In all five economies, its average is much higher than the $99 \%$ critical value for non-normality (9.21) and monthly values exceed the critical value virtually all the time. However, this result should be interpreted with some caution, because the critical value applies only under the null hypothesis of normality (Aucremanne, 2000).

- At least for the euro area and the United Kingdom, the above results do not seem to be significantly modified if the statistics are calculated on seasonally unadjusted data.

69. These results seem to confirm earlier findings that in these five economies the distribution of price changes tends to depart significantly from normality.

30. The characteristics of the cross-section distribution can vary for different levels of cross-section aggregation and of time-aggregation, such as 3-month or 12-month inflation rates (Bryan et al., 1997 and Aucremanne, 2000).

31. An exception seems to be Japan in the last ten years, where the average skewness is also small but negative. This would appear consistent with the prediction of the menu costs interpretation of price skewness (Ball and Mankiw, 1995). According to that view, if the trend inflation rate is positive firms experiencing positive price shocks will revise their actual prices at discrete intervals, while those experiencing negative shocks may simply allow the relative price of their goods to fall by not following the increase in the general price level. The opposite would occur under deflation.

32. A positive (negative) correlation between the mean and the standard deviation would arise if the distribution were consistently positively (negatively) skewed in one direction (Ball and Mankiw, 1995). The fact that this effect is not visible for the economies and the sample periods considered here may be due to the fact that, although the average of skewness is positive, its variance is very large relative to the average value. 


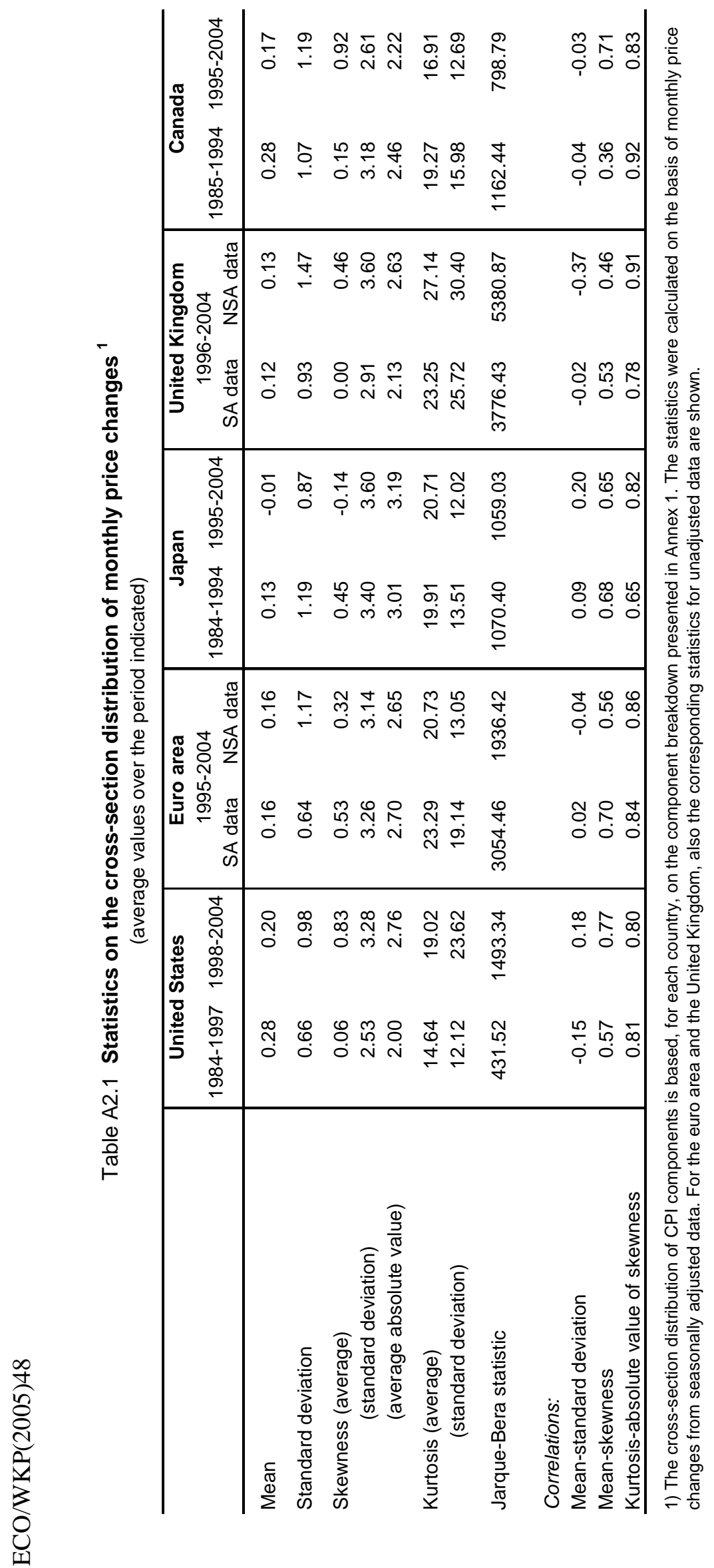




\section{WORKING PAPERS}

The full series of Economics Department Working Papers can be consulted at www.oecd.org/eco/Working_Papers/

460 Regulation and economic performance: product market reforms and productivity in the OECD (Forthcoming, on Olis and the Web on 28 November) Giuseppe Nicoletti and Stefano Scarpetta.

459. Innovation in the Business Sector

(November 2005) Florence Jaumotte and Nigel Pain

458. From Innovation Development to Implementation: Evidence from the Community Innovation Survey (November 2005) Florence Jaumotte and Nigel Pain

457. From Ideas to Development: the Determination of $R \& D$ and Patenting (November 2005) Florence Jaumotte and Nigel Pain

456. An Overview of Public Policies to Support Innovation (November 2005) Florence Jaumotte and Nigel Pain

455. Strengthening Regulation in Chile: The Case of Network Industries (November 2005) Alexander Galetovic and Luiz de Mello

454. Fostering Innovation in Chile

(November 2005) José-Miguel Benavente, Luiz de Mello and Nanno Mulder

453. Getting the most out of public sector decentralisation in Mexico (October 2005) Isabelle Joumard

452. Raising Greece's Potential Output Growth (October 2005) Vassiliki Koutsogeorgopoulou and Helmut Ziegelschmidt

451. Product Market Competition and Economic Performance in Australia (October 2005) Helmut Ziegelschmidt, Vassiliki Koutsogeorgopoulou, Simen Bjornerud and Michael Wise

450. House Prices and Inflation in the Euro Area (October 2005) Boris Cournède

449. The EU's Single Market: At Your Service? (October 2005) Line Vogt

448. Slovakia's introduction of a flat tax as part of wider economic reforms (October 2005) Anne-Marie Brook and Willi Leibfritz

447. The Education Challenge in Mexico: Delivering Good Quality Education to All (October 2005) Stéphanie Guichard

446. In Search of Efficiency: Improving Health Care in Hungary (October 2005) Alessandro Goglio

445. Hungarian Innovation Policy: What's the Best Way Forward? (October 2005) Philip Hemmings

444. The Challenges of EMU Accession Faced by Catch-Up Countries: A Slovak Republic Case Study (September 2005) Anne-Marie Brook 


\section{ECO/WKP(2005)48}

443. Getting better value for money from Sweden's healthcare system (September 2005) David Rae

442. How to reduce sickness absences in Sweden: lessons from international experience (September 2005) David Rae

441. The Labour Market Impact of Rapid Ageing of Government Employees: Some Illustrative Scenarios (September 2005) Jens Høj and Sylvie Toly

440. The New OECD International Trade Model (August 2005) Nigel Pain, Annabelle Mourougane, Franck Sédillot and Laurence Le Fouler

439. The French Tax system: Main characteristics, recent developments and some considerations for reform (July 2005) Willi Leibfritz and Paul O'Brien

438. The Effects of EMU on Structural Reforms in Labour and Product Markets (July 2005) Romain Duval and Jørgen Elmeskov

437. Product Market Competition andEconomic Performance in New Zealand (July 2005) Annabelle Mourougane and Michael Wise

436. Getting the Most out of Public Sector Decentralisation in Spain (July 2005) Isabelle Joumard and Claude Giorno

435. Sources of Inflation Persistence in the Euro Area (July 2005) Boris Cournède, Alexandra Janovskaia, Paul van den Noord

434. Measuring Cyclically-Adjusted Budget Balances for OECD Countries (July 2005) Nathalie Girouard and Christophe André

433. Product Market Competition and Economic Performance in the United Kingdom (June 2005) Maria Maher and Michael Wise

432. The Benefits of Liberalising Product Markets and Reducing Barriers to International Trade and Investment: the Case of the United States and the European Union (June 2005)

431. Boosting Growth through Greater Competition in Denmark (May 2005) Martin Jørgensen

430. Fifteen Years of Economic Reform in Russia: What Has Been Achieved: What Remains to be Done? (May 2005) Rudiger Ahrend and William Tompson

429. Assessing the OECD Job Strategy: Past Developments and Reforms (May 2005) Nicola Brandt, Jean-Marc Burniaux and Romain Duval

428. Ageing, Welfare Services and Municipalities in Finland (May 2005) Jens Lundsgaard

427. The Impact of Structural Policies on Trade-Related Adjustment and the Shift to Services (April 2005) Per Mathis Kongsrud and Isabelle Wanner

426. Product Market Competition and Economic Performance in Iceland (April 2005) Thomas Laubach and Michael Wise 